Universidade de São Paulo

Faculdade de Economia, Administração e Contabilidade

Departamento de Administração

Programa de Pós-Graduação em Administração

\title{
ENSAIOS EM FINANÇAS QUANTITATIVAS: \\ ApreÇAmEnTo DE DERIVATIVOS MULTIDIMENSIONAIS \\ VIA PROCESSOS DE LÉVY, E \\ TOPOlOGIA E PROPAGAÇÃO DO RISCO SISTÊMICO.
}

Edson Bastos e Santos
Orientador: Prof. Dr. José de Oliveira Siqueira
Área de Concentração: Métodos Quantitativos

SÃo PAUlo

Janeiro de 2010 
Profa. Dr. João Grandino Rodas

Reitora da Universidade de São Paulo

Prof. Dr. Carlos Roberto Azzoni

Diretor da Faculdade de Economia, Administração e Contabilidade

Prof. Dr. Adalberto Américo Fischmann

Chefe do Departamento de Administração

Prof. Dr. Lindolfo Galvão de Albuquerque

Coordenador do Programa de Pós-Graduação em Administração 
Universidade de São Paulo

Faculdade de Economia, Administração e Contabilidade

Departamento de AdministraÇÃo

Programa de Pós-Graduação em Administração

\title{
ENSAIOS EM FINANÇAS QUANTITATIVAS: APREÇAMENTO DE DERIVATIVOS MULTIDIMENSIONAIS VIA PROCESSOS DE LÉVY, E TOPOlOGIA E PROPAGAÇÃO DO RISCO SISTÊMICO.
}

\author{
Edson Bastos e Santos \\ Orientador: Prof. Dr. José de Oliveira Siqueira \\ Área de Concentração: Métodos Quantitativos
}

Tese de Doutorado apresentado ao Departamento de Administração da Faculdade de Economia, Administração e Contabilidade da Universidade de São Paulo como requisito para a obtenção do título de Doutor em Administração.

SÃo PAULO

Janeiro de 2010 
Registrado @ 2009 por Edson Bastos e Santos

Direitos reservados, 2009 pelo Banco Central do Brasil - BACEN

SBS - Quadra 3 - Bloco B - Edifício Sede

70074-900 Brasília, DF.

Sistema de edição do texto: $\mathrm{HT}_{\mathrm{E} X}$.

Sistema de edição das fórmulas matemáticas: $\mathcal{A} \mathcal{M S} \mathrm{T}_{\mathrm{E}} \mathrm{X}$.

Sistema de edição das referências bibliográficas: BIBTEX e ABNT-TEX.

Sistema de implementação das linguagens de edição: MiKTEX.

Sistema de produção de arquivos: PDFATEX.

Ficha Catalográfica

Elaborada pela Seção de Processamento Técnico do SBD/FEA/USP

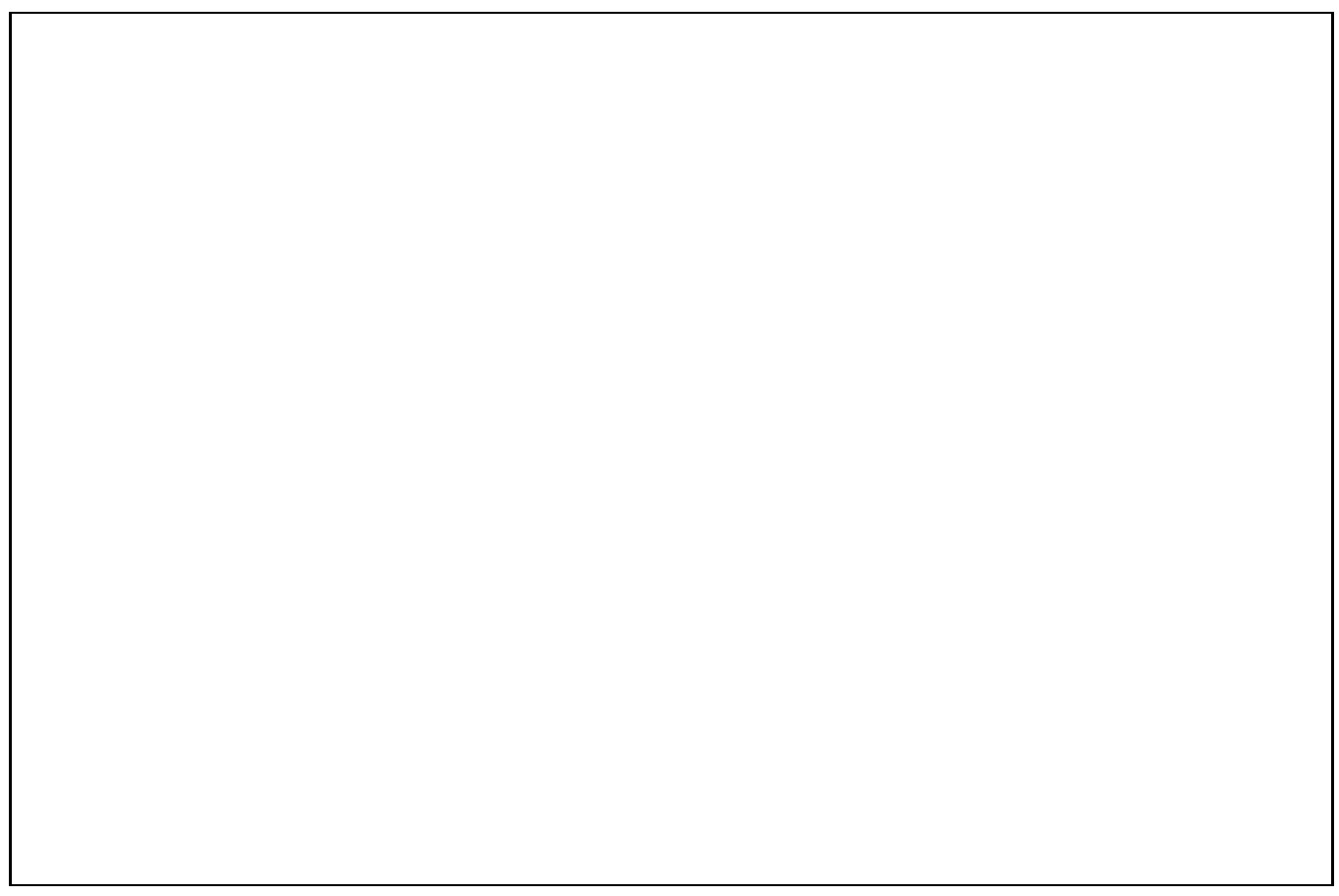


A minha amada esposa que sempre esteve ao meu lado, seja nos momentos alegres ou nos momentos dificeis, e, que me mostrou o caminho das luzes, quando olhava apenas as sombras, de forma análoga ao mito da caverna de Platão. Sem ela eu não saberia ser feliz e não seria metade da pessoa que sou. 


\section{AgRADECIMENTOS}

Ao meu orientador, Prof. Dr. José de Oliveria Siqueira, pela paciência e confiança em que depositou em mim durante várias anos, e pelo respeito com que tratou as minhas idéias, principalmente nas discussões onde os argumentos divergiam com probabilidade tendendo a 1.

Aos professores Nelson Tanaka, Joe Yoshino, e Rama Cont, por terem ido além das prerrogativas do professor e contribuírem de maneira significativa na minha carreira acadêmica, e, também ao Prof. Christian Zimmer, pois tiveram a paciência de analisar esta tese e promover as produtivas críticas e discussões.

Aos professores Marco Avellaneda, Jim Gatheral, Bruno Dupire, Sasha Stoikov, Chris Rogers, Pedro Paulo Schirmer, Adilson Simonis e Oswaldo do Valle da Costa, por encourajado meus projetos e terem sido pontuais nas minhas dúvidas, tiveram elas sido apresentadas dentro ou fora das salas de aula.

Ao Banco Central do Brasil, por ter promovido financeiramente minha pesquisa, e aos colegas Donizeti, Tabak, Simão, Agnaldo, José Cláudio, Paiva, Rodrigo, Maurel, Maurício, Ricardo e Valter por terem me apoiado diretamente ou indiretamente pelo entusiasmo demonstrado.

À minha esposa Lucia pela motivação constante em me apoiar nos momentos desafiadores deste trabalho, e por me retribuir com dedicação e carinho.

Aos meus queridos pais, Roberto e Neusa, que sempre estiveram ao meu lado neste meu percurso acadêmico e de vida, me apoiando no máximo de seus alcançes.

À minha família, vovô Elon; irmãs Tais e Simone; cunhados Marcos e Walter; sobrinhos Isabella, Giancarlo e Francesca; sogros Edelazil (in memorian) e Sebastião; e tias Flora e Dora por toda a motivação e convívio.

Aos colegas da FEA/USP, Iuri, Henrique, Claudinei e Marco; e, aos colegas do IEOR da Columbia University, Amal, Thiam, Arseniy, Rafael, Rodrigo, Ufei, Maria, Cecilia, Fabio, Felippo, Yuri e Rouba; pelas discussões enriquecedoras e pelas descontração durante o convívio acadêmico.

E, a Deus, por me proteger e estar sempre ao meu lado. 
"Somos meros viajantes neste Universo que não sabemos de onde veio, e nem para onde vai. A vida é um Mistério que temos que aceitar e acreditar que juntos, somos muito mais fortes. O importante é acreditar sempre no Bem, fazer sempre o nosso melhor. Tenho certeza de que assim, seremos mais felizes, mais prósperos, mais integros e muito mais humanos neste Universo infinito de alegrias e oportunidades."

(Filósofo e ano desconhecidos) 


\section{RESUMO}

Este estudo contempla dois ensaios em finanças quantitativas, relacionados, respectivamente, a modelos de apreçamento e risco sistêmico. No Capítulo 1, é apresentado uma alternativa para modelar opções multidimensionais, cujas estruturas de ganhos e perdas dependam das trajetórias dos processos dos preços dos ativos objetos. A modelagem sugerida considera os processos de Lévy, uma classe de processos estocásticos bastante ampla, que permite a existência de saltos (descontinuidades) no processo dos preços dos ativos financeiros, e tem como caso particular o movimento Browniano. Para descrever a dependência entre os processos, os conceitos estáticos de cópulas ordinárias são estendidos para o contexto dos processos de Lévy, levando em consideração a medida de Lévy, que caracteriza o comportamento dos saltos. São realizados estudos comparativos entre as cópulas dinâmicas de Clayton e de Frank, no apreçamento dos contratos derivativos do tipo asiático, utilizando-se processos gama e técnicas de simulação de Monte Carlo. No Capítulo 2, a estrutura e dinâmica interbancária das exposições mútuas entre as instituições financeiras no Brasil é explorada bem como o capital destas reservas, utilizando um conjunto de dados dados únicos que considera vários períodos entre 2007 e 2008. Para isto é mostrado que a rede de exposições pode ser modelada adequadamente como um gráfico estocástico dirigido de escala-livre (ponderada) seguindo distribuições que apresentam caudas grossas. A relação entre as conexões das instituições financeiras e seu colchão-de-capital também são investigados neste estido. Finalmente, a estrutura da rede é usada para explorar a extensão de risco sistêmico gerada no sistema individualmente pelas instituições financeiras. 


\section{ABSTRACT}

This study comprises two essays in quantitative finance, related, respectively, to models in asset pricing and systemic risk. In Chapter 1, it is presented an alternative to modeling multidimensional options, where the pay-offs depend on the paths of the trajectories of the underlying-asset prices. The proposed technique considers Lévy processes, a very ample class of stochastic processes that allows the existence of jumps (discontinuities) in the price process of financial assets, and as a particular case, comprises the Brownian motion. To describe the dependence among Lévy processes, extending the static concepts of the ordinary copulas to the Lévy processes context, considering the Lévy measure, which characterizes the jumps behavior of these processes. A comparison between the Clayton and the Frank dynamic copulas and their impact in asset pricing of Asian type derivatives contracts is studied, considering gamma processes and Monte Carlo simulation procedures. In Chapter 2, the structure and dynamics of interbank exposures in Brazil using a unique data set of all mutual exposures of financial institutions in Brazil is explored, as well as their capital reserves, at various periods in 2007 and 2008. It is shown that the network of exposures can be adequately modeled as a directed scale-free (weighted) graph with heavy-tailed degree and weight distributions. The relation between connectivity of a financial institution and its capital buffer are also investigated in this study. Finally, the network structure is used to explore the extent of systemic risk generated in the system by the individual institutions. 


\section{SUMÁRIO}

Agradecimentos $\ldots \ldots \ldots \ldots \ldots \ldots \ldots \ldots \ldots \ldots \ldots \ldots \ldots \ldots \ldots \ldots \ldots \ldots$, iii

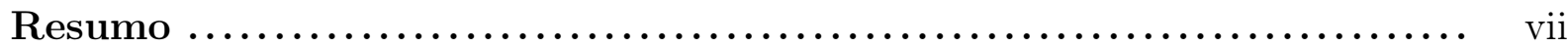

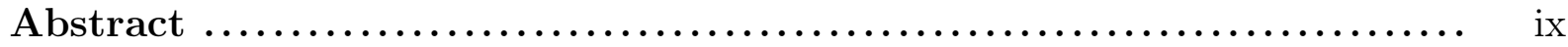

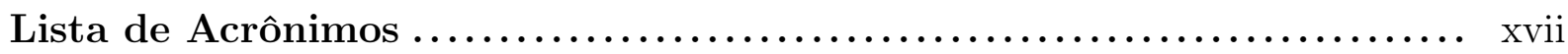

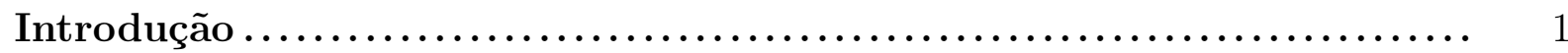

1. Apreçamento de Opções Multidimensionais por meio de Pro-

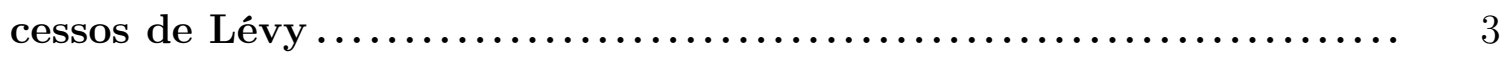

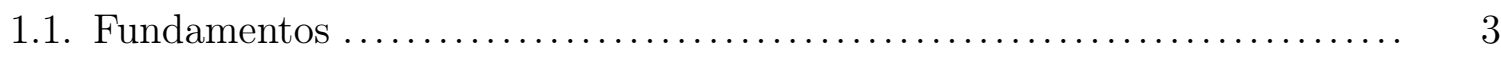

1.1.1. Breve Introdução aos Processos de Lévy ........................ 6

1.1.2. Medida de Salto e Medida de Lévy ............................ 6

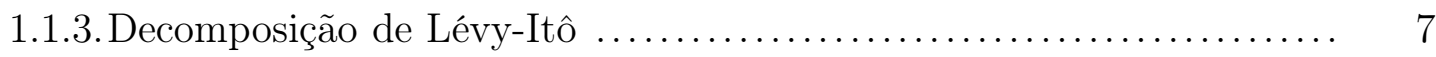

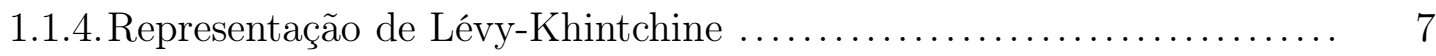

1.2. Cópulas para Vetores Aleatórios ............................... 8

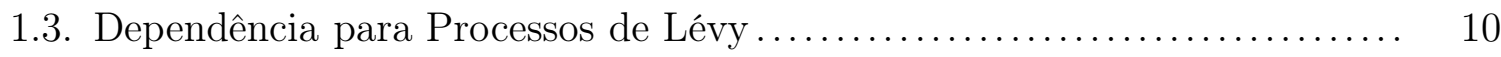

1.3.1. Cópulas para Processos de Lévy de Saltos Positivos ................ 13

1.3.2. Integral Caudal e Medidas de Lévy ............................. 13

1.3.3. Exemplos de Cópulas de Lévy Positivas......................... 15

1.3.4. Construção de Cópulas de Lévy Positivas ........................ 17

1.3.5. Interpretação Probabilística ................................... 18

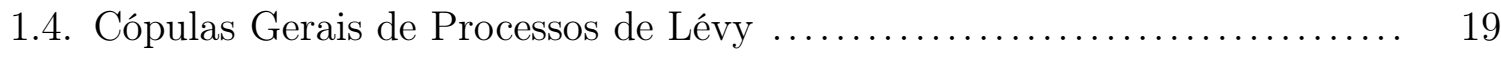

1.4.1. Medidas de Lévy com Densidades ............................ 20

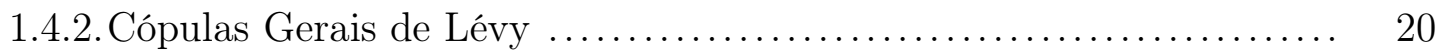

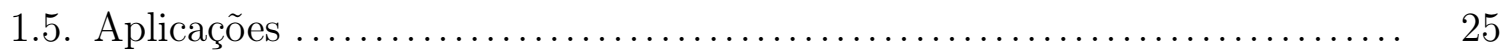

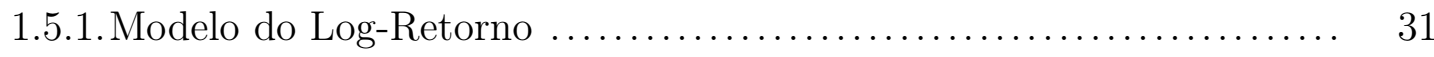

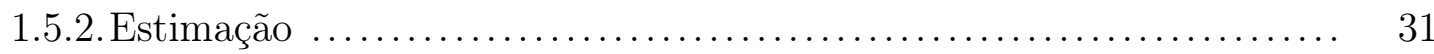

1.5.3. Simulação de Monte Carlo ..................................... 34

1.6. Análise ................................................... 37

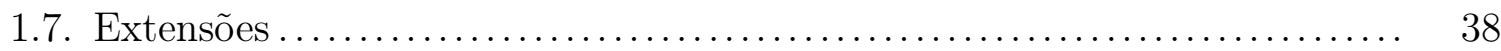

1.7.1. Extensões de cópulas positivas de Lévy aos Casos Multivariados .... 38

1.7.2. Extensões aos Casos Multivariados de cópulas de Lévy generalizadas 39 
2. Rede Interbancária Brasileira: Topologia e Propagação do Risco Sistêmico.......................................... 47

2.1. Contextualização Histórica do Risco Sistêmico ....................... 47

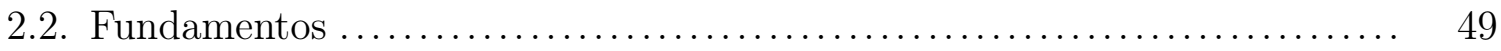

2.3. Descrição dos Dados ............................................ 51

2.3.1.Exposições Mútuas........................................ 51

2.3.2. Reserva de Capital ....................................... 52

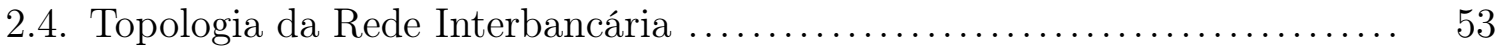

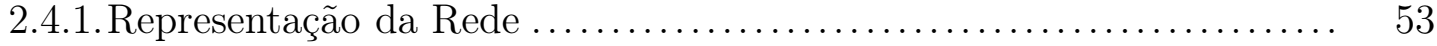

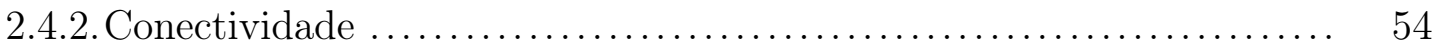

2.4.3. Magnitude das Exposições ..................................... 56

2.4.4. Relação entre a Magnitude da Exposição e Conectividade........... 57

2.4.5. Agrupamento e Afinidade .................................. 58

2.5. Estrutura de Capital ........................................ 59

2.5.1.Padrões Estatísticos do Colchão-de-Capital....................... 59

2.5.2. Distribuição dos Resíduos e Alavancagem........................ 62

2.6. Risco Sistêmico .............................................. 64

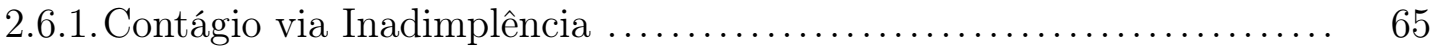

2.6.2. Riscos de Mercado e de Crédito................................. 68

2.6.3.Efeito de Liquidez ..................................... 69

2.7. Análise .................................................. 71

Conclusões.................................................... 84

Referências Bibliográficas ....................................... 85

Apêndices..................................................... 93

A.1. Estimativas de Máxima Verossimilhança ............................ 93

A.2. Coeficiente de Afinidade ........................................... 93 


\section{LISTA DE TABELAS}

1.1. Análise da influência das cópulas de Lévy de Clayton e Frank sobre o preços de opções asiáticas (venda e compra) considerando médias

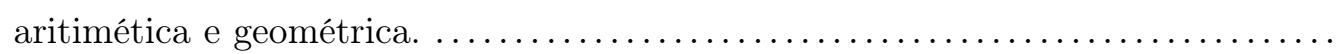

1.2. Análise da influência da dependência (linear) sobre o preço de opções asiáticas (compra e venda) considerando a média aritimética e a cópula de Lévy de Clayton. ...............................................

1.3. Análise da influência da dependência (linear) sobre o preço de opções asiáticas (compra e venda) considerando a média aritimética e a cópula de Lévy de Frank. ...............................................

2.1. Número de instituições financeiras por tipo de operação para o Sistema Financeiro Brasileiro. Fonte: Sisbacen. ..........................

2.2. Representatividade das instituições financeiras brasileiras em termos do total de ativos e quantidade. O total de ativos foi convertido de BRL (Reais) para USD (Dólares Americanos) considerando as seguintes paridades cambiais (BRL/USD): 1.9262 (Jun07), 1.7713 (Dez-07), 1.7491 (Mar-08), 1.5919 (Jun-08), 1.9143

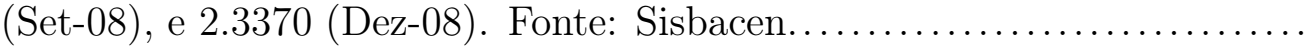

2.3. Estatísticas gerais e estimativas MLE para os parâmetros da distribuição potência: expoente de cauda $\alpha$, valores mínimo da cauda para o grau-de-entrada $k_{i n, m i n}$, grau-de-saída $k_{o u t, m i n}$, graus $k_{m i n}$,

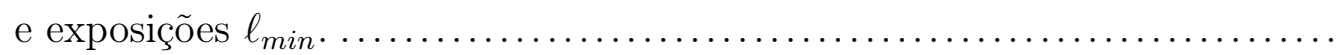

2.4. Rede interbancária brasileira: Coeficientes de Pearson $\rho_{\text {Pearson }}$, Kendall $\tau_{\text {Kendall }}$ e Spearman $\rho_{\text {Spearman }}$ para grau-de-entrada $k_{i n}$ vs. exposições-de-entrada $w_{\text {in }}$, grau-de-saída $k_{\text {out }}$ vs. exposiçõesde-saída $w_{\text {out }}$, e graus $k$ vs. exposições $w$.

2.5. Rede interbancária brasileira: coeficiente de afinidade para a matriz adjacente $\rho_{k}$ e para a matriz de exposições $\rho_{\ell}$, e suas respectivas variâncias $\sigma^{2}\left(\rho_{k}\right)$ e $\sigma^{2}\left(\rho_{\ell}\right)$, coeficiente de agrupamento global $\mathbb{E}(c)$ e diâmetro da rede $d$.

2.6. Modelos lineares plausíveis para o colchão-de-capital $B_{2}$ tal como definido na equação (2.7) para todas as datas aglutinadas, i.e., Junho 2007, Dezembro 2007, Março 2008, Junho 2008, Setembro 2008, e, Novembro 2008. 


\section{LisTA DE FiguRAS}

1.1. Análise da influência dos parâmetros da cópula de Lévy de Clayton. .......... 41

1.2. Análise da influência dos parâmetros da cópula de Lévy de Frank. ........... 42

2.1. Rede interbancária brasileira em Dezembro de $2007 . \ldots \ldots \ldots \ldots \ldots \ldots \ldots \ldots \ldots$

2.2. Gráfico Q-Q da distribuição dos graus da rede interbancária brasileira para datas consecutivas. ............................... $\quad 72$

2.3. Rede Interbancária Brasileira: distribuição do grau-de-entrada das

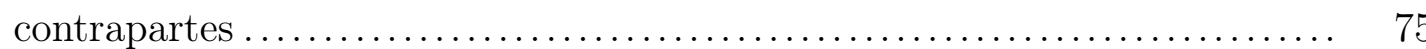

2.4. Rede Interbancária Brasileira: distribuição do grau-de-saída das contrapartes .

2.5. Rede Interbancária Brasileira: distribuição dos graus das contrapartes (soma do grau-de-entrada e grau-de-saída). ................. 77

2.6. Rede Interbancária Brasileira: distribuição das exposições em BRL. ...... 78

2.7. Graus vs. coeficiente de agrupamento local para a rede interbancária brasileira. A linha cinza representa a média do coeficiente, que é também denominado coeficiente de agrupamento global.

2.8. Rede interbancária brasileira: Impacto da Inadimplência e Índice de Risco Sistêmico. ..............................................

2.9. Estimador de Hill para o expoente de cauda $\alpha$ de uma distribuição t-Student escalonada considerando os resíduos (choques de capital) para todas as datas. Observe que $\alpha<1$ determina que a distribuição apresenta cauda grossas e momentos não bem definidos. 


\section{LISTA DE ACRÔNIMOS}

AIC: Akaike Information Criterium

BACEN: Banco Central do Brasil

BIC: Bayesian Information Criterium

BIS: Bank of International Settlements

BM\&F: Bolsa de Valores Mercadorias e Futuros

BOVESPA: Bolsa de Valores de São Paulo

BRL: Brazilian Reais

BSM: Black-Scholes-Merton

CMO: Collateralized Mortgage Obligations

DGP: Data Generating Process

DI: Default Impact

EMM: Equivalent Martingale Measure

FASB: Financial Accounting Standards Board

FMI: Fundo Monetário Internacional

FSA: Financial Services Authority

GMM: Generalized Method of Moments

IASB: International Accounting Standards Board

IID: Independently and Identically Distributed

MB: Movimento Browniano

MLE: $\quad$ Maximum Likelihood Estimate

NFLVR: No Free Lunch with Vanishing Risk

OLS: Ordinary Least Squares

PIDE: Partial Integral Differential Equation

SEC: Security and Exchange Commission

SI: $\quad$ Systemic Risk Index

USD: United States Dollars 
xviii 


\section{INTRODUÇÃO}

Esta tesa visa investigar dois problemas: (i) modelar o apreçamento de opções multidimensionais que levem em consideração os fatos estilizados do ativo-objeto e que sejam condizentes com as práticas de mercado, dentro do contexto do mercado acionário no Brasil. Tratar a escolha de um modelo de apreçamento de derivativos não é uma questão trivial, pois exige, a priori, não só um rigoroso diagnóstico dos fatos estilizados (propriedades estatísticas e econométricas) das séries-temporais que contem as informações de mercado, tais como as séries do preço e da volatilidade do ativo-objeto, como também o entendimento das hipóteses subjacentes aos modelos. Desta maneira, é possível desenvolver de maneira sistemática o problema de escolha, investigando estes fatores para as classes de modelos estocásticos com descontinuidades, ou processos de Lévy; e (ii) identificar as características da rede de inter-relacionamentos entre as instituições bancárias no Brasil, para obter um melhor entendimento dos fatores que causam a propagação do risco sistêmico, ou seja, caso um banco apresente dificuldades a tal ponto de inviabilizar o cumprimento de suas obrigações com as outras instituições financeiras, busca-se observar como este fato impacta as demais instituições financeiras que não têm nenhuma ligação direta com a instituição insolvente.

O objetivo principal do trabalho é progredir na solução destes problemas sob a perspectiva de métodos quantitativos, ou seja, obter um amplo entendimento dos temas, formulá-los matematicamente considerando toda a quantidade informacional disponível e aplicar métodos estatísticos, visando quantificar os problemas e facilitar a suas resoluções. Para isto é necessário desenvolver modelos que sejam compatíveis com os fatos observados por meio dos dados financeiros. Especificamente, os métodos estatísticos mais importantes neste trabalho são: processos estocásticos de Lévy; métodos de simulação de Monte Carlo; métodos de estimação não-paramétricos; redes estocásticas; teoria de valores extremos; e, análise multivariada.

Além disso, devemos destacar alguns objetivos intermediários. Em relação ao problema (i), podemos ressaltar que alguns modelos, apesar de não apresentarem as hipóteses desejadas, são capazes de produzir os efeitos desejados nas séries financeiras como, por exemplo, modelos de volatilidade estocástica baseado em difusões. Desta maneira, devemos analisar com cautela estas situações, pois é preciso ter em mente qual o objetivo principal do trabalho, i.e., obter modelos capazes de quantificar adequadamente os problemas, e para que este objetivo seja atingido, os modelos devem estar coerentes com as informações financeiras observadas no mercado financeiro, ou seja, devemos evitar qualquer método baseado em casualidade. Em relação ao problema (ii), investigar as propri- 
edades da rede formada pelas instituições bancárias, qual a importância de determinada instituição na estabilidade do sistema financeiro, e como a insolvências das instituições contagiam o sistema como um todo quando o risco se propaga neste.

Por último, este trabalho se justifica em função dos modelos, aqui desenvolvidos, trazerem informações importantes para os tomadores tanto para os agentes financeiros que atuam no mercado acionário, como para o BACEN. Os primeiros, caracterizados por fundos de investimentos, instituições financeiras e pessoas físicas, poderão formar preços com base nos modelos trabalhados no Capítulo 1, e, eventualmente, minimizar a possibilidade de arbitragens, tornando o mercado acionário brasileiro mais eficiente. Esta eficiência, por sua vez, contribui para que haja uma maior quantidade de agentes financeiros dispostos a atuar no mercado acionário, o que garante uma maior diversificação dos perfis destes agentes, e, conseqüentemente, traz maior liquidez e estabilidade para o mercado de ações. O BACEN, por outro lado poderá tomar decisões que envolvam risco sistêmico, que, em geral, carregam considerável incerteza, com maior acuracidade, possibilitando estabelecer exigências de alocação de capital das instituições financeiras por metodos alternativos aos estabelecidos no Novo Acordo da Basiléia. 


\section{Apreçamento de OpÇÕes Multidimensi- onAIS POR MEIO DE PROCESSOS DE LÉVY}

\subsection{Fundamentos}

Não é difícil se convencer que modelagem multivariada de alguns fenômenos financeiros é muito mais promissora do que considerar modelagem univariada de seus componentes separadamente. Apreçamento e hedging de uma cesta de opções, otimização de carteiras, simulação de cenários de riscos, etc., certamente ganham realismo na modelagem se as dependências entre os seus componentes forem levadas em consideração. Se além disso, a possibilidade de saltos nos processos envolvidos for levada em conta então mais um passo estará sendo dado em direção a modelos mais próximos das realizações observadas no mercado. A ocorrência de saltos em processos de log retornos, por exemplo, seria contemplada nesse modelo. A contrapartida é que modelos multidimensionais são mais difíceis de serem construídos e manejados que os univariados.

Uma das maneiras mais simples de modelar fenômenos multivariados é usar modelos gaussianos, onde a estrutura de dependência pode ser parametrizada em termos da matriz de correlações. Neste caso particular, as propriedades marginais, que são em parte caracterizadas pelas volatilidades, podem ser distinguidas das propriedades de dependência, que são dadas pela matriz de correlação. Outra razão para a utilização de modelos gaussianos é a possibilidade de simular séries temporais multivariadas gaussianas com matrizes de correlação arbitrárias.

No que concerne a introdução de saltos em um modelo multidimensional podemos modificar o tempo de um Movimento Browniano (MB) multidimensional com um subordinador univariado, vide (EBERLEIN, 2001) e (PRAUSE, 1999). Suponha que a escala temporal do mercado é modelada por um subordinador $Z=\left\{Z_{t}\right\}_{t \geq 0}$ (i.e., um processo de Lévy com trajetórias quase certamente crescentes), com expoente laplaciano $l(u)$, $B=\left\{B_{t}\right\}_{t \geq 0}$ é um MB $d$-dimensional com matriz de covariâncias $\Sigma$ e médias $\mu \in \mathbb{R}^{\mathrm{d}}$. Ao modificar a escala temporal de um MB com tendência determinística $\mu$ por meio de $Z$, obtém-se um novo processo de Lévy $d$-dimensional $X_{t}=B\left(Z_{t}\right)+\mu Z_{t}$. Esta abordagem permite construir e simular modelos multidimensionais, tais como o processo VariânciaGama, introduzido por Madan e Seneta (1990), Madan, Carr e Chang (1998) e Luciano e Schoutens (2006), o processo Gaussiano Invertido, desenvolvidos por Barndorff-Nielsen (1997, 1998), e o processo Hiperbólico Generalizado, estudados por Prause (1999) e Fa- 
jardo e Farias $(2004,2007)$. Por outro lado, a modelagem da estrutura de dependência nesta construção mostra-se um pouco rígida, pois, apenas distribuições marginais de um mesmo mesmo tipo podem ser utilizadas.

Para modelos de atividade finita, como o de Merton (1976), a estrutura de dependência pode ser obtida estabelecendo dependências entre os saltos individuais através de processos de Poisson unidimensionais, vide (LINDSKOG; MCNEIL, 2001). Se os saltos forem normais, a dependência pode ser estabelecida pela matriz de correlação. Se os saltos não forem normais, e.g., se assumirem distribuição de Laplace assimétrica, como no modelo de Kou (2002) e Kou (2004), então, a dependência pode ser modelada por cópulas. Naturalmente, esta abordagem só faz sentido quando a quantidade de fontes de riscos que produzem os saltos é pequena, por exemplo, quando todos os componentes (processos de preços dos ativos ativos financeiros) do modelo apresentam saltos no mesmo instante de tempo. Caso contrário, esta abordagem não é parcimoniosa, levando em conta uma quantidade muito grande de parâmetros. Outra limitação desta abordagem, é que todos os componentes do modelo devem ser processos compostos de Poisson.

Ainda, encontramos outros enfoques de modelagens em Finanças usando Processos de Lévy multivariados dos quais mencionamos dois. O primeiro, vide (FAJARDO; MORDECKI, 2006), lida com o processo bivariado reduzido, usando o Teorema de Girsanov, para um mercado auxiliar que os autores denominaram de dual. O segundo, vide (MATACHE; PETERSDORFF; SCHWAB, 2004), trata de log-retornos de contratos do tipo europeu, onde a dinâmica dos processos de Lévy satisfazem equações integro-diferenciais parciais parabólicas (PIDE).

Juntando as noções acima, um modelo multidimensional apropriado, usando o Processo de Lévy, deve apresentar as seguintes propriedades: Em primeiro lugar, deve haver liberdade na especificação da lei de qualquer componente individual. Em segundo, o leque de possibilidades de estruturas de dependência deve ser amplo, incluindo dependência perfeita que também chamaremos de completa e independência e que a transição entre estes dois extremos seja harmoniosa. Por último, a parametrização deve ser parcimoniosa, ou seja, com poucos parâmetros.

Estas características podem ser obtidas se a dependência for modelada de maneira independente do comportamento marginal dos componentes, i.e., a modelagem da estrutura de dependência pode ser efetuada de maneira separada das distribuições marginais, por meio de cópulas. Apesar deste procedimento ser algo relativamente recente, dois livros que tratam sobre o assunto são Nelsen (1999) e Joe (1997). Estas duas referências consideram variáveis aleatórias em apenas um determinado instante de tempo, sendo que é necessário 
estender estes conceitos para o ambiente dinâmico dos processos de Lévy, que é a proposta primordial neste estudo. A dependência entre os componentes de um processo de Lévy multidimensional pode ser completamente caracterizada por uma cópula de Lévy, i.e., uma função que possui as mesmas propriedade de uma cópula ordinária, entretanto, comportando as devidas modificações convenientes. Este procedimento fornece as ferramentas necessárias para construir processos de Lévy multidimensionais com dependências específicas. Existem várias famílias paramétricas de cópulas de Lévy que podem ser utilizadas para construir processos de Lévy de dimensão $n$, ou seja, podemos integrar $n$ processos de Lévy unidimensionais por meio de uma cópula parametrizada. No entanto, apesar dos modelos construídos por meio da abordagem cópula de Lévy descreverem todas as características de dependência multidimensional, eles podem se tornar matematicamente complexos e difíceis de serem computacionalmente implementados.

Para ilustrar a necessidade da cópula dinâmica podemos pensar que no caso de opções européias, no único horizonte temporal de exercício a dependência pode ser descrita através da cópula ordinária. Para outros tipos de opções (americana, com barreiras, exótica) há a necessidade da modelagem dinâmica da dependência nos vários instantes possíveis de exercícios, demandando o uso de cópulas de processos (no caso, de Lévy).

Apresentamos em seguida os resultados conhecidos sobre processos de Lévy. As provas dos resultados neste trabalho serão fornecidas apenas quando elas forem curtas ou apresentarem noções úteis à outros pontos do trabalho. Para as demais provas serão indicadas referências. Na Seção 2 recordamos conceitos provenientes das cópulas ordinárias. Na Seção 3, introduzimos a cópula de Lévy, que, em algumas vezes, denominamos cópula dinâmica. Na Seção 4, apresentamos generalizações dos resultados apresentados na Seção 3, e, por meio do Exemplo 29, propomos uma família de cópulas de Lévy, que denominamos Família de Frank Generalizada, dadas as suas similaridades às cópulas ordinárias de Frank. Na Seção 5 apresentamos exemplos de ativos financeiros e desenvolvemos a estrutura de inferência que está associada aos processos de Lévy multidimensionais. Fazemos um estudo de apreçamento de opções asiáticas através de simulação onde o modelo de base é composto por processos de Lévy e a estrutura de dependência dada pela cópula dinâmica de Lévy. Nesta seção estão concentradas as contribuições originais do trabalho. Na Seção 6, concluímos sobre os resultados obtidos no artigo, onde propomos uma extensão do Tau de Kendall para medir dependências não lineares entre processos de Lévy, resultado este que será explorado em trabalhos posteriores. 


\subsubsection{Breve Introdução aos Processos de Lévy}

São apresentados algumas definições e alguns resultados sobre o Processo de Lévy que serão utilizados no desenvolvimento a seguir. Para mais detalhes e provas de resultados indicamos (CONT; TANKOV, 2004) e (KALLSEN; TANKOV, 2006).

Um processo $\left\{X_{t}\right\}_{t \geq 0}$ em $\mathbb{R}^{d}$ com $\mathbb{P}\left(X_{0}=0\right)=1$ é denominado ser de Lévy se:

1. possui incrementos independentes, i.e., para toda seqüência de tempos $t_{0}, t_{1}, \ldots, t_{n}$ as variáveis aleatórias $X_{t_{0}}, X_{t_{1}}-X_{t_{0}}, \ldots, X_{t_{n}}-X_{t_{n-1}}$ são independentes.

2. os incrementos são estacionários, i.e., a lei de $X_{t+h}-X_{t}$ não depende de $t$. Isto significa que os parâmetros são constantes.

3. tem continuidade estocástica: $\forall \varepsilon>0$,

$$
\lim _{h \rightarrow 0} \mathbb{P}\left(\left|X_{t+h}-X_{t}\right| \geq \varepsilon\right)=0,
$$

onde |.| denota a norma euclidiana.

A terceira condição não implica em trajetórias amostrais contínuas. Ela serve para excluir processos com saltos em instantes fixos (não aleatórios). Descontinuidades podem ocorrer em tempos aleatórios.

\subsubsection{Medida de Salto e Medida de Lévy}

Para todo processo cádlág $\left\{X_{t}\right\}_{t \geq 0}$ com valores em $\mathbb{R}^{d}$ faz sentido definirmos $\Delta X_{t}=$ $X_{t}-X_{t-}$. A medida de contagem

$$
J_{X}(B)=\#\left\{\Delta X_{t} \neq 0,\left(t, \Delta X_{t}\right) \in B\right\}
$$

para $B \in \mathcal{B}\left([0, \infty) \times \mathbb{R}^{d}\right)$, é denominada medida de salto de $X$. Aqui, $\mathcal{B}$ denota os Borelianos.

Seja $\left\{X_{t}\right\}_{t \geq 0}$ um processo de Lévy em $\mathbb{R}^{d}$. Definimos a medida $\nu$ em $\mathbb{R}^{d}$, para $A \in$ $\mathcal{B}\left(\mathbb{R}^{d}\right)$ por

$$
\nu(A)=\mathbb{E}\left[\#\left\{t \in[0,1]: \Delta X_{t} \neq 0, \Delta X_{t} \in A\right\}\right]=\mathbb{E}\left[J_{X}([0,1] \times A)\right]
$$


como sendo a medida de Lévy de $X$. Esta medida pode ser interpretada como a quantidade média do número de saltos com dimensões em $A$, em uma unidade de tempo.

\subsubsection{Decomposição de Lévy-Itô}

Para $\left\{X_{t}\right\}_{t \geq 0}$ um processo de Lévy em $\mathbb{R}^{d}$ com medida de Lévy $\nu$, a decomposição de Lévy-Itô nos dá que

- $\nu$ é uma medida de Radon em $\mathbb{R}^{d} \backslash\{0\}$ e satisfaz

$$
\int_{|x| \leq 1}|x|^{2} \nu(\mathrm{d} x)<\infty \text { e } \int_{|x| \geq 1} \nu(\mathrm{d} x)<\infty .
$$

- $J_{X}$ é uma medida aleatória de Poisson em $[0, \infty) \times \mathbb{R}^{d}$ com intensidade $\nu(x) \mathrm{d} t$.

- Existem $\gamma \in \mathbb{R}^{d}$ e um MB d-dimensional $\left\{B_{t}\right\}_{t \geq 0}$ tal que,

$$
\begin{array}{r}
X_{t}=\gamma t+B_{t}+\int_{|x| \geq 1, s \leq t} x J_{X}(\mathrm{~d} s \times \mathrm{d} x)+ \\
\lim _{\varepsilon \searrow 0} \int_{\varepsilon \leq|x|<1, s<t} x \tilde{J}_{X}(\mathrm{~d} s \times \mathrm{d} x),
\end{array}
$$

onde $\tilde{J}_{X}$ é a medida de Poisson compensada pela sua média.

\subsubsection{Representação de Lévy-Khintchine}

Podemos falar da função característica do vetor aleatório $X_{t}$ que devido a decomposição de Lévy-Itô resulta em

$$
\mathbb{E}\left[\exp \left(i<z, X_{t}>\right)\right]=\exp (t \psi(z)), \quad z \in \mathbb{R}^{d},
$$

com

$$
\begin{aligned}
\psi(z) & =-\frac{1}{2}<z, \boldsymbol{\Sigma} z>+i<\gamma, z> \\
& +\int_{\mathbb{R}^{d}}\left(\exp (i<z, x>)-1-i<z, x>\mathbf{1}_{\{|x| \leq 1\}}\right) \nu(\mathrm{d} x),
\end{aligned}
$$

onde $\boldsymbol{\Sigma}$ é a matriz de covariâncias do MB que compõe o processo de Lévy. 
Com isso temos que o processo de Lévy pode ser parametrizado pela tripla $(\Sigma, \nu, \gamma)$ resultante da fórmula de Lévy-Khintchine.

\subsection{Cópulas para Vetores Aleatórios}

A distribuição de um vetor aleatório $d$-dimensional $\{\mathbf{X}\}$ é dada pela sua função de densidade acumulada (c.d.f.)

$$
F(\mathbf{x})=\mathbb{P}[\mathbf{X} \leq \mathbf{x}]
$$

Por distribuição marginal ou marginal de $\left(X_{1}, \ldots, X_{d}\right)$ entendemos as distribuições de $X_{1}, \ldots$ e $X_{d}$ separadamente. Estas distribuições marginais são descritas pelas suas funções de distribuições $F_{X_{k}}\left(x_{k}\right)=\mathbb{P}\left[X_{k} \leq x_{k}\right], \quad k=1, \ldots, d$ que são obtidas a partir da c.d.f. $d$-dimensional:

$$
F_{X_{k}}\left(x_{k}\right)=F\left(\infty, \ldots, \infty, x_{k}, \infty, \ldots, \infty\right)
$$

A distribuição de um vetor aleatório $d$-dimensional, pode ser 'decomposta em suas distribuições marginais e a estrutura de dependência entre essas distribuições marginais. Dois vetores com as mesmas distribuições marginais, mas com estruturas de dependência diferentes possuem distribuições distintas. Desta maneira, um vetor aleatório com distribuições marginais $F_{X_{1}}\left(x_{1}\right), \ldots$ e $F_{X_{d}}\left(x_{d}\right)$, será igual a $F(\mathbf{x})=\prod_{k=1}^{d} F_{X_{k}}\left(x_{k}\right)$ se os seus componentes forem independentes e, $F(\mathbf{x})=\min _{k=1, \ldots, d}\left\{F_{X_{k}}\left(x_{k}\right)\right\}$ se eles forem perfeitamente dependentes, i.e., um dos componentes é uma função determinística estritamente crescente dos outros componentes.

A cópula de um vetor aleatório $d$-dimensional é uma função $d$-variada que caracteriza a estrutura de dependência e não depende das marginais. A c.d.f. pode ser obtida por meio da cópula $C(\mathbf{x})$ e de suas marginais, i.e., $F(\mathbf{x})=C\left(F_{X_{1}}\left(x_{1}\right), \ldots, F_{X_{d}}\left(x_{d}\right)\right)$.

Podemos mostrar que a cópula de uma distribuição é invariante a transformações estritamente crescentes dos componentes do vetor aleatório, vide (NELSEN, 1999). Assim, para todo conjunto de $d$ funções estritamente crescentes $f_{1}, \ldots$ e $f_{d}$, a cópula de $\left(X_{1}, \ldots, X_{d}\right)$ é a mesma que a cópula de $\left(f_{1}\left(X_{1}\right), \ldots, f_{d}\left(X_{d}\right)\right)$. O termo estrutura de dependência refere-se as características de uma distribuição que não dependem das marginais e, ao combinar esta estrutura às marginais é possível reconstruir inteiramente a distribuição. Uma abordagem entrópica de medida de dependência é sugerida por Joe (1989).

Muito tem sido feito em termos de aplicações de cópulas ordinárias em Finanças. 
Apenas para citar alguns exemplos, temos (RODRIGUEZ, 2007), (CHERUBINI; LUCIANO, 2002) e (CHERUBINI; LUCIANO; VECCHIATO, 2004).

Vamos agora formalizar a c.d.f.. A primeira propriedade está relacionada com a idéia de volume de uma função crescente para funções de dimensões múltiplas:

Definição 1.1 (F-Volume) Seja $F$ uma função real d-variada com domínio $\mathcal{D}(F)$. Para $a, b \in \overline{\mathbb{R}}^{d}$, tal que $a \leq b$, i.e., $a_{k} \leq b_{k}$ para $k=1, \ldots, d$, seja $\left.\left.B=\right] a ; b\right]$ uma caixa d-dimensional, cujos vértices pertencem a $\mathcal{D}(F) . O F$-volume de $B$ é definido como

$$
V_{F}(B)=\sum \operatorname{sinal}(c) F(c)
$$

sendo que a soma é realizada em todos os $2^{d}$ vértices $c \in \overline{\mathbb{R}}^{d}$ de $B$ e, sinal $(c)$ é definido como

$$
\operatorname{sinal}(c) \triangleq\left\{\begin{array}{rl}
1, & \text { se } c_{k}=a_{k} \text { em quantidade par } \\
-1, & \text { se } c_{k}=a_{k} \text { em quantidade impar }
\end{array} .\right.
$$

\section{Definição 1.2 (Funções $d$-crescente e aderente)}

1. Uma função real $F$, d-variada, é denomina d-crescente se $V_{F}(B) \geq 0$ para todas as $d$-caixas $B$ cujos vértices pertencem à $\mathcal{D}(F)$.

2. Seja $\mathcal{D}(F)=S_{1} \times \cdots \times S_{d}$ o domínio da função $F$. Para cada $S_{k}$, seja $a_{k}=\inf S_{k}$, para $a_{k} \in \overline{\mathbb{R}} . F$ é uma função aderente se $F(t)=0, t \in \overline{\mathbb{R}}^{d}$, para todo $t \in \mathcal{D}(F)$ existir $t_{k}=a_{k}$ pelo menos para um $k$. Isto equivale a dizer que $F$ é aderente se ela se anular na borda inferior de seu domínio.

Definição 1.3 (Cópula) Uma cópula d-dimensional é uma função $C$ com domínio $\mathcal{D}(C)=$ $[0 ; 1]^{d}$, tal que:

1. C é uma função aderente e d-crescente.

2. $C$ possui marginais $C_{k}, k=1, \ldots, d$, que satisfaz $C_{k}(u)=u$ para todo $u \in[0 ; 1]$.

Cópulas podem ser interpretadas como funções de distribuições com marginais uniformes.

Teorema 1.3.1 (Sklar) Seja F uma função de distribuição d-dimensional com margi- 
nais $F_{1}, \ldots, F_{d}$. Assim, existe uma cópula d-dimensional $C$, tal que, para todo $x \in \overline{\mathbb{R}}^{d}$,

$$
F\left(x_{1}, \cdots, x_{d}\right)=C\left(F_{1}\left(x_{1}\right), \cdots, F_{n}\left(x_{d}\right)\right)
$$

Se $F_{1}, \ldots, F_{d}$ são todas contínuas, então $C$ é única, caso contrário, $C$ será unicamente determinada em $\mathcal{D}(C)=\mathcal{I}\left(F_{1}\right) \times \ldots \times \mathcal{I}\left(F_{d}\right)$. De maneira inversa, se $C$ é uma d-cópula e $F_{1}, \ldots, F_{d}$ são funções de distribuições, então, a função $F$ definida pela equação (1.2) é um função de distribuição d-dimensional com marginais $F_{1}, \ldots, F_{d}$.

Conforme Kolev, Anjos e Mendes (2006), uma conseqüência da Definição 1.3, é possibilidade de escrever a Cópula $d$-dimensional da seguinte maneira:

$$
C\left(F_{1}\left(x_{1}\right), \cdots, F_{n}\left(x_{d}\right)\right)=\prod_{i=1}^{d} F_{i}\left(x_{i}\right)+D\left(F_{1}\left(x_{1}\right), \cdots, F_{d}\left(x_{d}\right)\right)
$$

para $D\left(F_{1}\left(x_{1}\right), \cdots, F_{d}\left(x_{n}\right)\right) \in[0 ; 1]^{d}$ e $D\left(F_{1}\left(x_{1}\right), \cdots, F_{d}\left(x_{d}\right)\right)$ representa toda a informação da dependência de $\left\{X_{1}, \cdots, X_{d}\right\}$.

Uma classe de cópulas ordinárias bastante usada em Finanças, é a Arquimedeana, que pode ser definida pela seguinte proposição:

Proposição 1.4 Seja $\phi:[0 ; 1] \longrightarrow[0 ; \infty]$ uma função contínua estritamente crescente, então,

$$
C(u, v)=\phi^{-1}(\phi(u)+\phi(v))
$$

é uma cópula Arquimedeana se e somente se $\phi$ for convexa e $\phi(0) \triangleq 1$. $\phi$ é conhecida como a função geradora da família.

Uma prova desta proposição pode ser encontrada em (NELSEN, 1999, p.90). Para a família Clayton, $\phi(t)=\left(t^{-\phi}-1\right) / \phi$ e para a cópula independente $C_{\perp}, \phi(t)=-\ln (t)$. Para conhecer outras famílias de cópulas pertencentes a classe Arquimedeanas consultar (NELSEN, 1999, p.94-97).

\subsection{Dependência para Processos de Lévy}

Vamos agora discutir a modelagem multivariada concebida usando o Processo de Lévy. Modelamos a estrutura de dependência separadamente das marginais e para empreender a primeira parte usamos a cópula. Por uma questão didática vamos inicialmente 
desenvolver o caso bidimensional e depois damos a versão multidimensional.

Para cada $t>0$ fixado, temos que o processo de Lévy bidimensional $\left(X_{t}, Y_{t}\right)$ é um vetor aleatório. Assim, a estrutura de dependência deste vetor pode ser parametrizada pela cópula $C_{t}$ associada a $\left(X_{t}, Y_{t}\right)$ para cada $t>0$. Entretanto, esta abordagem apresenta desvantagens:

1. Salvo no caso dos processos estáveis, a cópula $C_{t}$ pode depender de $t$. $C_{s}$ para certo $s \neq t$ não pode, em geral, ser calculada a partir de $C_{t}$, pois ela também depende de suas marginais.

2. Para uma dada distribuição infinitamente divisível de $X_{t}$ e $Y_{t}$, não é possível definir em quais circunstâncias a cópula $C_{t}$ representará uma distribuição bidimensional infinitamente divisível.

3. As distribuições dos componentes de um processo de Lévy multidimensional são usualmente especificadas pelas suas medidas de Lévy. Assim, seria estranho usar cópulas de distribuições de probabilidade.

A propriedade da cópula de variáveis aleatórias serem invariantes às transformações estritamente crescentes das marginais, não é adequada para caracterizar o conceito de dependência no contexto dos processos de Lévy. A propriedade de divisibilidade infinita de uma variável aleatória é destruída por transformações estritamente crescentes sobre si mesma. Assim, é necessário redefinir o conceito de dependência, estabelecendo alguma outra forma de transformação, que mantenha as propriedades da estrutura dinâmica de um processo de Lévy.

Uma maneira de driblar essas dificuldades é recorrer a representação de LévyKhintchine de forma a descrever a dependência em termos da tripla $(\gamma, \boldsymbol{\Sigma}, \nu)$ do processo.

Claro que usando esta representação é possível caracterizar a dependência via subordinação de um MB por um processo de Lévy crescente conforme mencionado na introdução. Aqui, o interesse é fazer a caracterização via cópulas.

Sabemos pela Decomposição de Lévy-Itô que o termo contínuo do processo de Lévy é independente do termo que produz os saltos. Com isso, é possível modelar a dependência dos saltos de maneira separada da parte contínua. Como a estrutura de dependência da parte contínua de um processo de Lévy (MB) é inteiramente caracterizada pela matriz 
de covariâncias e como este tipo de dependência é muito bem conhecida, a partir deste ponto vamos considerar apenas os processos de Lévy sem o componente gaussiano, i.e., com $\Sigma=0$. Em outras palavras, usaremos cópulas para caracterizar dependências dos saltos nas trajetórias do processo.

Para dar uma noção de como a dependência pode ser caracterizada pela tripla $(\gamma, \Sigma, \nu)$ do processo mostramos em seguida como suas marginais e a independência entre elas podem ser representadas em termos de sua medida de Lévy.

Proposição 1.5 (Marginais do Processo de Lévy) Seja $\left(X_{t}, Y_{t}\right)_{t \geq 0}$ um processo de Lévy com trinca $(\gamma, \Sigma, \nu)$. A marginal $\left\{X_{t}\right\}_{t \geq 0}$ possui tripla caracterizadora $\left(\gamma_{X}, \Sigma_{X}, \nu_{X}\right)$, dada por:

$$
\begin{aligned}
\Sigma_{X} & =\Sigma_{11} \\
\nu_{X}(B) & =\nu(B \times]-\infty ; \infty[), \forall B \in \mathcal{B}(\mathbb{R}) \\
\gamma_{X} & =\gamma_{1}+\int_{\mathbb{R}^{2}} x\left(\mathbf{1}_{\left\{x^{2} \leq 1\right\}}-\mathbf{1}_{\left\{x^{2}+y^{2} \leq 1\right\}}\right) \nu(\mathrm{d} x \times \mathrm{d} y) .
\end{aligned}
$$

Isto significa que as marginais de uma medida de Lévy podem ser calculadas da mesma maneira que as marginais de uma medida de probabilidade.

O resultado segue diretamente das propriedades de uma transformação linear de um processo de Lévy como vistas em Cont e Tankov (2004, Teorema 4.1, p.105).

Proposição 1.6 (Independência dos Processos de Lévy) Seja $\left(X_{t}, Y_{t}\right)_{t \geq 0}$ um processo de Lévy com medida de Lévy $\nu$ sem o termo gaussiano. Seus componentes são independentes se e somente se o suporte de $\nu$ está contido no conjunto $\{\{x, y\}: x y=0\}$, i.e., se e somente se os componentes não apresentam saltos no mesmo instante de tempo. Neste caso,

$$
\nu(B)=\nu_{X}\left(B_{X}\right)+\nu_{Y}\left(B_{Y}\right)
$$

sendo que $B_{X}=\{x:\{x, 0\} \in B\}$ e $B_{Y}=\{y:\{0, y\} \in B\}$, e $\nu_{X}$ e $\nu_{Y}$ são as medidas de Lévy de $\left\{X_{t}\right\}_{t \geq 0} e\left\{Y_{t}\right\}_{t \geq 0}$.

Para uma prova do resultado, veja (CONT; TANKOV, 2004, Proposição 5.3, p.144). 


\subsubsection{Cópulas para Processos de Lévy de Saltos Positivos}

Conforme Cont e Tankov (2004, p.145), para parametrizar a dependência entre os saltos de processos de Lévy, a medida de Lévy executará o mesmo papel que a medida de probabilidade executa para as variáveis aleatórias. Assim, para modelar a dependência, é necessário criar cópulas para as medidas de Lévy. A principal diferença da cópula ordinária para a cópula de uma medida de Lévy é que esta última não é necessariamente finita, i.e., ela tem uma singularidade no zero que não é integrável. Também, cópulas de Lévy são definidas em intervalos infinitos, ao invés de intervalos em $[0 ; 1]^{2}$. Cópulas bidimensionais de Lévy para processos com saltos positivos são funções $C^{\mathcal{L}}:[0 ; \infty]^{2} \longrightarrow[0 ; \infty]$ e, de uma forma geral, elas são funções $C^{\mathcal{L}}: \overline{\mathbb{R}}^{2} \longrightarrow \overline{\mathbb{R}}$.

Para o caso de processos de Lévy com saltos positivos, o papel da função de distribuição é exercido pela integral caudal.

\subsubsection{Integral Caudal e Medidas de Lévy}

Para toda medida de Lévy $\nu$ em $[0 ; \infty[$, definimos a sua integral caudal da seguinte maneira:

$$
\begin{aligned}
U\left(x_{1}, x_{2}\right) & =0 \text { se } x_{1}=\infty \text { ou } x_{2}=\infty ; \\
U\left(x_{1}, x_{2}\right) & =\nu\left(\left[x_{1} ; \infty\left[,\left[x_{2} ; \infty[) \text { para }\left\{x_{1}, x_{2}\right\} \in \mathbb{R}_{+}^{2} \backslash\{0\} ;\right.\right.\right.\right. \\
U(0,0) & =\infty .
\end{aligned}
$$

Uma integral caudal bidimensional, com as propriedades de continuidade apresentadas na Definição 1.2, define uma medida positiva $\nu$ em $\mathbb{R}_{+}^{2} \backslash\{0\}$. Entretanto, para que seja uma medida de Lévy, $\nu$ deve satisfazer a condição de integrabilidade apresentada na Decomposição de Lévy-Itô:

$$
\int_{[0 ; \infty]^{2}}\left(|x|^{2} \wedge 1\right) \nu(\mathrm{d} x)<\infty \Longleftrightarrow \int_{[0 ; \infty]^{2}}\left(|x|^{2} \wedge 1\right) U(\mathrm{~d} x)<\infty,
$$

sendo que $U$ é uma medida de Lebesgue, que existe porque $U$ é uma função crescente. $\mathrm{O}$ seguinte lema mostra quando esta condição de integrabilidade é satisfeita.

Lema 1.7 Seja $U$ uma integral caudal bidimensional com marginais $U_{1}$ e $U_{2}$. $U$ define uma medida de Lévy em $\mathbb{R}_{+}^{2} \backslash\{0\}$, i.e., a condição de integrabilidade apresentada na equa- 
ção (1.6) é satisfeita se e somente se as marginais de $U$ correspondem a medidas de Lévy em $\mathbb{R}_{+}$, i.e., para $k \in\{1,2\}$,

$$
\int_{0}^{1} x^{2} U_{k}(\mathrm{~d} x)<\infty
$$

Aos interessados na prova, referenciamos (CONT; TANKOV, 2004, Lema 5.2, p.147).

Teorema 1.7.1 Seja $\left(X_{t}, Y_{t}\right)_{t \geq 0}$ um processo de Lévy bidimensional com saltos positivos, integral caudal $U$ e marginais da integral caudal $U_{1}$ e $U_{2}$. Existe uma cópula de Lévy bidimensional $C^{\mathcal{L}}$ que caracteriza a estrutura de dependência de $\left(X_{t}, Y_{t}\right)_{t \geq 0}$, i.e., para todo $x_{1}, x_{2} \in[0 ; \infty]$,

$$
U\left(x_{1}, x_{2}\right)=C^{\mathcal{L}}\left(U_{1}\left(x_{1}\right), U_{2}\left(x_{2}\right)\right)
$$

Se $U_{1}$ e $U_{2}$ forem contínuas, esta cópula de Lévy é única. Caso contrário, ela será unicamente determinada em $\mathcal{D}\left(C^{\mathcal{L}}\right)=\mathcal{I}\left(U_{1}\right) \times \mathcal{I}\left(U_{2}\right)$. No sentido inverso, seja $\left\{X_{t}\right\}_{t \geq 0} e$ $\left\{Y_{t}\right\}_{t \geq 0}$ dois processos de Lévy unidimensionais com saltos positivos que possuem integrais caudais $U_{1}$ e $U_{2}$ e, $C^{\mathcal{L}}$ é uma cópula positiva de Lévy bidimensional. Assim, existe um processo de Lévy com cópula de Lévy $C^{\mathcal{L}}$ com integrais caudais marginais $U_{1}$ e $U_{2}$, sendo que a integral caudal será dada pela equação (1.8).

A prova deste teorema pode ser encontrado em (CONT; TANKOV, 2004). A primeira parte deste teorema dispõe que todos os tipos de dependência existentes entre processos de Lévy, incluindo dependência completa e independência, podem ser representadas por cópulas de Lévy e, a segunda parte do teorema, mostra que é possível construir modelos baseados em processos de Lévy multivariados ao especificar a estrutura de dependência dos saltos separadamente das distribuições unidimensionais dos componentes do modelo. A distribuição dos componentes podem apresentar estruturas bastante diferentes e, em particular, é possível acoplar processos compostos de Poisson com os de atividades infinitas.

Conforme Cont e Tankov (2004, p.148), quando a dependência é especificada por meio de uma cópula de Lévy e, a cópula e as integrais caudais marginais são suficientemente suaves, a medida de Lévy pode ser calculada pela seguinte diferenciação:

$$
\nu\left(x_{1}, x_{2}\right)=\left.\frac{\partial^{2} C^{\mathcal{L}}\left(y_{1}, y_{2}\right)}{\partial y_{1} \partial y_{2}}\right|_{y_{1}=U_{1}\left(x_{1}\right), y_{1}=U_{2}\left(x_{2}\right)} \nu_{1}\left(x_{1}\right) \nu_{2}\left(x_{2}\right)
$$




\subsubsection{Exemplos de Cópulas de Lévy Positivas}

Apresentamos em seguida as cópulas de Lévy correspondentes às várias estruturas de dependência básicas.

Exemplo 1.8 (Independência) Seja $\left(X_{t}, Y_{t}\right)_{t \geq 0}$ um processo de Lévy com componentes independentes. Pela Proposição 1.6, a medida de Lévy deste processo é dada por

$$
\begin{aligned}
\nu(B) & =\nu_{1}\left(B_{X}\right)+\nu_{2}\left(B_{Y}\right) \\
\nu\left(\left[x_{1} ; \infty\right] \times\left[x_{2} ; \infty\right]\right) & =\nu_{1}\left(\left[x_{1} ; \infty\right]\right)+\nu_{2}\left(\left[x_{2} ; \infty\right]\right) \\
& =\nu\left(\left[x_{1} ; \infty\right] \times[0 ; \infty]\right) \mathbf{1}_{\left\{x_{2}=0\right\}}+\nu\left([0 ; \infty] \times\left[x_{2} ; \infty\right]\right) \mathbf{1}_{\left\{x_{1}=0\right\}} \\
U\left(x_{1}, x_{2}\right) & =U\left(x_{1}, 0\right) \mathbf{1}_{\left\{x_{2}=0\right\}}+U\left(0, x_{2}\right) \mathbf{1}_{\left\{x_{1}=0\right\}} \\
& =U_{1}\left(x_{1}\right) \mathbf{1}_{\left\{x_{2}=0\right\}}+U_{2}\left(x_{2}\right) 1_{\left\{x_{1}=0\right\}} .
\end{aligned}
$$

A cópula de Lévy de processos independentes é calculada usando a equação (1.8):

$$
\begin{aligned}
C_{\perp}^{\mathcal{L}}\left(y_{1}, y_{2}\right) & =U\left(U_{1}^{-1}\left(y_{1}\right), U_{2}^{-1}\left(y_{2}\right)\right) \\
& =U_{1}\left(U_{1}^{-1}\left(y_{1}\right)\right) \mathbf{1}_{\left\{U_{2}^{-1}\left(y_{2}\right)=0\right\}}+U_{2}\left(U_{2}^{-1}\left(y_{2}\right)\right) \mathbf{1}_{\left\{U_{1}^{-1}\left(y_{1}\right)=0\right\}} \\
& =y_{1} \mathbf{1}_{\left\{y_{2}=\infty\right\}}+y_{2} \mathbf{1}_{\{y 1=\infty\}} .
\end{aligned}
$$

Quando $U_{1}$ e $U_{2}$ não forem contínuas, a equação (1.9) será apenas uma das possibilidades de cópulas de Lévy para o processo bidimensional $\left(X_{t}, Y_{t}\right)_{t \geq 0}$.

No outro extremo temos a dependência completa dos saltos ou comonotonicidade dos componentes de um processo de Lévy com saltos positivos. Para discuti-la vamos definir o conceito de um conjunto crescente.

Definição 1.9 Um subconjunto $S \subset \overline{\mathbb{R}}^{2}$ é denominado crescente se para todo dois vetores $\left\{v_{1}, v_{2}\right\} \in S$ e $\left\{u_{1}, u_{2}\right\} \in S$, ou $v_{k}<u_{k}$ ou $v_{k}>u_{k}$ para $\forall k$.

Um elemento de um conjunto crescente é completamente determinado por apenas uma coordenada, o que motiva a seguinte definição de dependência dos saltos:

Definição 1.10 Seja $X=\left(X_{t}^{1}, X_{t}^{2}\right)_{t \geq 0}$ um processo de Lévy com saltos positivos. Seus saltos são perfeitamente dependentes ou comonotônicos se existir um subconjunto crescente $S \in] 0 ; \infty\left[^{2}\right.$, de modo que, todo salto $\Delta X$ é um elemento de $S$. 
Se os saltos de dois processos de Lévy que se movem puramente por saltos forem perfeitamente dependentes, a trajetória de um deles pode ser reconstruída por meio do conhecimento da trajetória do outro.

Proposição 1.11 (Dependência Perfeita) Seja $X=\left(X_{t}^{1}, X_{t}^{2}\right)_{t \geq 0}$ um processo de Lévy com saltos positivos. Se os seus saltos forem completamente dependentes, então, a (possivel) cópula de Lévy de X é uma cópula de Lévy completamente dependente, que é definida por:

$$
C_{\|}^{\mathcal{L}}\left(x_{1}, x_{2}\right)=\min \left(x_{1}, x_{2}\right)
$$

De maneira inversa, se uma cópula de Lévy de $X$ é dado por $C_{\|}^{\mathcal{L}}$ e, as integrais caudais de seus componentes forem contínuas, então, os saltos de $X$ são completamente dependentes.

Demonstração Os saltos de $X$ são perfeitamente dependentes se e somente se existir um subconjunto crescente $S \in] 0 ; \infty\left[^{2}\right.$, tal que, a medida de Lévy $\nu$ está concentrada em $S$. Desta maneira, para todo $x=\left(x_{1}, x_{2}\right)$ e $y=\left(y_{1}, y_{2}\right)$,

$$
U(x)=\nu(\{y \geq x\} \cap S)=\int_{\{y \geq x\} \cap S} \nu(\mathrm{d} y)
$$

Por meio desta igualdade é possível obter as desigualdades para as marginais:

$$
U_{k}\left(x_{k}\right)=\nu\left(\left\{y_{k} \geq x_{k}\right\} \cap S\right)=\int_{\left\{y_{k} \geq x_{k}\right\} \cap S} \nu(\mathrm{d} y), k \in\{1,2\}
$$

Conforme Kallsen e Tankov (2006) é possível verificar que $U(x) \leq U_{k}\left(x_{k}\right)$, para qualquer $k \mathrm{e}$,

$$
\left\{y \in S: y_{k} \geq x_{k}\right\} \cap S=\{y \in S: y \geq x\} \cap S
$$

para algum $k$, o que implica em

$$
U(x)=\min \left(U_{1}\left(x_{1}\right), U_{2}\left(x_{2}\right)\right) .
$$

Por outro lado, quando a integral caudal de $X$ apresenta a forma da equação (1.10) a medida de Lévy está concentrada no conjunto $\left\{\left(x_{1}, x_{2}\right): U_{1}\left(x_{1}\right)=U_{2}\left(x_{2}\right)\right\}$. Se as integrais caudais $U_{1}$ e $U_{2}$ forem contínuas, então este conjunto é crescente.

Exemplo 1.12 (Dependência de Processos Estáveis) Cópulas de Lévy de processos estáveis satisfazem

$$
C^{\mathcal{L}}\left(c x_{1}, c x_{2}\right)=c C^{\mathcal{L}}\left(x_{1}, x_{2}\right), \forall c>0
$$

ou seja, elas são funções homogêneas de ordem 1. Portanto, pela Decomposição de Lévy- 
Itô, para a medida de Lévy de processos estáveis vale

$$
\nu(B)=c^{\alpha} \nu(c B), \forall c>0, \forall B \in \mathcal{B}\left(\mathbb{R}^{2}\right)
$$

de modo que a integral caudal satisfaz

$$
U\left(c x_{1}, c x_{2}\right)=c^{-\alpha} U\left(x_{1}, x_{2}\right)
$$

Concluímos que a cópula de Lévy de um processo estável é homogênea de ordem 1, ao substituir as marginais $\alpha$-estáveis nesta última fórmula. Antecipamos que este exemplo é uma cópula de Lévy da família Arquimedeana com gerador $\phi(x)=\frac{\exp \{-x\}}{1-\exp \{-x\}}$ (Proposição 1.14).

\subsubsection{Construção de Cópulas de Lévy Positivas}

A fórmula

$$
C^{\mathcal{L}}\left(y_{1}, y_{2}\right)=U\left(U_{1}^{-1}\left(y_{1}\right), U_{2}^{-1}\left(y_{2}\right)\right)
$$

não coopera na interpretação das cópulas de Lévy, pois ela não é construtiva. Isto motivou desenvolver outras maneiras de obtê-las:

Proposição 1.13 Seja C uma 2-cópula (ordinária) e $f(x)$ uma função convexa crescente definida como $f:[0 ; 1] \longrightarrow[0 ; \infty]$.

$$
C^{\mathcal{L}}(x, y)=f\left(C\left(f^{-1}(x), f^{-1}(y)\right)\right)
$$

define uma cópula de Lévy positiva bidimensional.

Demonstração $C^{\mathcal{L}}$ ser uma função 2-crescente provém da Definição 1.3. $C^{\mathcal{L}}$ ser aderente e ter as propriedades das marginais são de constatação imediata.

Um exemplo de função $f:[0 ; 1] \longrightarrow[0 ; \infty]$ que pode ser utilizada nesta proposição é dada por $f(x)=\frac{x}{1-x}$. Por analogia, cópulas Arquimedeanas permitem construir cópulas de Lévy Arquimedeanas.

Proposição $\mathbf{1 . 1 4}$ Seja $\phi(u)$ uma função convexa estritamente decrescente $\phi:[0 ; \infty] \longrightarrow$ $[0 ; \infty]$, tal que, $\phi(0)=\infty$ e $\phi(\infty)=0$. Então,

$$
C^{\mathcal{L}}(x, y)=\phi^{-1}(\phi(x)+\phi(y))
$$


fornece-nos uma cópula de Lévy positiva bidimensional.

Demonstração Segue novamente da Definição 1.3, dado que $\phi^{-1}(-u)$ é crescente e convexa.

Exemplo 1.15 (Família Clayton de cópulas de Lévy) Para $\phi(u)=u^{-\theta} \operatorname{com} \theta>0$, obtém-se a seguinte família paramétrica de cópulas de Lévy:

$$
C_{\theta}^{\mathcal{L}}(u, v)=\left(u^{-\theta}+v^{-\theta}\right)^{-1 / \theta}
$$

que relembra a família de cópulas de Clayton, veja (NELSEN, 1999, p.96). Como casos limites temos a completa dependência $(\theta \longrightarrow \infty)$ e a independência $(\theta \downarrow 0)$.

Exemplo 1.16 (Família Frank de cópulas de Lévy) Para $\phi(u)=-\log (1-\exp (-\theta u)$ $\operatorname{com} \theta>1$, tem-se a seguinte família de cópulas de Lévy:

$$
C_{\theta}^{\mathcal{L}}(u, v)=\frac{-1}{\theta} \log \left\{1-\left(e^{-\theta u}-1\right)\left(e^{-\theta v}-1\right)\right\}
$$

que relembra a família de cópulas de Frank, veja (NELSEN, 1999, p.97). Nos casos limites temos a completa dependência $(\theta \longrightarrow \infty)$ e a independência $(\theta \downarrow 1)$.

Até onde sabemos esta proposta de extensão da família Frank de cópulas é inédita.

\subsubsection{Interpretação Probabilística}

As cópulas de Lévy não são funções de distribuições, mas as suas derivadas possuem uma interpretação probabilística. Kallsen e Tankov (2006), provam o seguinte lema:

Lema 1.17 Seja $C^{\mathcal{L}}$ uma cópula de Lévy bidimensional. Para todo $x \in[0 ; \infty]$, a função

$$
C_{x}^{\mathcal{L}}(y)=\frac{\partial}{\partial x} C^{\mathcal{L}}(x, y)
$$

existe e é contínua para todo $y \in[0 ; \infty]$ a menos de um conjunto enumerável. Desta maneira, $C_{x}^{\mathcal{L}}(y)$ é uma função de distribuição de uma variável aleatória positiva, de maneira que, $C_{x}^{\mathcal{L}}(y)$ é uma função crescente e satisfaz $C_{x}^{\mathcal{L}}(0)=0$ e $C_{x}^{\mathcal{L}}(\infty)=1$. 
A interpretação desse resultado é objeto do teorema seguinte, que mostra que $C^{\mathcal{L}}$ determina uma distribuição de saltos (transformados) do segundo componente, condicionado ao tamanho do salto do primeiro componente. Esta propriedade será útil para simular processos de Lévy. Para uma prova veja (TALEB, 1997).

Teorema 1.17.1 Seja $\left(X_{t}, Y_{t}\right)_{t \geq 0}$ um processo de Lévy bidimensional com saltos positivos, possuindo integrais caudais marginais $U_{1}$ e $U_{2}$ e cópula de Lévy igual a $C^{\mathcal{L}}$. Seja $\Delta X_{t} e$ $\Delta Y_{t}$ o tamanho dos saltos dos dois componentes do processo no instante de tempo $t$. Se $U_{1}$ possuir uma densidade não-negativa em $x, C_{U_{1}(x)}^{\mathcal{L}}$ é a função de distribuição de $U_{2}\left(\Delta Y_{t}\right)$ condicionada em $\Delta X_{t}=x$ :

$$
C_{U_{1}(x)}^{\mathcal{L}}(y)=\mathbb{P}\left[U_{2}\left(\Delta Y_{t}\right) \mid \Delta X_{t}=x\right]
$$

A extensão para o caso multivariado do que foi feito nesta seção é apresentada na Seção ??.

\subsection{Cópulas Gerais de Processos de Lévy}

Vamos estender os conceitos para os processos de Lévy que apresentam saltos tanto positivos como negativos, como segue:

Definição 1.18 (Cópula de Lévy) $C^{\mathcal{L}}(x, y):[-\infty ; \infty]^{2} \longrightarrow[-\infty ; \infty]$ é uma cópula de Lévy se satisfizer as seguintes propriedades:

1. $C^{\mathcal{L}}$ é 2-crescente;

2. $C^{\mathcal{L}}(0, x)=C^{\mathcal{L}}(x, 0)=0, \forall x ; e$,

3. $C^{\mathcal{L}}(x, \infty)-C^{\mathcal{L}}(x,-\infty)=C^{\mathcal{L}}(\infty, x)-C^{\mathcal{L}}(-\infty, x)=x$.

Com isto observamos que a cópula de Lévy positiva pode ser estendida para uma cópula de Lévy geral ao estabelecermos que $C^{\mathcal{L}}(x, y)=0$ se $x<0$ ou $y<0$. 


\subsubsection{Medidas de Lévy com Densidades}

Começamos com este caso porque aí a modelagem é simples. Considere, inicialmente, a idéia de uma integral caudal de uma medida de Lévy definida em $\mathbb{R}$.

Definição 1.19 Seja $\nu$ uma medida de Lévy em $\mathbb{R}$. A integral caudal de $\nu$ é uma função $U: \overline{\mathbb{R}} \backslash\{0\} \longrightarrow[0 ; \infty]$ definida como

$$
\begin{aligned}
U(x) & =\nu([x ; \infty[), x \in] 0 ; \infty[ \\
U(x) & =-\nu([-\infty ; x[), x \in]-\infty ; 0[, \\
U(\infty) & =U(-\infty)=0 .
\end{aligned}
$$

Os sinais foram estabelecidos de maneira tal que a integral caudal é uma função decrescente tanto para $x \in] 0 ; \infty[$, como para $x \in]-\infty ; 0[$.

A construção de densidades de Lévy bidimensionais por meio de cópulas de Lévy suficientemente suaves e densidades de Lévy unidimensionais sai do resultado seguinte.

Proposição 1.20 Seja $C^{\mathcal{L}}$ uma cópula de Lévy bidimensional, contínua em $\overline{\mathbb{R}}^{2}$, tal que $\frac{\partial^{2} C^{\mathcal{L}}(u, v)}{\partial u \partial v}$ existe em $\mathbb{R}^{2}$ e sejam $U_{1}$ e $U_{2}$ as integrais caudais unidimensionais com densidades $\nu_{1}$ e $\nu_{2}$. Assim,

$$
\left.\frac{\partial^{2} C^{\mathcal{L}}(u, v)}{\partial u \partial v}\right|_{u=U_{1}\left(x_{1}\right), v=U_{2}\left(x_{2}\right)} \nu_{1}\left(x_{1}\right) \nu_{2}\left(x_{2}\right)
$$

é a densidade de Lévy de uma medida de Lévy com densidades de Lévy marginais $\nu_{1}$ e $\nu_{2}$.

\subsubsection{Cópulas Gerais de Lévy}

No caso da cópula de Lévy e as integrais caudais marginais não forem suficientemente suaves, a integral caudal multidimensional deve substituir a densidade de Lévy. A fim de evitar a singularidade da medida de Lévy na origem vamos desmembrar o domínio dessa medida em regiões (quadrantes ou cantos) similares a considerada na medida positiva e trabalhá-las separadamente. No caso unidimensional são necessárias duas integrais caudais: $U^{+}$e $U^{-}$e no caso bidimensional, quatro: $U^{++}, U^{+-}, U^{-+}$e $U^{--}$.

Definição 1.21 Seja $\nu$ uma medida de Lévy em $\mathbb{R}$. Esta medida apresenta duas integrais 
caudais, $U^{+}:[0 ; \infty] \longrightarrow[0 ; \infty]$ para a parte positiva $e, U^{-}:[-\infty ; 0] \longrightarrow[-\infty ; 0]$ para a parte negativa, definidas como:

$$
\begin{aligned}
U^{+}(x) & =\nu([x ; \infty[), x \in] 0 ; \infty[ \\
U^{+}(0) & =\infty, U^{+}(\infty)=0, \\
U^{-}(x) & =\nu(]-\infty, x]), x \in]-\infty ; 0[, \\
U^{-}(-\infty) & =0, U^{-}(0)=-\infty .
\end{aligned}
$$

Seja $\nu$ uma medida de Lévy em $\mathbb{R}^{2}$ com integrais caudais marginais $U_{1}^{+}, U_{1}^{-}, U_{2}^{+}$ e $U_{2}^{-}$. Esta medida possui quatro integrais caudais, i.e., $U^{++}, U^{+-}, U^{-+}$e $U^{--}$, sendo que, cada integral caudal é definida no seu respectivo quadrante, incluindo o eixo das coordenadas, como segue:

$$
\begin{aligned}
& U^{++}(x, y)=\nu([x ; \infty[\times[y ; \infty[), x, y \in] 0 ; \infty[ \\
& \left.U^{+-}(x, y)=-\nu([x ; \infty[\times]-\infty, y]), x \in\right] 0 ; \infty[, y \in]-\infty ; 0[ \\
& \left.U^{-+}(x, y)=-\nu(]-\infty, x\right] \times[y ; \infty[), x \in]-\infty ; 0[, y \in] 0 ; \infty[ \\
& \left.\left.\left.\left.\left.U^{--}(x, y)=\nu(]-\infty, x\right] \times\right]-\infty, y\right]\right), x, y \in\right]-\infty ; 0[.
\end{aligned}
$$

Se $x$ ou $y$ for igual a $-\infty$ ou $+\infty$, a integral caudal correspondente é igual a zero. Se $x$ ou $y$ for igual a 0 , a integral caudal satisfaz as seguintes condições marginais:

$$
\begin{aligned}
& U^{++}(x, 0)-U^{+-}(x, 0)=U_{1}^{+}(x) \\
& U^{-+}(x, 0)-U^{--}(x, 0)=U_{1}^{-}(x) \\
& U^{++}(0, y)-U^{-+}(0, y)=U_{2}^{+}(y) \\
& U^{+-}(0, y)-U^{--}(0, y)=U_{2}^{-}(y) .
\end{aligned}
$$

Quando uma medida de Lévy bidimensional precisa mensurar qualquer eixo das coordenadas sua integral caudal não é unicamente determinada pois não fica claro qual das integrais caudais deve conter a densidade nos eixos. Desta maneira, conjuntos diferentes para as integrais caudais podem representar a mesma medida de Lévy.

Teorema 1.21.1 Seja $\nu$ uma medida de Lévy em $\mathbb{R}^{2}$ com suas integrais caudais marginais 
$U_{1}^{+}(x), U_{1}^{-}(x), U_{2}^{+}(y)$ e $U_{2}^{-}(y)$. Existe uma cópula de Lévy $C^{\mathcal{L}}$ satisfazendo,

$$
\begin{aligned}
U^{++}(x, y) & \left.=C^{\mathcal{L}}\left(U_{1}^{+}(x), U_{2}^{+}(y)\right), x, y \in\right] 0 ; \infty[ \\
U^{+-}(x, y) & \left.=C^{\mathcal{L}}\left(U_{1}^{+}(x), U_{2}^{-}(y)\right), x \in\right] 0 ; \infty[, y \in]-\infty ; 0[ \\
U^{-+}(x, y) & \left.=C^{\mathcal{L}}\left(U_{1}^{-}(x), U_{2}^{+}(y)\right), x \in\right]-\infty ; 0[, y \in] 0 ; \infty[ \\
U^{--}(x, y) & \left.=C^{\mathcal{L}}\left(U_{1}^{-}(x), U_{2}^{-}(y)\right), x, y \in\right]-\infty ; 0[.
\end{aligned}
$$

Se as integrais caudais marginais são absolutamente contínuas e, $\nu$ não mensura os eixos das coordenadas, a cópula de Lévy é única. De maneira inversa, se $C^{\mathcal{L}}$ é uma cópula de Lévy e $U_{1}^{+}(x), U_{1}^{-}(x), U_{2}^{+}(y)$ e $U_{2}^{-}(y)$ são integrais caudais unidimensionais de medidas de Lévy então as fórmulas acima definem as integrais caudais da medida de Lévy bidimensional.

Demonstração A cópula de Lévy pode ser construída em cada um dos quatro quadrantes ao utilizar o Teorema 1.7.1 e o Lema 1.7. Com esta construção, é possível obter uma função 2-crescente em cada um dos quadrantes, mas não para todo $\mathbb{R}^{2}$. Apesar disto, o fato de cada uma das quatro partes serem contínuas nos seus respectivos domínios, incluindo os eixos das coordenadas e serem iguais à zero nos extremos das caudas garante que $C^{\mathcal{L}}$ é uma função 2-crescente em $\overline{\mathbb{R}}^{2}$.

Exemplo 1.22 (Processos de Lévy Independentes) Dado que a medida de Lévy bidimensional de um processo de Lévy com componentes independentes tem suporte nos eixos das coordenadas, a correspondente cópula de Lévy não é única. Neste caso, a Proposição 1.6 garante que para todo $x$ e $y$, tal que, $x y \neq 0$, integral caudal correspondente é igual a zero. Assim, $C^{\mathcal{L}}(x, y)=0$ se $x$ e y forem finitos. Pelas fórmulas (1.19) vemos que cada cópula de Lévy que satisfaça esta propriedade é independente. Exemplos de cópulas de Lévy independentes são $x \mathbf{1}_{\{y=\infty\}}+y \mathbf{1}_{\{x=\infty\}} e-x \mathbf{1}_{\{y=-\infty\}}-y \mathbf{1}_{\{x=-\infty\}}$.

Exemplo 1.23 (Dependência Perfeita) Para processos de Lévy com saltos de sinais arbitrários, é possivel distinguir dois tipos de dependência completa. No primeiro (dependência completa positiva) existe um subconjunto crescente $S \subset \mathbb{R}^{2}$, tal que, cada salto $\Delta X$ de um processo bidimensional pertence ao conjunto S. Nesta situação, ao utilizar o mesmo método da Proposição 1.11, tem-se

$$
\begin{aligned}
& U^{++}(x, y)=\min \left(U_{1}^{+}(x), U_{2}^{+}(y)\right) \\
& U^{--}(x, y)=\min \left(-U_{1}^{-}(x),-U_{2}^{-}(y)\right) \\
& U^{+-}(x, y)=U^{-+}(x, y) \triangleq 0 .
\end{aligned}
$$

Desta maneira, $C_{\uparrow \uparrow}^{\mathcal{L}}(x, y)=\min (|x|,|y|) 1_{\{x y \geq 0\}}$ é uma possivel cópula para este processo. 
No caso de dependência completa negativa, os saltos de um processo bidimensional devem estar contidos em um subconjunto decrescente em $\mathbb{R}^{2}$, i.e., o conjunto $S$, tal que para todo dois vetores $\left(v_{1}, v_{2}\right) \in S e\left(u_{1}, u_{2}\right) \in S$, tanto $\nu_{1}>u_{1}$ e $v_{2}<u_{2}$ ou, $\nu_{1}<u_{1}$ e $v_{2}>u_{2}$. Neste caso:

$$
\begin{aligned}
& U^{+-}(x, y)=-\min \left(U_{1}^{+}(x),-U_{2}^{-}(y)\right) \\
& U^{-+}(x, y)=-\min \left(-U_{1}^{-}(x), U_{2}^{+}(y)\right) \\
& U^{++}(x, y)=U^{--}(x, y) \triangleq 0
\end{aligned}
$$

$e C_{\uparrow \downarrow}^{\mathcal{L}}(x, y)=-\min (|x|,|y|) 1_{\{x y \leq 0\}}$.

Exemplo 1.24 (Família Clayton Generalizada) Considere a cópula de Lévy apresentada na equação (1.14). É possivel definir uma família de cópulas de Lévy uniparamétrica, que inclui a independência e as dependências completas positiva e negativa.

$$
C_{\theta}^{\mathcal{L}}(u, v)=\left\{\begin{array}{ll}
\left(|u|^{-\theta}+|v|^{-\theta}\right)^{-1 / \theta} \mathbf{1}_{\{u v \geq 0\}}, & \text { se } \theta>0 \\
-\left(|u|^{\theta}+|v|^{\theta}\right)^{1 / \theta} \mathbf{1}_{\{u v \leq 0\}}, & \text { se } \theta<0
\end{array} .\right.
$$

Ao calcular os limites, tem-se que

$$
\begin{aligned}
& C_{\theta}^{\mathcal{L}} \longrightarrow C_{\uparrow \downarrow}^{\mathcal{L}}, \text { quando } \theta \longrightarrow-\infty \\
& C_{\theta}^{\mathcal{L}} \longrightarrow C_{\perp}^{\mathcal{L}}, \text { quando } \theta \longrightarrow 0 \\
& C_{\theta}^{\mathcal{L}} \longrightarrow C_{\uparrow \uparrow}^{\mathcal{L}}, \text { quando } \theta \longrightarrow \infty .
\end{aligned}
$$

Exemplo 1.25 (Família Frank Generalizada) Considere agora a cópula de Lévy apresentada na equação (1.15). Neste caso definimos uma família de cópulas de Lévy uniparamétrica, que também inclui a independência e as dependências completas positiva e negativa.

$$
C_{\theta}^{\mathcal{L}}(u, v)=\left\{\begin{array}{cc}
\frac{-1}{\theta} \log \left\{1-\left(e^{-\theta|u|}-1\right)\left(e^{-\theta|v|}-1\right)\right\} \mathbf{1}_{\{u v \geq 0\}} & \text { se } \theta>0 \\
\frac{1}{\theta} \log \left\{1-\left(e^{\theta|u|}-1\right)\left(e^{\theta|v|}-1\right)\right\} \mathbf{1}_{\{u v \leq 0\}} & \text { se } \theta<0
\end{array} .\right.
$$

Tem-se, ao calcular os limites, que

$$
\begin{aligned}
& C_{\theta}^{\mathcal{L}} \longrightarrow C_{\uparrow \downarrow}^{\mathcal{L}}, \text { quando } \theta \longrightarrow-\infty \\
& C_{\theta}^{\mathcal{L}} \longrightarrow C_{\perp}^{\mathcal{L}}, \text { quando }|\theta|<\infty \\
& C_{\theta}^{\mathcal{L}} \longrightarrow C_{\uparrow \uparrow}^{\mathcal{L}}, \text { quando } \theta \longrightarrow \infty .
\end{aligned}
$$


A dificuldade nessa construção reside no fato das Proposições 1.13 e 1.14 não poderem ser estendidas diretamente. Uma possível solução é agrupar cópulas de Lévy positivas, adaptadas de forma a especificar as dependências dos saltos de diferentes sinais separadamente. Ou seja, tomamos $C^{\mathcal{L}++}, C^{\mathcal{L}--}, C^{\mathcal{L}-+}$ e $C^{\mathcal{L}+-}$ cópulas de Lévy positivas e as reunimos segundo a expressão:

$$
\begin{aligned}
C^{\mathcal{L}}(x, y)= & C^{\mathcal{L}++}\left(c_{1}|x|, c_{2}|y|\right) \mathbf{1}_{\{x \geq 0, y \geq 0\}}+C^{\mathcal{L}--}\left(c_{3}|x|, c_{4}|y|\right) \mathbf{1}_{\{x \leq 0, y \leq 0\}} \\
& -C^{\mathcal{L}+-}\left(c_{5}|x|, c_{6}|y|\right) \mathbf{1}_{\{x \geq 0, y \leq 0\}}-C^{\mathcal{L}-+}\left(c_{7}|x|, c_{8}|y|\right) \mathbf{1}_{\{x \leq 0, y \geq 0\}} .(1
\end{aligned}
$$

Note que $C^{\mathcal{L}}$ é 2 -crescente se as constantes $c_{1}, \ldots, c_{8}$ forem positivas. As condições marginais implicam em quatro restrições adicionais, e.g., para $x>0$ tem-se que $C^{\mathcal{L}}(x, \infty)-$ $C^{\mathcal{L}}(x,-\infty)=c_{1} x+c_{5} x=x$, o que implica em $c_{1}+c_{5}=1$. As outras restrições implicam $c_{3}+c_{7}=1, c_{2}+c_{8}=1$ e $c_{4}+c_{6}=1$. Desta maneira, é possível reescrever a equação acima como:

$$
\begin{aligned}
C^{\mathcal{L}}(x, y)= & C^{\mathcal{L}++}\left(c_{1}|x|, c_{2}|y|\right) \mathbf{1}_{\{x \geq 0, y \geq 0\}}+C^{\mathcal{L}--}\left(c_{3}|x|, c_{4}|y|\right) \mathbf{1}_{\{x \leq 0, y \leq 0\}} \\
& -C^{\mathcal{L}+-}\left(\left(1-c_{1}\right)|x|,\left(1-c_{4}\right)|y|\right) \mathbf{1}_{\{x \geq 0, y \leq 0\}} \\
& -C^{\mathcal{L}-+}\left(\left(1-c_{3}\right)|x|,\left(1-c_{2}\right)|y|\right) \mathbf{1}_{\{x \leq 0, y \geq 0\}}
\end{aligned}
$$

que define uma cópula de Lévy se as constantes $c_{1}, c_{2}, c_{3}, c_{4} \in[0 ; 1]$.

Vamos interpretar esta construção. As medidas de Lévy marginais são denotadas por $\nu_{1}$ e $\nu_{2}$. Olhamos cada membro do lado direito da equação (1.25) originando uma medida de Lévy separadamente. A integral caudal do primeiro quadrante é

$$
U^{++}(x, y)=C^{\mathcal{L}++}\left(c_{1} U_{1}^{+}(x), c_{2} U_{2}^{+}(y)\right)
$$

Isto corresponde a uma medida de Lévy associada a um processo de Lévy de saltos positivos. Suas medidas de Lévy marginais são $c_{1} \nu_{1}(\mathrm{~d} x) \mathbf{1}_{\{x>0\}}$ e $c_{2} \nu_{2}(\mathrm{~d} y) \mathbf{1}_{\{y>0\}}$. Os outros quadrantes são vistos de maneira análoga. Dessa forma, vemos que a cópula apresentada pela equação (1.25) é a soma de quatro partes independentes, cada uma delas correspondendo a um quadrante do domínio da medida de Lévy. A componente referente ao primeiro quadrante regula apenas os saltos positivos de $x$ e positivos de $y$ com as marginais dadas acima e a estrutura de dependência dada por $C^{\mathcal{L}++}$. A segunda parte independente referente ao segundo quadrante regula os saltos negativos de $x$ e positivos de $y$. Suas marginais são dadas por $\left(1-c_{3}\right) \nu_{1}(\mathrm{~d} x) \mathbf{1}_{\{x<0\}}$, e $\left(1-c_{2}\right) \nu_{2}(\mathrm{~d} y) \mathbf{1}_{\{y>0\}}$. Sua estrutura de dependência é regulada pela cópula de Lévy positiva $C^{\mathcal{L}-+}$. As outras duas partes independentes relativas ao terceiro e quarto quadrantes são interpretadas de maneira análoga. 
A cópula apresentada na equação (1.25) é denominada cópula de Lévy de proporções constantes porque a proporção de saltos nos dois componentes correlacionados não depende do tamanho dos saltos (apenas do seu sinal). Estas últimas estão longe de representar o universo de todas a cópulas, porém elas são numerosas o suficiente para satisfazerem a maioria das aplicações práticas. Somado a isso, as cópulas de Lévy de processos estáveis sempre podem ser representadas pela forma dada pela equação (1.25).

Disponibilizamos no Apêndice as extensões necessárias para as cópulas de Lévy generalizadas multivariadas.

\subsection{Aplicações}

Apresentamos uma forma de aplicação da cópula de Lévy. Como no caso das cópulas ordinárias, a escolha apropriada da cópula de Lévy permite distinguir a dependência linear de outras formas de dependências para modelar os log-retornos de ativos financeiros. Esta distinção possui aplicações em modelos de gestão de risco, onde os movimentos conjuntos de saltos negativos nos log-retornos de ativos financeiros são importantes.

Inicialmente, a cópula ordinária foi sugerida como um instrumento viável para modelar opções européias que dependem de mais de um ativo objeto, também denominadas opções multivariadas, vide (CHERUBINI; LUCIANO; VECCHIATO, 2004, capítulo 8). Basicamente existem dois tipos de contratos de opções multivariadas. O primeiro trata de uma cesta de ativos, isto é, o ativo objeto $S_{T}$ é uma carteira, que pode ser representada por

$$
\begin{aligned}
\tilde{S}_{T} & =\sum_{i=1}^{N} \alpha_{i} S_{T}^{i} \\
\text { sujeito à } \sum_{i=1}^{N} \alpha_{i} & =1 \text { e } \alpha_{i} \geq 0 .
\end{aligned}
$$

$S^{i}, \quad i=1, \ldots, N$ são os ativos da carteira que apresentam dependências entre si e $T=$ data de exercício do artigo-objeto.

O outro contrato trata de uma escolha de performance, ou seja, o ativo objeto é o ativo que atingiu a melhor performance durante o prazo de validade do contrato, i.e.,

$$
\tilde{S}_{T}=S_{T}^{\varphi}
$$


onde

$$
\varphi=\arg \max _{1 \leq i \leq N}\left(\frac{S_{T}^{i}}{S_{0}^{i}}\right) \text { ou } \varphi=\arg \min _{1 \leq i \leq N}\left(\frac{S_{T}^{i}}{S_{0}^{i}}\right) .
$$

O parâmetro $\varphi$ tem como objetivo identificar o ativo que obteve o resultado ótimo, e dependendo do tipo de contrato, i.e., se tratar-se de opção de compra (call) ou de venda (put), este argumento pode maximizar ou minimizar a performance. Entretanto, a utilização de cópulas ordinárias para apreçar opções que dependem da trajetória (pathdependent) de $\tilde{S}$ é inadequada, pois estes contratos dependem da informação em toda a trajetória do processo estocástico que gera os preços dos ativos em análise (DGPs). O conhecimento da estrutura de dependência dos ativos no instante terminal do processo não é suficiente para mensurar o preço do contrato adequadamente. Segue abaixo a função de ganhos e perdas no vencimento $H_{T}$ de algumas opções enquadradas na classe de dependentes das trajetórias:

1. opção lookback de compra padrão

$$
H_{T}=\tilde{S}_{T}-\min _{0 \leq t \leq T}\left(\tilde{S}_{t}\right)
$$

2. opção lookback de venda padrão

$$
H_{T}=\max _{0 \leq t \leq T}\left(\tilde{S}_{t}\right)-S_{T}
$$

3. opção lookback de compra sobre o máximo

$$
H_{T}=\max \left\{\max _{0 \leq t \leq T}\left(\tilde{S}_{t}\right)-K, 0\right\}
$$

4. opção lookback de venda sobre o mínimo

$$
H_{T}=\max \left\{K-\min _{0 \leq t \leq T}\left(\tilde{S}_{t}\right), 0\right\}
$$

5. opção asiática de compra sobre a média do preço do ativo-objeto

$$
H_{T}=\max \left\{\langle\tilde{S}\rangle_{T}-K, 0\right\}
$$


6. opção asiática de venda sobre a média do preço do ativo-objeto

$$
H_{T}=\max \left\{K-\langle S\rangle_{T}, 0\right\}
$$

7. opção asiática de compra sobre a média do preço de exercício

$$
H_{T}=\max \left\{\tilde{S}-\langle\tilde{S}\rangle_{T}, 0\right\}
$$

8. opção asiática de venda sobre a média do preço de exercício

$$
H_{T}=\max \left\{\langle\tilde{S}\rangle_{T}-\tilde{S}, 0\right\}
$$

onde $\tilde{S}$ representa o ativo objeto que pode depender de mais de um ativo, $K$ o valor de exercício, $\langle\tilde{S}\rangle_{T}$ a média do ativo ao longo do tempo até o instante $T$. Existem duas maneiras de calcular esta média, em detalhes, aritiméticamente $\langle S\rangle_{A}=T^{-1} \sum_{t=0}^{T} \tilde{S}_{t}$ ou geometricamente, $\langle\tilde{S}\rangle_{G}=\left(\prod_{t=0}^{T} \tilde{S}_{t}\right)^{T^{-1}}$.

O preço de do derivativo $V_{t}$ será dado pela expressão

$$
V_{t}=e^{-(T-t) r_{f}} \mathbb{E}^{\mathbb{Q}}\left[H_{T} \mid \mathcal{F}_{t}\right]
$$

onde $H_{T}$ não necessariamente está limitado as formas apresentadas nas equações (1.30) até (1.37), e, $r_{f}$ representa a taxa livre de risco.

Observe que a esperança do lado direito da equação (1.38) é realizada na medida neutralizadora do risco, isto é, na medida $\mathbb{Q} .{ }^{1}$ Diferentemente da medida $\mathbb{P}$, que pode ser estimada objetivamente ou subjetivamente por meio de dados históricos, a medida $\mathbb{Q}$ é medida sintética, ou seja, é construída por algum modelo estatístico de modo a possuir a propriedade que, sob ela, o processo dos $\log$-retornos $\left\{X_{t}\right\}_{t \geq 0}$ é um martingale. ${ }^{2}$ Pode-

\footnotetext{
${ }^{1}$ Devido as propriedades de $\mathbb{Q}$ alguns autores a denominam de medida EMM, ou medida martingale equivalente.

${ }^{2}$ Podemos definir um processo martingale como:

Definição 1.26 Seja $\left\{X_{t}\right\}_{t \geq 0}$ um processo de Lévy definido no espaço de probabilidade filtrado $\left(\Omega,\left\{\mathcal{F}_{t}\right\}_{t \geq 0}, \mathbb{P}\right)$. Dizemos que $\left\{X_{t}\right\}_{t \geq 0}$ é um processo martingale em relação a medida medida $\mathbb{P}$ se

$$
\mathbb{E}^{\mathbb{P}}\left[X_{t+\Delta t} \mid \mathcal{F}_{t}\right]=X_{t}, \text { q.c. }
$$
}

onde $\Delta t>0$. 
mos interpretar a propriedade martingale de um processo como, dada toda a informação disponível em $\mathcal{F}_{t}$, ela determina que o melhor previsor do preço no futuro é o preço de hoje. Entretanto, seria interessante que a informação contida na medida $\mathbb{P}$ contribua para a construção de $\mathbb{Q}$, tornando o modelo descrito pela equação (1.38) economicamente interpretável.

A derivada de Radon Nikodym $d \mathbb{Q} / d \mathbb{P}$, vide (SHIRYAEV, 1999, p.434), nos permite calcular a esperança no lado direito da equação (1.38) na medida observada $\mathbb{P}$, como segue:

$$
V_{t}=e^{-(T-t) r_{f}} \mathbb{E}^{\mathbb{P}}\left[\frac{d \mathbb{Q}}{d \mathbb{P}} H_{T} \mid \mathcal{F}_{t}\right]
$$

Para que $\frac{d \mathbb{Q}}{d \mathbb{P}}$ faça sentido, as medidas $\mathbb{P}$ e $\mathbb{Q}$ devem ser equivalentes, ${ }^{3}$ ou seja, a medida $\mathbb{Q}$ não deve atribuir probabilidade zero para nenhum evento (conjunto) onde $\mathbb{P}$ atribua probabilidade positiva, e vice e versa. Isto significa se existe a possibilidade de ocorrências de eventos adversos ou benéficos, eles devem contribuir para a formação do preço $V_{t}$, o que não ocorre se atribuir probabilidade zero a estes eventos sob a medida $\mathbb{Q}$.

Sem muita formalização, temos que o Teorema Fundamental de Apreçamento de Ativos, vide (SHIRYAEV, 1999, p.413), nos diz que a existência de uma medida $\mathbb{Q}$ garante as propriedades de não arbitragem ${ }^{4}$, e pelo Segundo Teorema Fundamental de Apreçamento de Ativos, vide (SHIRYAEV, 1999, p.481), temos que a unicidade da medida $\mathbb{Q}$ implica completitude do mercado, ou seja, existe um único preço livre de arbitragem. Desta maneira, caso exista mais de uma medida $\mathbb{Q}$ equivalente a $\mathbb{P}$ então não teremos um preço único, mas um intervalo de valores de preços que o derivativo poderá assumir. O preço que será praticado no mercado, dependerá, assim, das preferências (propriedades das funções de utilidades) dos agentes financeiros.

Esta questão pode ser resolvida estimando-se a derivada de Radom-Nykodim $d \mathbb{Q} / d \mathbb{P}$. Fajardo e Mordecki (2006) abordaram a questão da mudança de medida no contexto bivariado. A metodologia sugerida por eles permite o desenvolvimento de fórmulas analíticas para alguns tipos de opções, tais como: opção de inadimplência, opções de Margrabe, opções de swap, e, opções quanto. Entretanto, esta metodologia está fundamentada na

\footnotetext{
${ }^{3}$ Podemos definir medidas equivalentes como:

Definição 1.27 Sejam $\nu$ e $\eta$ duas medidas de Lévy definidas no espaço mensurável $(\Omega, \mathcal{F})$ e $A \subset \mathcal{F}$ um conjunto não vazio. Dizemos que $\nu$ e $\eta$ são medidas equivalentes, ou simplesmente, $\nu \sim \eta$, se e somente se, para todo $A \subset \mathcal{F}$,

$$
\nu(A)=0 \Longleftrightarrow \eta(A)=0 .
$$

${ }^{4}$ Mais tecnicamente, no contexto dos processos de Lévy, estes devem ser $\sigma$-martingales e a existência de uma medida $\mathbb{Q}$ que atenda esta propriedade garante a condição de NFLVR (No Free Lunch with Vanishing Risk), isto é, não existe almoço grátis quando o risco se extingue, condição equivalente a de não arbitragem. Para maiores detalhes vide (DELBAEN; SCHACHERMAYER, 1998).
} 
hipótese que a função de payoffs $H_{T}$ do derivativo é homogênea nos ativos-objetos, o que limita a sua aplicação.

Desta maneira, seguiremos a abordagem mais comum, proposta por Geber e Shiu (1994), que utiliza a transformada de Esscher e permite nos lidar de maneira mais objetiva com a questão da existência de um preço livre de arbitragem, conforme é mostrado pelo seguinte teorema:

Teorema 1.27.1 Seja $\left\{X_{t}\right\}_{0 \leq t \leq T}$ um processo de Lévy definido no espaço de probabilidade filtrado $\left(\Omega,\left\{\mathcal{F}_{t}\right\}_{0 \leq t \leq T}, \mathbb{P}\right)$ e caracterizado por pela tripla $(\gamma, \Sigma, \nu)$. Para um $\theta \in \mathbb{R}$, se

$$
\mathbb{E}^{\mathbb{P}}\left[e^{\theta X_{T}}\right]<\infty
$$

então

$$
\frac{d \mathbb{P}^{\theta}}{d \mathbb{P}}=\frac{e^{\theta X_{T}}}{E^{\mathbb{P}}\left[e^{\theta X_{T}}\right]}=e^{\theta X_{T}-\psi(\theta) T},
$$

onde $\mathbb{E}^{\mathbb{P}}\left[e^{\theta X_{T}}\right]=e^{\psi(\theta) T} . \mathbb{P}^{\theta}$ define a medida de probabilidade, tal que $\mathbb{P}$ e $\mathbb{P}^{\theta}$ são equivalentes, e $\left\{X_{t}\right\}_{t \geq 0}$ sob a medida $\mathbb{P}^{\theta}$ é caracterizado pela tripla $\left(\gamma^{\theta}, \Sigma^{\theta}, \nu^{\theta}\right)$ dado

$$
\begin{aligned}
\gamma^{\theta} & =\gamma+\theta \Sigma+\int_{-\infty}^{\infty}\left(e^{\theta \cdot x}-1\right) x \mathbf{1}_{\{|x| \leq 1\}} \nu(\mathrm{d} x) \\
\Sigma^{\theta} & =\Sigma \\
\nu^{\theta}(\mathrm{d} x) & =e^{\theta x} \nu(\mathrm{d} x) .
\end{aligned}
$$

A prova deste teorema pode ser encontrada em (HUBALEK; SGARRA, 2006). A condição descrita pela equação (1.40) garante a existência de uma medida $\mathbb{P}^{\theta}$ equivalente a $\mathbb{P}$, e, pelo Teorema Fundamental de Apreçamento de Ativos, garantimos que o preço será livre de arbitragem (não existe almoço grátis). A transformada de Esscher é descrita pela equação (1.41) e possui a propriedade de alterar não só a tendência determinística $\gamma$, como também a medida de Lévy $\nu$. Observe que o componente que descreve o processo de difusão $\Sigma$, não se altera, sendo que o Teorema de Girsanov torna-se um caso particular desta transformada, correspondendo ao caso quando $\nu=0$.

Entretanto, o processo, sob à medida equivalente $\mathbb{P}^{\theta}$, não é necessariamente um processo martingale. Assim, conforme é apontado por Hubalek e Sgarra (2006, equação 33) ou Shiryaev (1999, equação 37, p.688), devemos introduzir a condição adicional

$$
\psi(\theta+1)-\psi(\theta)=0
$$


e se seguirmos a mesma linha de raciocínio da equação (1.40), necessitamos também que

$$
\mathbb{E}^{\mathbb{P}}\left[e^{(\theta+1) X_{T}}\right]<\infty
$$

Resolver a equação (1.45), significa obter as raízes de um polinômio, que em geral não são iguais. Desta maneira, quando houver duas ou mais raízes distintas, temos pelo Segundo Teorema Fundamental de Apreçamento de Ativos que o mercado é incompleto, ou seja, haverá mais de um preço livre de arbitragem sendo negociado pelos agentes de mercado.

Existem algumas abordagens para lidar com a incompletitude de mercado, entretanto, não nos aprofundaremos na discussão para não fugir do escopo deste trabalho. Apenas para ilustrar, podemos citar os seguintes critérios:

- medida martingale de mínima entropia, vide (FRITTELLI, 2000):

$$
\mathbb{Q}=\arg \min I(\mathbb{Q}, \mathbb{P})
$$

onde $I$ é a entropia relativa, vide (COVER; THOMAS, 2006), entre $\mathbb{Q}$ e $\mathbb{P}$, que mede o quanto a distribuição $\mathbb{Q}$ diverge em relação a $\mathbb{P}$, e pode ser expressa como:

$$
I(\mathbb{Q}, \mathbb{P})= \begin{cases}\mathbb{E}^{\mathbb{P}}\left[\frac{d \mathbb{Q}}{d \mathbb{P}} \log \left(\frac{d \mathbb{Q}}{d \mathbb{P}}\right)\right], & \text { se } \mathbb{P}>0 \\ +\infty, & \text { se } \mathbb{P}=0\end{cases}
$$

- medida martingale do máximo preço, vide (KAROUI; QUENEZ, 1995):

$$
\mathbb{Q}=\arg \max \mathbb{E}^{\mathbb{Q}}\left[H_{T} \mid \mathcal{F}_{t}\right]
$$

Este critério avalia o preço sob à perspectiva do vendedor de um derivativo, visando, assim, obter o preço máximo.

- medida martingale de máxima utilidade, vide (ROUGE; KAROUI, 2000):

$$
\mathbb{Q}=\arg \max \mathbb{E}^{\mathbb{Q}}\left[u\left(H_{T}\right) \mid \mathcal{F}_{t}\right]
$$

onde $u$ é uma função de utilidade que orientará o comportamento do investidor, ou agente representativo do mercado. Este critério avalia o preço sob a perspectiva do comprador, ou seja, o comprador quer maximizar a sua satisfação ao comprar um instrumento financeiro. 


\subsubsection{Modelo do Log-Retorno}

É fácil observar que os ganhos e perdas destes contratos dependem de toda informação da trajetória. Neste caso, a cópula de Lévy é o instrumento adequado, pois ela é capaz de modelar toda a informação desejada. Para aplicar a teoria apresentada no apreçamento dos contratos acima mencionados, vamos assumir que as hipóteses referentes aos processos de de Lévy são válidas, ou seja, temos estacionariedade, incrementos independentes e continuidade estocástica. Note que as duas primeiras hipóteses podem ser testadas, respectivamente, por testes de raízes unitárias, vide (MADDALA; KIM, 1999), e pelo BDS, vide (BROOCK et al., 1996). Seja o processo do log-retorno dado pelo modelo

$$
Y_{t}^{i}=\ln \left(\frac{S_{t}^{i}}{S_{t-1}^{i}}\right)=X_{t}^{i, u}-X_{t}^{i, d}
$$

onde $X_{t}^{i, u}$ é um processo gama do ativo $i$, que orientará o comportamento dos saltos positivos $(u)$ e $X_{t}^{i, d}$ um processo gama que orientará os saltos negativos $(d)$. O processo gama é um processo da classe de Lévy, onde a medida de Lévy é dada por

$$
\nu_{i}^{u, d}(x)=\frac{c_{i}^{u, d} \exp \left\{-\lambda_{i}^{u, d} x\right\}}{x} \mathbf{1}_{\{x>0\}},
$$

onde $\lambda_{i}^{u, d}>0$ determina a taxa de decaimento dos saltos, ou seja, a probabilidade de ocorrerem saltos grandes, e $c_{i}^{u, d}>0$ determina a freqüência dos saltos, sejam pequenos ou grandes, veja (CONT; TANKOV, 2004). O modelo é colocado como a diferença de dois processos Gamas, haja vista que processo gama é um subordinador e possui apenas saltos positivos. Adicionalmente, e sem perda de generalidade, o modelo assume que $\lambda_{i}^{u, d}=\tilde{\lambda}$, isto é, as freqüências de saltos positivos e negativos por unidade de tempo são iguais. Fizermos estas escolhas por conveniência e para facilitar a ilustração da teoria apresentada.

\subsubsection{Estimação}

Existem várias abordagens econométricas para estimar um modelo, dentre as quais as mais freqüentemente utilizadas em finanças são Máxima Verossimilhança (MLE) e Método Generalizado dos Momentos (GMM). O GMM é o método mais robusto, quando comparado com o MLE, sendo preferível sob a perspectiva dos econometristas. A necessidade da robustez ocorre por não se conhecer a verdadeira distribuição que gera ou produz os log-retornos das séries financeiras. Esta robustez tem como custo a perda da 
eficiência do estimador quando se considera o critério do erro quadrático mínimo (MSE). Entretanto, esta perda de eficiência não prejudica a consistência do estimador GMM, mesmo na condição de especificação incorreta do modelo (distribuição dos log-retornos). Por outro lado, o método MLE gera estimadores eficientes, considerando-se o critério MSE. Entretanto, erros na especificação do modelo podem afetar seriamente a consistência do estimador, qualidade indispensável para as aplicações em finanças. Adicionalmente, quando o número de observações é relativamente grande, como é o caso das séries diárias de log-retornos, o problema de eficiência passa a ser secundário, pois utilizamos, em tal situação, as propriedades assintóticas dos estimadores.

Outra questão a ser levantada é que para muitas distribuições não-gaussianas produzidas por atividade infinita de saltos de um processo de Lévy podem não apresentar expressões analíticas que permitam calcular a função de máxima verossimilhança, o que inviabilizaria a utilização do método MLE. Em contrapartida, pelo método GMM, podemos obter estimativas dos parâmetros fazendo uso de um número finito de momentos, o que é sempre possível obter por meio dos dados observados. Dado estas considerações, fica evidente que as vantagens do GMM quando comparado com o MLE, desta maneira adotaremos o método GMM em nossas aplicações.

Considerando o modelo descrito na subseção anterior, o processo do log-retorno apresentará incrementos ostentando a seguinte pdf (função de densidade de probabilidade) sob a medida $\mathbb{P}$ :

$$
Y_{\Delta t}^{i} \sim p_{\Delta t}^{i, u}\left(x_{u}\right) p_{\Delta t}^{i, d}\left(x_{d}\right), x_{u}>0 \text { e } x_{d}>0
$$

onde

$$
p_{\Delta t}^{i, u, d}=\frac{\tilde{\lambda}_{i}^{\left(c^{u, d} \Delta t\right)}}{\Gamma\left(c_{i}^{u, d} \Delta t\right)} x_{u, d}^{\left(c_{i}^{u, d} \Delta t\right)-1} \exp \left\{-\tilde{\lambda}_{i} x_{u, d}\right\}
$$

e $\Gamma(\cdot)$ é a função gama. Como decorrência, temos os seguintes momentos-centrados:

$$
\begin{aligned}
\mu_{0, \Delta t}^{i} & =\left(\frac{c_{i}^{u}-c_{i}^{d}}{\tilde{\lambda}_{i}}\right) \Delta t \\
\mu_{2, \Delta t}^{i} & =\left(\frac{c_{i}^{u}+c_{i}^{d}}{\tilde{\lambda}_{i}^{2}}\right) \Delta t \\
\mu_{3, \Delta t}^{i} & =2\left(\frac{c_{i}^{u}-c_{i}^{d}}{\tilde{\lambda}_{i}^{3}}\right) \Delta t \\
\mu_{4, \Delta t}^{i} & =3\left[\frac{\left(c_{i}^{u}+c_{i}^{d}\right)^{2} \Delta t+2\left(c_{i}^{u}+c_{i}^{d}\right)}{\tilde{\lambda}_{i}^{4}}\right] \Delta t .
\end{aligned}
$$

Temos que $\Delta t$ representa a unidade de medida do tempo, que em geral, na prática, é um dia útil (base 252). Também, usualmente, são válidas as seguintes propriedades 
$c_{i}^{u, d}(T)=T c_{i}^{u, d}(\Delta t)$ e $\tilde{\lambda}_{i}(T)=\tilde{\lambda}_{i}(\Delta t)$. Observe que o parâmetro $\tilde{\lambda}_{i}$ não é influenciado sobre a mudança de escala, ou seja, probabilidade de saltos grandes continua a mesma. Por outro lado, $c_{i}^{u, d}$ depende do tempo, i.e., a freqüência dos saltos é diretamente proporcional ao tempo. Assim, mesmo que $\tilde{\lambda}_{i}$ não dependa do tempo, a medida que $T$ aumenta, uma maior quantidade de saltos ocorrem, e, conseqüentemente, espera-se, uma maior observação de saltos grandes. Levando em consideração os resultados analíticos para os momentos de $Y_{t}^{i}$, é relativamente fácil estimar os parâmetros dos processos dos log-retornos por meio do método GMM, vide (HALL, 2005), que pode ser expresso como

$$
\arg \min _{\theta^{i}}\left(g^{i}\left(\zeta^{i}, Y_{t}^{i}\right)\right)^{\top^{t}}\left(W^{i}\right)^{-1} g^{i}\left(\zeta^{i}, Y_{t}^{i}\right)
$$

onde $\zeta^{i}=\left(c_{i}^{u}, c_{i}^{d}, \tilde{\lambda}_{i}\right) \mathrm{e}$

$$
g^{i}\left(\zeta^{i}, Y_{t}^{i}\right)=\left[\begin{array}{c}
T^{-1} \sum_{t=1}^{T} Y_{t}-\mu_{0, \Delta t}^{i}\left(\zeta^{i}\right) \\
T^{-1} \sum_{t=1}^{T}\left(Y_{t}-T^{-1} \sum_{t=1}^{T} Y_{t}\right)^{2}-\mu_{2, \Delta t}^{i}\left(\zeta^{i}\right) \\
T^{-1} \sum_{t=1}^{T}\left(Y_{t}-T^{-1} \sum_{t=1}^{T} Y_{t}\right)^{3}-\mu_{3, \Delta t}^{i}\left(\zeta^{i}\right) \\
T^{-1} \sum_{t=1}^{T}\left(Y_{t}-T^{-1} \sum_{t=1}^{T} Y_{t}\right)^{4}-\mu_{\Delta t}^{i}\left(\zeta^{i}\right)
\end{array}\right] .
$$

A matriz de pesos $W^{i}$ pode ser estimada pelo procedimento sugerido por Newey e West (1987) utilizando o truncamento que depende do tamanho da amostra para determinar quantas matrizes defasadas de covariâncias devem ser incluídas no procedimento, no caso, a parte inteira de $4(100 T)^{2 / 9}$.

Note que os parâmetros estimados por GMM são obtidos por meio da equação (1.55), que envolve necessariamente algum método de otimização, o que pode envolver questões numéricas. Entretanto, se houverem restrições impostas aos parâmetros a serem estimados, o ponto de partida ou solução inicial do problema de otimização pode não atingir um mínimo global, ou seja, os parâmetros estimados representam uma solução sub-ótima, i.e., um mínimo local.

Para exemplificar, considere as séries temporais diárias dos log-retornos das ações Petrobrás PN (ticker: PETR4 e $i=1$ ) e Vale do Rio Doce PNA N1 (ticker: VALE5 e $i=$ 2), para o período de 2.01.2002 até 2.10.2008, ou seja, uma amostra de tamanho $T=1533$ e intervalo de tempo $\Delta t=1$ (dia útil). Para termos certeza que os parâmetros obtidos fossem resultantes de um mínimo global, utilizamos a função Minimize do Mathematica 6.0, evitando a questão do parágrafo anterior. Esta abordagem produziu as seguintes estimativas para os parâmetros do modelo sob a medida $\mathbb{P}: c_{1}^{u}=1.28947, c_{1}^{d}=1.17862$, $\tilde{\lambda}_{1}=1.73504, c_{2}^{u}=3.74614, c_{2}^{d}=3.50189$, e $\tilde{\lambda}_{2}=2.96173$. 
Uma questão que surge é como realizar a mudança de medida, ou seja, como obter uma medida martingale $\mathbb{Q}$ equivalente equivalente $\mathbb{P}$. A solução está em estimar a derivada de Radom-Nykodim por meio da transformada de Esscher, conforme abordagem sugerida na subseção anterior [equações (1.41) e (1.45)]. Observe que as condições, apresentadas pelas equações (1.40) e (1.46), são satisfeitas vis-à-vis a pdf apresentada na equação (1.50), para $\tilde{\lambda}_{i}>\theta_{i}$, produzindo o seguinte resultado

$$
\mathbb{E}^{\mathbb{P}}\left[e^{\theta_{i} Y_{\Delta t}^{i}}\right]=\tilde{\lambda}_{i}^{\left(c_{i}^{u}+c_{i}^{d}\right) \Delta t}\left(\tilde{\lambda}_{i}-\theta_{i}\right)^{-c_{i}^{u} \Delta t}\left(\tilde{\lambda}_{i}+\theta_{i}\right)^{-c_{i}^{d} \Delta t}<\infty
$$

Assim, garantimos a existência da medida martingale e de um preço livre de arbitragem (Teorema Fundamental de Apreçamento de Ativos). Por outro lado, pela equação (1.45) temos uma única raíz finita, i.e., $\theta_{1}=-0.573527$ e $\theta_{2}=-0.597897$, que atendem a condição $\tilde{\lambda}_{i}>\theta_{i}$. Desta maneira, temos um mercado completo (Segundo Teorema Fundamental de Apreçamento de Ativos) e o preço do derivativo $V_{t}$ poderá ser obtido pela equação (1.39), onde

$$
\frac{d \mathbb{Q}}{d \mathbb{P}}=e^{\theta_{i} Y_{\Delta t}-\psi_{i}\left(\theta_{i}\right) \Delta t} e \psi_{i}\left(\theta_{i}\right)=\frac{1}{\Delta t} \log \mathbb{E}^{\mathbb{P}}\left[e^{\theta Y_{\Delta t}^{i}}\right]
$$

\subsubsection{Simulação de Monte Carlo}

Conhecendo os parâmetros que descrevem o processo de Lévy, isto é a tripla $(\gamma, \Sigma, \nu)$, sob a medida $\mathbb{Q}$, que podem ser obtidos pelo procedimento sugerido na subseção anterior, podemos, por meio do método de simulação de Monte Carlo calcular numericamente os preços dos derivativos discutidos neste artigo. Utilizamos o procedimento sugerido por Rosiński (2001) para gerar os processos gama. Adaptamos os algoritmos para que seja possível simular os processos de Lévy para qualquer unidade de tempo, i.e., fazemos,

$$
X_{t}^{i, u, d}=\sum_{j=1}^{n(j)}\left(\lambda_{i}^{u, d}\right)^{-1} \exp \left\{-\frac{\Gamma_{i, j}^{u, d}}{T c_{i}^{u, d}}\right\} V_{i, j}^{u, d} \mathbf{1}_{\left\{U_{i, j}^{u, d} \leq t\right\}}
$$

onde $c_{i}^{u d}$ e $\lambda_{i}^{u, d}$ são os parâmetros do processo gama medidos para uma unidade de tempo, $T$ é o valor terminal(vencimento do contrato), $\left\{U_{i, j}^{u, d}(0, T)\right\}_{j=1, \ldots, n(j)} \mathrm{e}\left\{V_{i, j}^{u, d}(T)\right\}_{j=1, \ldots, n(j)}$ são seqüências I.I.D. de valores observados, respectivamente, de uma distribuição uniforme no intervalo $[0, T]$ e de uma distribuição exponencial com parâmetro $T$. $\Gamma_{i, j}^{u, d}=\sum_{z=1}^{j} W_{i, z}^{u, d}$, onde $\left\{W_{i, z}^{u, d}(1)\right\}_{z=1, \ldots, n(j)}$ é uma seqüência I.I.D. de valores obtidos de uma distribuição exponencial padronizada e $n(j)=\inf \left\{j: \Gamma_{i, j}^{u, d} \leq \tau\right\}$ é o truncamento da somatória que teoricamente deveria ser indexada em todo conjunto dos naturais. O truncamento $n(j)$ 
depende do parâmetro $\tau$ que determinará a precisão do processo. Quanto maior for $\tau$ teremos uma maior quantidade de termos $\Gamma_{i, j}^{u, d}$ influenciando o processo. Como $\Gamma_{i, j}^{u, d}$ é um processo estritamente crescente, a medida que $j \longrightarrow \infty$, temos que $\Gamma_{i, j}^{u, d} \longrightarrow \infty$ e, conseqüentemente, $\exp \left(-\Gamma_{i, j}^{u, d}\right) \longrightarrow 0$. Assim, como $\tau$ limita os valores aceitáveis de $j$, então significa que ele define a partir de qual magnitude os saltos passam a ser desprezados para compor $X_{t}^{i, u, d}$.

O procedimento de Rosiński (2001) refere-se exclusivamente a séries univariadas marginais, sendo necessário, portanto, incluir uma estrutura da cópula de Lévy para que se possa gerar as séries multivariadas. Consideramos aqui apenas o caso bivariado, i.e., $i=1,2$.

O parâmetro $\Gamma_{2, j}^{u, d}$ pode escrito como uma função de $\Gamma_{1, j}^{u, d}$, por meio da função inversa da equação (1.17), i.e.,

$$
\Gamma_{2, j}^{u, d}=\left(C_{\Gamma_{1, j}^{u, d}}^{\mathcal{L}}\right)^{-1}\left(F_{j}^{u, d}\right),
$$

onde $F_{j}^{u, d}$ representa uma distribuição acumulada, ou seja, $\left\{F_{j}^{u, d}\right\}_{j=1, \ldots, n(j)}$ é uma seqüência I.I.D. de variáveis uniformes padronizadas. Note que neste ponto estamos introduzindo a dependência entre os processos. Aplicando as cópulas de Clayton [equação 1.14] e de Frank [equação 1.15], temos, respectivamente, que,

$$
\begin{aligned}
& \text { Clayton } \quad: \quad \Gamma_{2, j}^{u, d}=\Gamma_{1, j}^{u, d}\left\{\left(F_{j}^{u, d}\right)^{-\frac{\xi^{u, d}}{1+\xi^{u, d}}}-1\right\}^{-\frac{1}{\xi^{u, d}}} \\
& \text { Frank } \quad: \quad \Gamma_{2, j}^{u, d}=\frac{1}{\xi^{u, d}} \log \left(1+\exp \left\{\xi^{u, d} \Gamma_{1, j}^{u, d}\right\}\right)\left(\frac{F_{j}^{u, d}}{1-F_{j}^{u, d}}\right) .
\end{aligned}
$$

Em nossa análise foram utilizados dois softwares: Mathematica 6.0 e Matlab 7.4. Este último mostrou-se bem mais veloz na geração das séries bivariadas acima. Um procedimento de Monte Carlo com $m=10^{2}$ repetições com uma precisão $\tau=10^{3}$, custou algumas frações de segundos no Matlab 7.4 num computador Pentium Duo 2 Core. As Figuras 1.1. e 1.2. nos permitem visualizar as diferentes estruturas das cópulas de Clayton e Frank. Consideramos os seguintes parâmetros, $c_{1}^{u, d}=c_{2}^{u, d}=\lambda_{1}^{u, d}=\lambda_{1}^{u, d}=10, m=10^{3}$, $T=1$, e $\tau=10^{3}$. Podemos ver claramente que a medida que os parâmetros $\theta$ das respectivas cópulas variam $\xi^{u, d}=\left(10^{-3}, 10^{-2}, 10^{-1}, 10^{0}, 10^{1}, 10^{2}, 10^{3}, 10^{4}\right)$, a estrutura de dependência entre as variáveis log-retornos dos ativos 1 e 2 assumem formas que podem afetar bastante os preços dos contratos de opções multivariados com dependências nas trajetórias. 
Das opções mencionadas neste artigo, consideramos as asiáticas de compra e venda sobre a média do preço do ativo-objeto, que neste caso será uma carteira composta pelos dois ativos em análise. Observe que foram calculadas as médias aritiméticas e geométricas. Os resultados apresentados na Tabela 1.1., referem-se aos preços das opções asiáticas de compra usando médias aritimética $(\mathrm{AmC})$ e geométrica $(\mathrm{AgC})$ e das opções asiáticas de venda usando médias aritimética $(\mathrm{AmP})$ e geométrica $(\mathrm{AgP})$, que são obtidos pela equação (1.38), onde o preço de cada ativo é dado por $S_{t}^{i}=S_{0}^{i} \exp \left\{Y_{t}^{i}\right\}$, para $S_{0}^{1}=40$ e $S_{0}^{2}=60$. Foram considerados ambas as cópulas (Clayton e Frank), preço de exercício $K=(20,30, \ldots, 80)$, a proporção de cada um ativo na carteira $\alpha_{1}=(0,0,20, \ldots, 1)$ e $\alpha_{2}=1-\alpha_{1}, r_{f}=0,08, T=1$. Apesar da taxa livre de risco $r_{f}$ ter sido considerada de maneira determinística, isto é, constante ao longo do tempo, é relativamente fácil flexibilizar está hipótese para o contexto local ou estocástico, isto é, a taxa livre de risco é modelada por uma função determinística do tempo (local) ou por um processos estocástico com reversão a média (estocástica). Note que o preço das opções de compra diminuem a medida que o preços de exercícios aumentam e os preços das opções de venda diminuem. Em relação as cópulas, vemos que, para os parâmetros considerados, i.e., $\xi^{u, d}=10^{-1}$ para cópula de Clayton e $\xi^{u, d}=10^{3}$ para a cópula de Frank, a cópula de Frank gera distribuições menos voláteis para os log-retornos das séries, considerando uma dependência linear semelhante, i.e., a mesma auto-correlação serial do processo dos log-retornos, o que implica preços menores para as opções utilizando a cópula de Frank (vide Tabela 1.1.). Nos casos extremos de $\alpha_{1}=0$ ou $\alpha_{1}=1$, temos que a carteira é formada apenas pelo ativo 1 e 2 respectivamente,sendo portanto, os casos de opções univariadas, casos particulares. No que se refere as médias aritiméticas e geométricas, temos que as opções de compra apresentam preços maiores para as médias aritiméticas, e as opções de venda apresentam preços maiores para as médias geométricas. Isso se dá principalmente pelo fato da média aritimética ser sempre maior ou igual que a média geométrica, ou em outras palavras, $\langle\tilde{S}\rangle_{A} \geq\langle\tilde{S}\rangle_{G}$. Deixamos para os interessados o manuseio dos outros contratos apresentados no início desta seção, cujas complexidades são bem menores que as opções asiáticas avaliadas aqui. Por último analisamos o efeito da dependência sobre o valor das opções asiáticas considerando a média aritimética, vide Tabelas 1.2. e 1.3., onde as auto-correlações seriais do processo dos log-retornos foram obtidas considerando os parâmetros $\xi^{u, d}=10(\rho=0,187), \xi^{u, d}=0,8(\rho=0,0943)$, e $\xi^{u, d}=0,5(\rho=0,0482)$ para a cópula de Clayton e $\xi^{u, d}=10^{2}(\rho=0,1259), \xi^{u, d}=10$ $(\rho=0,1068)$, e $\xi^{u, d}=1(\rho=0,0741)$ para a cópula de Frank. Note que a medida que a dependência linear diminui (auto-correlação serial do processo), temos que o preço das opções aumentam. Este resultado vai em conformidade com os princípios de diversificação do risco idiosincrático das ações, haja vista que o ativo objeto é uma carteira de ativos. Quanto mais diversificada for esta carteira, haverá uma tendência de remanescer apenas o risco sistêmico, e conseqüentemente, o preço da opção atingirá o valor máximo dado 
uma mesma estrutura de dependência. Este último resultado deve ser analisado com bastante interesse pois ele permite uma melhoria relevante no processo gestão do risco de mercado. Os programas computacionais utilizados neste trabalho estão disponíveis no site "www.ime.usp.br/ nitanaka/".

\subsection{Análise}

Uma maneira sistematizada de descrever a estrutura de dependência entre duas variáveis estocásticas é por meio de funções de cópulas, entretanto, com a necessidade de melhores instrumentos de gestão de risco, verifica-se um rápido desenvolvimento do mercado de instrumentos financeiros, criam-se derivativos que dependem não só da trajetória do processo do preço, como também, de uma quantidade finitas de ativos. Neste contexto, o estudo apresentou o desenvolvimento recente da teoria de cópulas realizado principalmente por Cont e Tankov (2004) e Kallsen e Tankov (2006), que estende o conceito da cópula ordinária, i.e., cópula para um vetor aleatório, para processos de Lévy, i.e., a cópula de Lévy, permitindo mitigar de uma maneira mais eficiente o processo de apreçamento dos instrumentos financeiros acima citados. A construção de modelos por meio de cópulas de Lévy é uma abordagem que permite especificar a estrutura de dependência entre os logretornos de maneira bastante flexível. Foi apresentado um modelo relativamente didático, considerando as suas preocupações econométricas e utilizando técnicas de simulação de Monte Carlo. O exemplo visou estabelecer uma conexão entre a teoria desenvolvida e a sua aplicação na área de apreçamento de contratos derivativos, mostrando que o método sugerido neste artigo é viável e computacionalmente eficiente. Uma das limitações da análise da aplicação realizada no artigo é a utilização de uma medida de dependência linear (auto-correlação serial), dada a inexistência de uma medida de dependência do processo, ao análogo ao Tau de Kendall para variáveis aleatórias. Uma tentativa seria utilizar a seguinte medida

$$
\tau^{\mathcal{L}}=2 \int_{0}^{\infty} \int_{0}^{\infty} \int_{0}^{\infty} \int_{0}^{\infty} \mathbf{1}_{\left\{\left(x_{2}-x_{1}\right)\left(y_{2}-y_{1}\right) \geq 0\right\}} f_{Y_{1} \mid X_{1}} f_{X_{1}} f_{Y_{2} \mid X_{2}} f_{X_{2}} \mathrm{~d} x_{1} \mathrm{~d} x_{2} \mathrm{~d} y_{1} \mathrm{~d} y_{2}-1
$$

onde

$$
f_{Y \mid X}=\left(\frac{\partial^{2}}{\partial y^{2}} C^{\mathcal{L}}(x, y)\right)
$$

e $f_{X}(x)$ seria a distribuição marginal do log-retorno de $X$. Esta seria uma extensão natural do tau de Kendal, entretanto, a obtenção de soluções analíticas é relativamente difícil. 
Por último, a aplicação desta teoria também poderia ser estendida na gestão de outros riscos, sendo que o novo Acordo da Basiléia II, vide BIS (2005), vem orientando as instituições financeiras a realizarem análises quantitativas de riscos de mercado, crédito, liquidez e operacional, exigindo que os modelos de risco sejam robustos às hipóteses tradicionais de mercado, principalmente em países emergentes como o Brasil, onde a economia não é considerada estável, o que significa que os modelos gaussianos nem sempre são adequados.

\subsection{Extensões}

$? ?$

\subsubsection{Extensões de cópulas positivas de Lévy aos Casos Multi- variados}

Segue um sumário das definições e resultados estendidos aos casos multivariados:

Definição 1.28 (Cópula de Lévy Positiva) Uma cópula de Lévy positiva d-dimensional é uma função d-crescente e aderente $C^{\mathcal{L}}:[0 ; \infty]^{d} \longrightarrow[0 ; \infty]$ com marginais $C_{k}^{\mathcal{L}}, k=$ $1,2, \ldots, d$, que satisfazem $C_{k}^{\mathcal{L}}(u)=u$ para todo $u \in[0 ; \infty]$.

Teorema 1.28.1 Seja U uma integral caudal de um processo de Lévy com saltos positivos d-dimensional e, seja $U_{1}, \ldots, U_{d}$ as integrais caudais de seus componentes. Existe uma cópula de Lévy positiva d-dimensional $C^{\mathcal{L}}$, tal que, todos os vetores $\left\{x_{1}, \cdots, x_{d}\right\}$ em $\mathbb{R}_{+}^{d}$,

$$
U\left(x_{1}, \cdots, x_{d}\right)=C^{\mathcal{L}}\left(U_{1}\left(x_{1}\right), \cdots, U_{d}\left(x_{d}\right)\right)
$$

Se $U_{1}, \ldots, U_{d}$ são contínuas, então, $C^{\mathcal{L}}$ é única, caso contrário, é unicamente determinada em $\mathcal{D}\left(C^{\mathcal{L}}\right)=\mathcal{I}\left(U_{1}\right) \times \cdots \times \mathcal{I}\left(U_{d}\right)$. De maneira inversa, se $C^{\mathcal{L}}$ é uma cópula de Lévy positiva d-dimensional e $U_{1}, \ldots, U_{d}$ são as integrais caudais de medidas de Lévy em $[0 ; \infty[$, então, a função $U$ definida acima é uma integral caudal de um processo de Lévy $n$-dimensional com saltos positivos possuindo marginais $U_{1}, \ldots, U_{d}$. 
A cópula de Lévy independente no caso multivariado possui a seguinte forma:

$$
C_{\perp}^{\mathcal{L}}\left(x_{1}, \cdots, x_{d}\right)=x_{1} 1_{\left\{x_{2}=\infty, \ldots, x_{d}=\infty\right\}}+\cdots+x_{d} 1_{\left\{x_{1}=\infty, \ldots, x_{d-1}=\infty\right\}},
$$

e a cópula de Lévy no caso de dependência perfeita é

$$
C_{\|}^{\mathcal{L}}\left(x_{1}, \cdots, x_{d}\right)=\min \left(x_{1}, \cdots, x_{d}\right) .
$$

Finalmente, é possível apresentar uma versão multidimensional da Proposição 1.14:

Proposição 1.29 Seja $\phi(u)$ uma função estritamente decrescente $\phi:[0 ; \infty] \longrightarrow[0 ; \infty]$, tal que, $\phi(0)=\infty$ e $\phi^{-1}$ possui derivadas de ordem igual a $n$ em $] 0 ; \infty[$ com sinal se alternando com $k$, i.e., $(-1)^{k} \frac{d^{k} \phi^{-1}(t)}{\mathrm{d} t^{k}}>0$. Assim,

$$
C^{\mathcal{L}}\left(x_{1}, \cdots, x_{d}\right)=\phi^{-1}\left(\phi\left(x_{1}\right)+\cdots+\phi\left(x_{d}\right)\right)
$$

define uma cópula de Lévy positiva d-dimensional.

\subsubsection{Extensões aos Casos Multivariados de cópulas de Lévy ge- neralizadas}

Damos a seguir um sumário das definições estendidas aos casos multivariados:

Definição 1.30 (Cópula de Lévy) Uma cópula de Lévy n-dimensional é uma função $C^{\mathcal{L}}: \overline{\mathbb{R}}^{n} \longrightarrow \overline{\mathbb{R}}$ com as seguintes propriedades:

1. $C^{\mathcal{L}}$ é $n$-crescente;

2. $C^{\mathcal{L}}$ é igual a zero se pelo menos um dos seus argumentos for igual a zero;

3. $C^{\mathcal{L}}$ possui marginais uniformes.

Para construir uma medida de Lévy multidimensional por meio de cópulas de Lévy, é necessário introduzir o seguinte intervalo:

$$
\mathbf{I}(x)=\left\{\begin{array}{rr}
{[x ; \infty[,} & \text { se } x>0 \\
]-\infty ; x], & \text { se } x<0
\end{array} .\right.
$$


Ao utilizar esta notação, é possível construir as integrais caudais de uma medida de Lévy em qualquer ponto, salvo naqueles que estão sobre os eixos, como segue:

$$
\nu\left(\mathbf{I}\left(x_{1}\right) \times \cdots \times \mathbf{I}\left(x_{n}\right)\right)=(-1)^{\left(\operatorname{sinal} x_{1} \times \cdots \times \operatorname{sinal} x_{n}\right)} C^{\mathcal{L}}\left(U_{1}^{\text {sinal } x_{1}}\left(x_{1}\right), \ldots, U_{n}^{\text {sinal } x_{n}}\left(x_{n}\right)\right),
$$

sendo que $U_{1}^{+}, U_{1}^{-}, \ldots, U_{n}^{+}, U_{n}^{-}$são as integrais caudais marginais unidimensionais. O fato da não unicidade nos eixos pode ser resolvido como foi feito no caso bidimensional. 

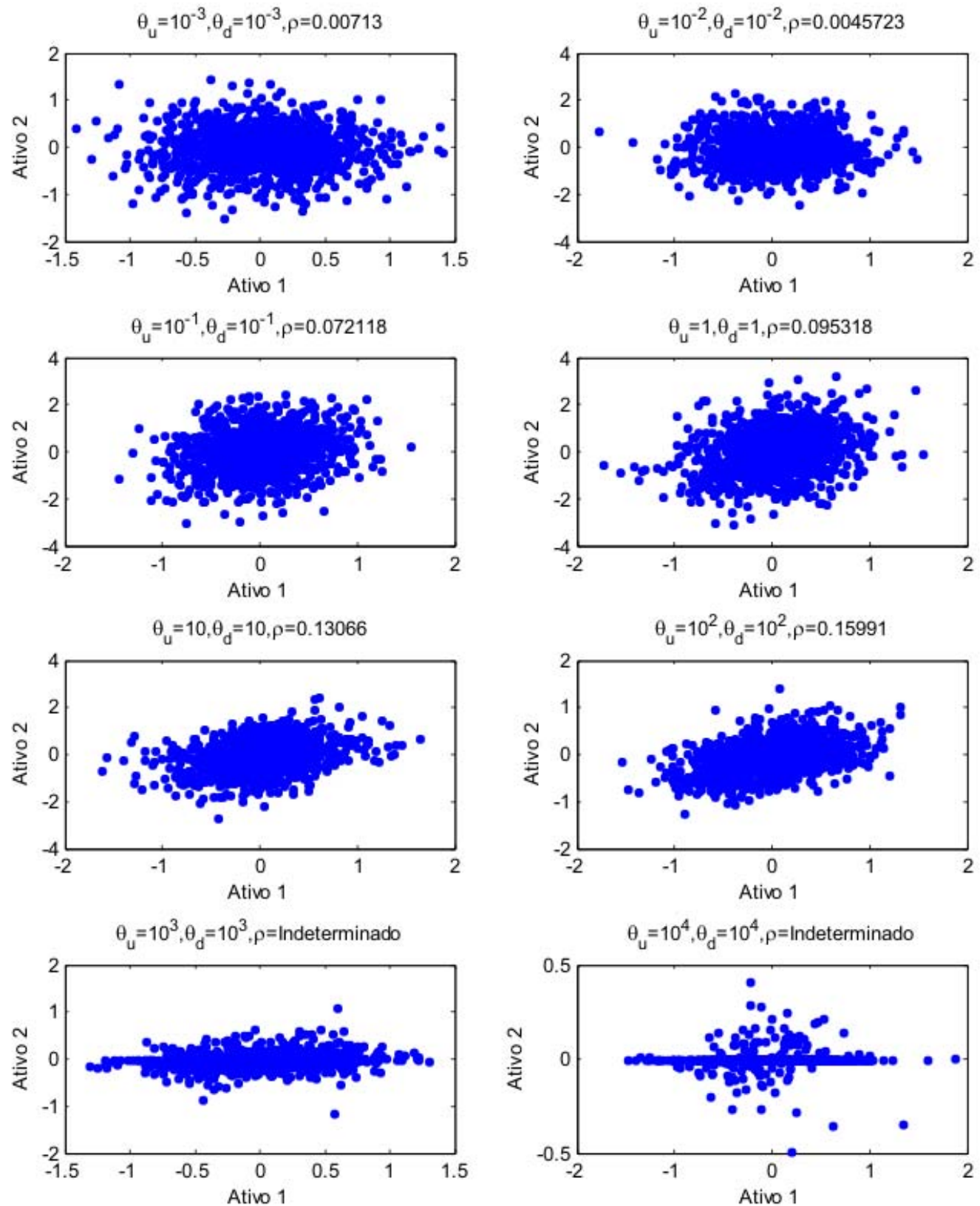

Figura 1.1.: Análise da influência dos parâmetros da cópula de Lévy de Clayton. 

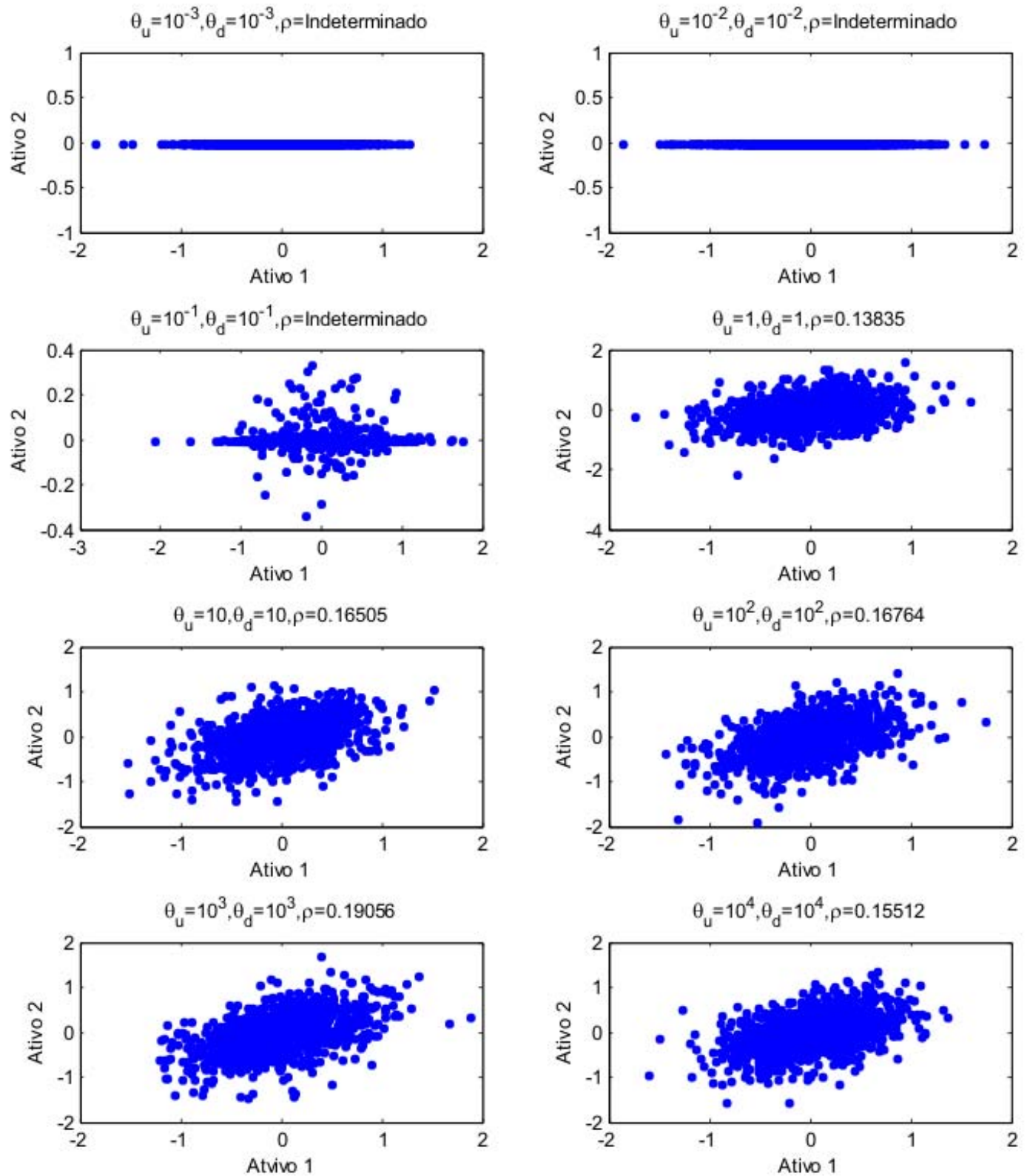

Figura 1.2.: Análise da influência dos parâmetros da cópula de Lévy de Frank. 


\begin{tabular}{|c|c|c|c|c|c|c|c|c|c|}
\hline & \multicolumn{2}{|c|}{$\mathrm{AmC}$} & \multicolumn{2}{|c|}{$\mathrm{AgC}$} & \multicolumn{2}{|c|}{ AmP } & \multicolumn{2}{|c|}{ AgP } \\
\hline$\alpha$ & Strike & Clayton & Frank & Clayton & Frank & Clayton & Frank & Clayton & Frank \\
\hline \multirow[t]{7}{*}{0} & 20 & 29.1272 & 29.1178 & 29.1223 & 29.1178 & 0 & 0 & 0 & 0 \\
\hline & 30 & 21.8472 & 21.8378 & 21.8423 & 21.8378 & 0 & 0 & 0 & 0 \\
\hline & 40 & 14.5672 & 14.5579 & 14.5624 & 14.5579 & 0 & 0 & 0 & 0 \\
\hline & 50 & 7.2944 & 7.2779 & 7.2902 & 7.2779 & 0.0071 & 0 & 0.0078 & 0 \\
\hline & 60 & 0.1133 & 0 & 0.1103 & 0 & 0.1059 & 0.0021 & 0.1079 & 0.0021 \\
\hline & 70 & 0 & 0 & 0 & 0 & 7.2726 & 7.282 & 7.2775 & 7.282 \\
\hline & 80 & 0 & 0 & 0 & 0 & 14.5526 & 14.562 & 14.5575 & 14.562 \\
\hline \multirow[t]{7}{*}{0.2} & 20 & 26.3975 & 26.39 & 26.2615 & 26.2579 & 0 & 0 & 0 & 0 \\
\hline & 30 & 19.1175 & 19.11 & 18.9815 & 18.9779 & 0 & 0 & 0 & 0 \\
\hline & 40 & 11.8376 & 11.83 & 11.7016 & 11.6979 & 0 & 0 & 0 & 0 \\
\hline & 50 & 4.5675 & 4.5501 & 4.4324 & 4.418 & 0.0099 & 0 & 0.0108 & 0 \\
\hline & 60 & 0.0687 & 0.0626 & 0.0548 & 0.0496 & 2.791 & 2.7925 & 2.9131 & 2.9116 \\
\hline & 70 & 0 & 0 & 0 & 0 & 10.0023 & 10.0098 & 10.1383 & 10.1419 \\
\hline & 80 & 0 & 0 & 0 & 0 & 17.2823 & 17.2898 & 17.4183 & 17.4219 \\
\hline \multirow[t]{7}{*}{0.4} & 20 & 23.6678 & 23.6621 & 23.4006 & 23.3979 & 0 & 0 & 0 & 0 \\
\hline & 30 & 16.3878 & 16.3822 & 16.1207 & 16.118 & 0 & 0 & 0 & 0 \\
\hline & 40 & 9.1079 & 9.1022 & 8.8407 & 8.838 & 0 & 0 & 0 & 0 \\
\hline & 50 & 2.2706 & 2.2474 & 2.1502 & 2.1299 & 0.4427 & 0.4251 & 0.5895 & 0.5718 \\
\hline & 60 & 0.124 & 0.1253 & 0.0984 & 0.0993 & 5.576 & 5.5829 & 5.8176 & 5.8211 \\
\hline & 70 & 0.0088 & 0.0088 & 0.0048 & 0.0048 & 12.7408 & 12.7464 & 13.0039 & 13.0066 \\
\hline & 80 & 0 & 0 & 0 & 0 & 20.012 & 20.0176 & 20.2791 & 20.2818 \\
\hline \multirow[t]{7}{*}{0.6} & 20 & 20.9381 & 20.9343 & 20.5398 & 20.538 & 0 & 0 & 0 & 0 \\
\hline & 30 & 13.6581 & 13.6544 & 13.2599 & 13.2581 & 0 & 0 & 0 & 0 \\
\hline & 40 & 6.4584 & 6.4565 & 6.2103 & 6.2103 & 0.0802 & 0.0821 & 0.2304 & 0.2322 \\
\hline & 50 & 1.4244 & 1.4183 & 1.3026 & 1.2972 & 2.3262 & 2.3238 & 2.6026 & 2.5991 \\
\hline & 60 & 0.1869 & 0.1879 & 0.1479 & 0.1489 & 8.3686 & 8.3734 & 8.7279 & 8.7307 \\
\hline & 70 & 0.03 & 0.0301 & 0.0181 & 0.0182 & 15.4917 & 15.4955 & 15.8781 & 15.8799 \\
\hline & 80 & 0.0067 & 0.0067 & 0.003 & 0.003 & 22.7484 & 22.7521 & 23.1429 & 23.1447 \\
\hline \multirow[t]{7}{*}{0.8} & 20 & 18.2084 & 18.2065 & 17.679 & 17.6781 & 0 & 0 & 0 & 0 \\
\hline & 30 & 10.9548 & 10.9532 & 10.5845 & 10.584 & 0.0263 & 0.0266 & 0.1855 & 0.1859 \\
\hline & 40 & 4.497 & 4.4968 & 4.2607 & 4.2618 & 0.8485 & 0.8501 & 1.1416 & 1.1436 \\
\hline & 50 & 1.1733 & 1.1724 & 1.045 & 1.0442 & 4.8047 & 4.8058 & 5.2058 & 5.206 \\
\hline & 60 & 0.25 & 0.2505 & 0.198 & 0.1985 & 11.1614 & 11.1638 & 11.6388 & 11.6402 \\
\hline & 70 & 0.0668 & 0.0664 & 0.0443 & 0.0443 & 18.2582 & 18.2596 & 18.7651 & 18.766 \\
\hline & 80 & 0.0176 & 0.0176 & 0.0096 & 0.0096 & 25.4889 & 25.4908 & 26.0103 & 26.0112 \\
\hline \multirow[t]{7}{*}{1} & 20 & 15.4905 & 15.4905 & 14.9759 & 14.9759 & 0.0118 & 0.0118 & 0.1577 & 0.1577 \\
\hline & 30 & 8.5391 & 8.5391 & 8.1784 & 8.1784 & 0.3403 & 0.3403 & 0.6401 & 0.6401 \\
\hline & 40 & 3.409 & 3.409 & 3.1708 & 3.1708 & 2.4902 & 2.4902 & 2.9126 & 2.9126 \\
\hline & 50 & 1.0815 & 1.0815 & 0.9425 & 0.9425 & 7.4426 & 7.4426 & 7.9642 & 7.9642 \\
\hline & 60 & 0.3131 & 0.3131 & 0.2481 & 0.2481 & 13.9542 & 13.9542 & 14.5498 & 14.5498 \\
\hline & 70 & 0.1123 & 0.1123 & 0.0786 & 0.0786 & 21.0334 & 21.0334 & 21.6602 & 21.6602 \\
\hline & 80 & 0.0343 & 0.0343 & 0.0204 & 0.0204 & 28.2354 & 28.2354 & 28.8819 & 28.8819 \\
\hline
\end{tabular}

Tabela 1.1.: Análise da influência das cópulas de Lévy de Clayton e Frank sobre o preços de opções asiáticas (venda e compra) considerando médias aritimética e geométrica. 


\begin{tabular}{|c|c|c|c|c|c|c|c|}
\hline \multirow[b]{3}{*}{$\alpha$} & \multirow[b]{3}{*}{ Strike } & \multicolumn{6}{|c|}{$\rho$} \\
\hline & & \multicolumn{3}{|c|}{$\overline{A m C}$} & \multicolumn{3}{|c|}{$\mathrm{AmP}$} \\
\hline & & 0.187 & 0.0943 & 0.0482 & 0.187 & 0.0943 & 0.0482 \\
\hline \multirow[t]{7}{*}{0} & 20 & 30.2216 & 30.4886 & 30.7076 & 0 & 0 & 0.0009 \\
\hline & 30 & 22.9622 & 23.2132 & 23.4386 & 0.0205 & 0.0045 & 0.0118 \\
\hline & 40 & 15.9056 & 16.1152 & 16.2451 & 0.2439 & 0.1865 & 0.0983 \\
\hline & 50 & 9.6632 & 9.8058 & 9.6717 & 1.2814 & 1.1571 & 0.8049 \\
\hline & 60 & 5.186 & 5.1585 & 4.7653 & 4.0843 & 3.7897 & 3.1784 \\
\hline & 70 & 2.5303 & 2.4476 & 2.0408 & 8.7085 & 8.3588 & 7.7338 \\
\hline & 80 & 1.1742 & 1.1361 & 0.8775 & 14.6323 & 14.3272 & 13.8505 \\
\hline \multirow[t]{7}{*}{0.2} & 20 & 27.2313 & 27.5794 & 27.6216 & 0 & 0 & 0 \\
\hline & 30 & 19.9689 & 20.3037 & 20.3484 & 0.0175 & 0.0042 & 0.0068 \\
\hline & 40 & 12.934 & 13.2025 & 13.1556 & 0.2626 & 0.183 & 0.0939 \\
\hline & 50 & 7.0536 & 7.1098 & 6.8331 & 1.6621 & 1.3702 & 1.0514 \\
\hline & 60 & 3.245 & 3.143 & 2.7405 & 5.1335 & 4.6834 & 4.2388 \\
\hline & 70 & 1.3336 & 1.2596 & 0.9581 & 10.502 & 10.08 & 9.7363 \\
\hline & 80 & 0.541 & 0.5058 & 0.3654 & 16.9894 & 16.6061 & 16.4236 \\
\hline \multirow[t]{7}{*}{0.4} & 20 & 24.2411 & 24.6702 & 24.5364 & 0 & 0 & 0 \\
\hline & 30 & 16.9792 & 17.3989 & 17.2592 & 0.0181 & 0.0086 & 0.0028 \\
\hline & 40 & 10.0402 & 10.3494 & 10.1225 & 0.359 & 0.2391 & 0.146 \\
\hline & 50 & 4.7369 & 4.6989 & 4.3318 & 2.3356 & 1.8685 & 1.6352 \\
\hline & 60 & 1.751 & 1.6584 & 1.3534 & 6.6297 & 6.108 & 5.9368 \\
\hline & 70 & 0.5947 & 0.5507 & 0.3775 & 12.7534 & 12.2803 & 12.2409 \\
\hline & 80 & 0.1815 & 0.1476 & 0.125 & 19.6201 & 19.1572 & 19.2683 \\
\hline \multirow[t]{7}{*}{0.6} & 20 & 21.2509 & 21.761 & 21.4512 & 0 & 0 & 0 \\
\hline & 30 & 14.0071 & 14.4966 & 14.179 & 0.0362 & 0.0156 & 0.0078 \\
\hline & 40 & 7.3431 & 7.6338 & 7.2608 & 0.6521 & 0.4327 & 0.3695 \\
\hline & 50 & 2.8697 & 2.8377 & 2.4572 & 3.4587 & 2.9165 & 2.8458 \\
\hline & 60 & 0.8527 & 0.7905 & 0.6382 & 8.7216 & 8.1493 & 8.3068 \\
\hline & 70 & 0.2224 & 0.1927 & 0.1523 & 15.3713 & 14.8315 & 15.1009 \\
\hline & 80 & 0.0443 & 0.0441 & 0.05 & 22.4731 & 21.9628 & 22.2786 \\
\hline \multirow[t]{7}{*}{0.8} & 20 & 18.2615 & 18.8518 & 18.366 & 0.0008 & 0 & 0 \\
\hline & 30 & 11.0871 & 11.6352 & 11.1442 & 0.1064 & 0.0633 & 0.0581 \\
\hline & 40 & 5.0073 & 5.3085 & 4.848 & 1.3066 & 1.0166 & 1.0419 \\
\hline & 50 & 1.6736 & 1.688 & 1.4378 & 5.2529 & 4.676 & 4.9116 \\
\hline & 60 & 0.451 & 0.445 & 0.4029 & 11.3102 & 10.7131 & 11.1567 \\
\hline & 70 & 0.1013 & 0.1071 & 0.1056 & 18.2405 & 17.6551 & 18.1394 \\
\hline & 80 & 0.0078 & 0.0303 & 0.0271 & 25.4269 & 24.8583 & 25.3408 \\
\hline \multirow[t]{7}{*}{1} & 20 & 15.2919 & 15.9581 & 15.3003 & 0.0215 & 0.0155 & 0.0194 \\
\hline & 30 & 8.3882 & 9.0045 & 8.405 & 0.3978 & 0.3418 & 0.4041 \\
\hline & 40 & 3.3621 & 3.7285 & 3.3253 & 2.6517 & 2.3459 & 2.6043 \\
\hline & 50 & 1.1278 & 1.2336 & 1.085 & 7.6973 & 7.1309 & 7.644 \\
\hline & 60 & 0.3393 & 0.3883 & 0.3684 & 14.1887 & 13.5655 & 14.2073 \\
\hline & 70 & 0.0741 & 0.109 & 0.1195 & 21.2035 & 20.5662 & 21.2384 \\
\hline & 80 & 0.0062 & 0.0255 & 0.0433 & 28.4155 & 27.7627 & 28.4422 \\
\hline
\end{tabular}

Tabela 1.2.: Análise da influência da dependência (linear) sobre o preço de opções asiáticas (compra e venda) considerando a média aritimética e a cópula de Lévy de Clayton. 


\begin{tabular}{|c|c|c|c|c|c|c|c|}
\hline & \multicolumn{6}{|c|}{$\bar{\rho}$} \\
\hline & & \multicolumn{3}{|c|}{$\mathrm{AmC}$} & \multicolumn{3}{|c|}{$\mathrm{AmP}$} \\
\hline$\alpha$ & Strike & 0.1259 & 0.1068 & 0.0741 & 0.1259 & 0.1068 & 0.0741 \\
\hline \multirow[t]{7}{*}{0} & 20 & 32.1586 & 32.7549 & 36.6994 & 0.0041 & 0.0013 & 0.0387 \\
\hline & 30 & 24.977 & 25.6092 & 29.824 & 0.1025 & 0.1356 & 0.4433 \\
\hline & 40 & 18.3596 & 19.0198 & 23.6615 & 0.765 & 0.8261 & 1.5607 \\
\hline & 50 & 12.8714 & 13.4749 & 18.4543 & 2.5567 & 2.5612 & 3.6335 \\
\hline & 60 & 8.7148 & 9.1665 & 14.2188 & 5.6801 & 5.5328 & 6.6779 \\
\hline & 70 & 5.711 & 6.1052 & 10.8583 & 9.9563 & 9.7515 & 10.5973 \\
\hline & 80 & 3.6876 & 4.0198 & 8.2757 & 15.2128 & 14.946 & 15.2947 \\
\hline \multirow[t]{7}{*}{0.2} & 20 & 28.7777 & 29.3913 & 32.3945 & 0 & 0 & 0.0098 \\
\hline & 30 & 21.5626 & 22.1944 & 25.3658 & 0.0649 & 0.083 & 0.261 \\
\hline & 40 & 14.9378 & 15.5583 & 19.114 & 0.72 & 0.7268 & 1.2892 \\
\hline & 50 & 9.6596 & 10.1849 & 14.0518 & 2.7218 & 2.6334 & 3.5069 \\
\hline & 60 & 5.93 & 6.3276 & 10.1315 & 6.2722 & 6.056 & 6.8665 \\
\hline & 70 & 3.4866 & 3.8035 & 7.2442 & 11.1087 & 10.8119 & 11.2592 \\
\hline & 80 & 2.0066 & 2.2586 & 5.1765 & 16.9087 & 16.547 & 16.4714 \\
\hline \multirow[t]{7}{*}{0.4} & 20 & 25.4008 & 26.0292 & 28.1109 & 0 & 0 & 0.0021 \\
\hline & 30 & 18.1736 & 18.8099 & 20.9816 & 0.0527 & 0.0607 & 0.1527 \\
\hline & 40 & 11.5988 & 12.1563 & 14.6581 & 0.7579 & 0.687 & 1.1093 \\
\hline & 50 & 6.6259 & 7.1084 & 9.7925 & 3.065 & 2.9191 & 3.5236 \\
\hline & 60 & 3.5049 & 3.8174 & 6.3629 & 7.2239 & 6.908 & 7.3739 \\
\hline & 70 & 1.7264 & 1.9676 & 4.0943 & 12.7253 & 12.3383 & 12.3853 \\
\hline & 80 & 0.7961 & 0.996 & 2.5822 & 19.075 & 18.6466 & 18.1532 \\
\hline \multirow[t]{7}{*}{0.6} & 20 & 22.0247 & 22.667 & 23.8331 & 0.0007 & 0 & 0.0003 \\
\hline & 30 & 14.8179 & 15.4451 & 16.6603 & 0.0739 & 0.0581 & 0.1074 \\
\hline & 40 & 8.3947 & 8.9204 & 10.348 & 0.9306 & 0.8134 & 1.0752 \\
\hline & 50 & 3.9692 & 4.3549 & 5.8393 & 3.785 & 3.5278 & 3.8464 \\
\hline & 60 & 1.6299 & 1.8564 & 3.1523 & 8.7257 & 8.3093 & 8.4393 \\
\hline & 70 & 0.5841 & 0.7355 & 1.6387 & 14.9599 & 14.4683 & 14.2057 \\
\hline & 80 & 0.1719 & 0.2934 & 0.8893 & 21.8276 & 21.3062 & 20.7362 \\
\hline \multirow[t]{7}{*}{0.8} & 20 & 18.6526 & 19.3064 & 19.5571 & 0.0054 & 0.0017 & 0.0003 \\
\hline & 30 & 11.5127 & 12.1276 & 12.4071 & 0.1454 & 0.1028 & 0.1302 \\
\hline & 40 & 5.4779 & 5.954 & 6.3275 & 1.3906 & 1.2091 & 1.3306 \\
\hline & 50 & 1.9897 & 2.2404 & 2.6267 & 5.1824 & 4.7755 & 4.9098 \\
\hline & 60 & 0.6039 & 0.7148 & 0.9946 & 11.0765 & 10.5299 & 10.5576 \\
\hline & 70 & 0.1338 & 0.1944 & 0.3688 & 17.8864 & 17.2894 & 17.2118 \\
\hline & 80 & 0.015 & 0.0451 & 0.1694 & 25.0475 & 24.4201 & 24.2923 \\
\hline \multirow[t]{7}{*}{1} & 20 & 15.2919 & 15.9581 & 15.3003 & 0.0215 & 0.0155 & 0.0194 \\
\hline & 30 & 8.3882 & 9.0045 & 8.405 & 0.3978 & 0.3418 & 0.4041 \\
\hline & 40 & 3.3621 & 3.7285 & 3.3253 & 2.6517 & 2.3459 & 2.6043 \\
\hline & 50 & 1.1278 & 1.2336 & 1.085 & 7.6973 & 7.1309 & 7.644 \\
\hline & 60 & 0.3393 & 0.3883 & 0.3684 & 14.1887 & 13.5655 & 14.2073 \\
\hline & 70 & 0.0741 & 0.109 & 0.1195 & 21.2035 & 20.5662 & 21.2384 \\
\hline & 80 & 0.0062 & 0.0255 & 0.0433 & 28.4155 & 27.7627 & 28.4422 \\
\hline
\end{tabular}

Tabela 1.3.: Análise da influência da dependência (linear) sobre o preço de opções asiáticas (compra e venda) considerando a média aritimética e a cópula de Lévy de Frank. 


\section{ReDE INTERBANCÁRIA BrasileIRA: TOPO- LOGIA E PROPAGAÇÃo Do Risco SistÊMICO}

\subsection{Contextualização Histórica do Risco Sistêmico}

Em 1995, a Rússia adotou uma política monetária restritiva (alta nas taxas de juros e redução da quantidade de moeda em circulação). Para compensar esta política, muitas empresas russas passaram a pagar suas dívidas, com bancos, fornecedores e funcionários, por meio de mercadorias e serviços. Esta prática reduziu significativamente as receitas do governo russo, que para diminuir o déficit na sua balança de pagamentos, emitiu títulos com vencimentos de curto prazo. Entretanto, esta medida não foi suficiente para aliviar a situação financeira russa, levando o banco central russo a desvalorizar o rublo em $50 \%$ e a emitir papel-moeda, causando uma elevada inflação. Investidores, na tentativa de converterem seus recursos em dólares, desvalorizaram ainda mais a moeda russa. Para agravar a situação, em 1998, a queda no preço do petróleo reduziu ainda mais as receitas do governo russo, e conseqüentemente, em agosto de 1998, o governo russo declarou moratória.

Durante a crise russa, o Brasil adotava uma política de câmbio fixa, visando o controle da inflação. Os investidores, preocupados que outros países emergentes adotassem medidas semelhantes ao governo russo, buscaram retirar seus investimentos do Brasil. No segundo semestre de 1998, visando equilibrar a sua balança de pagamentos e as suas reservas internacionais, o Brasil obteve um empréstimo junto ao FMI (Fundo Monetário Internacional) de US\$ 41,5 bilhões (fonte: Sisbacen). Entretanto, em janeiro de 1999, o governador Itamar Franco anunciou a moratória do Estado de Minas Gerais (segundo maior estado brasileiro), que acentuou a saída de dólares do país, obrigando o governo brasileiro a desvalorizar a sua moeda.

No final da década de 90, a Argentina apresentava dificuldades para exportar os seus produtos, devido à forte valorização do dólar frente às outras moedas e a política de câmbio fixo adotada pelo governo argentino. Em 2001, o elevado déficit na balança comercial levou o país a uma recessão econômica. Objetivando reduzir o montante de juros pagos sobre a sua dívida externa, o governo argentino resolveu desvalorizar sua moeda. Estas medidas não agradaram os credores argentinos, que não quiseram renegociar a dívida do país. Em dezembro de 2001, as reservas argentinas haviam praticamente se esgotado e o governo argentino declarou a moratória. 
A desconfiança dos investidores externos, causada pela crise Argentina, ficou evidente na eleição presidencial brasileira em 2002. As pesquisas eleitorais indicavam que o candidato à presidência, Sr. Luiz Inácio Lula da Silva, que sempre esteve vinculado a movimentos trabalhistas de esquerda no Brasil, tinha grande probabilidade de ganhar as eleições. Os investidores retiraram investimentos do país, pois estavam preocupados que o Brasil adotasse medidas semelhantes às do governo argentino, o que causou uma forte desvalorização da moeda brasileira.

Mais recentemente, os bancos de investimentos Merrill Lynch e Lehman Brothers haviam assumidos grandes exposições ao mercado imobiliário subprime nos Estados Unidos. Este mercado tem como característica a securititização de financiamentos imobiliários de imóveis já hipotecados à terceiros, ou seja, o primeiro credor hipotecário tem prioridade na execução da garantia, sendo assim necessário que o valor do imóvel seja bem superior ao valor do financiamento, para eventualmente cobrir as perdas dos outros credores hipotecários. Além disso, o principal instrumento de securtitização deste mercado é o Collateralized Mortgage Obligations (CMO), sendo o mercado subprime é caracterizado pelas tranches com alto risco de crédito (clientes que não atendem as exigências normais para financiamentos imobiliários patrocinados pelas agências de fomento americanas) e risco de pré-pagamento (cláusula contratual que concede aos devedores dos financiamentos imobiliários o direito de pagar antecipadamente os montantes devidos), o que evidencia ainda mais os riscos associados ao mercado subprime.

Desde 2006, os Estados Unidos vêm buscando controlar os efeitos do déficit da sua balança de pagamentos sobre a inflação, por meio do aumento sucessivo das taxas de juros, o que impactou de maneira negativa o valor do imóveis e, causou perdas aos bancos que que atuam no mercado imobiliário e, principalmente, nas que atuavam no mercado subprime. Em decorrência destes fatores, em julho/2008, as instituições financeiras contabilizaram perdas que totalizavam US\$ 435 bilhões (fonte: Bloomberg), prejudicando severamente a liquidez destas instituições. Conseqüentemente, em outubro/2008, os bancos Merrill Lynch e Lehman Brothers se viram em posições financeiras difíceis, ocasionando assim a concordata do primeiro e a venda do segundo para o Bank of America.

Para deixar a situação ainda mais crítica, o Citibank, o segundo maior banco norteamericano, com ativos que excedem US\$ 2 trilhões, também vem apresentando problemas e perdas sucessivas em seus demonstrativos financeiros. Assim, para evitar maiores danos à economia americana, em novembro/2008, o governo americano anunciou a compra de ações preferenciais no mercado primário no valor US\$27 bilhões (fonte: Bloomberg).

Todos estes efeitos já apresentam reflexos no Brasil, como pode ser verificado pela 
desvalorização da moeda brasileira, que no final de julho/2008 era negociada em torno de $\mathrm{R} \$ / \mathrm{US} \$ 1,5658$ e no começo de novembro/2008 passou a ser negociada em torno de R\$/US\$2,4996 (fonte: Sisbacen), ou seja uma desvalorização de 60\%. Neste contexto, em outubro/2008, o governo Brasileiro, por meio da medida provisória $n^{\circ} 422$, e o BACEN, por meio da Resolução $\mathrm{n}^{\circ} 3.622$ e das Circulares $\mathrm{n}^{\circ} 3.410, \mathrm{n}^{\circ} 3.411$ e $\mathrm{n}^{\mathrm{o}} 3.412$, vêm tomando algumas iniciativas para conter repercussões maiores. Os objetivos destas providências foram a autorização, por parte do BACEN, de operações de redesconto visando prover linhas de empréstimos à bancos de pequeno e médio porte, bem como a redução das obrigações de depósito compulsório para que seja aumentada a liquidez do Sistema Financeiro Nacional.

Situações de estresse econômico como estas apresentadas tornam necessário e justificável o estudo do impacto destas conjunturas no bom comportamento do sistema financeiro, ou, mais especificamente, no mercado interbancário. No contexto micro, as instituições financeiras realocam a liquidez através do mercado interbancário, transferindo o excedente de caixa de banco para outro que apresenta necessidades de caixa. No contexto macro, o mercado interbancário fortifica a integração entre as instituições financeiras, entretanto, tal integração agrava o risco sistêmico, ou seja, aumenta a interligação das exposições aos riscos financeiros entre os bancos. Conseqüentemente, o mercado interbancário é um importante veículo de propagação do risco sistêmico, principalmente, em situações de estresse, pois as dificuldades financeiras apresentadas por banco ou uma economia podem se espalhar pelos outros bancos ou outras economias causando danos irreparáveis.

\subsection{Fundamentos}

A recente crise financeira enfatizou a importância do risco sistêmico, definido como risco de nível-macro que pode influenciar integralmente a estabilidade de um sistema financeiro. O controle do risco sistêmico foi a principal motivação das recentes ajudas financeiras concedida às grandes instituições financeiras nos Estados Unidos. Reguladores tiveram grandes dificuldades em antecipar o impacto da insolvência, em parte, devido à pouca visibilidade e falta de indicadores pertinentes a estrutura do sistema financeiro. Conseqüentemente, ao adotar uma política baseada em Muito Grande para Falhar ou Too Big to Fail, não foi o critério certo, pois esta política não leva em consideração o quanto uma instituição financeira contribui para estabilidade do sistema financeiro ou mesmo a possibilidade de contágio via propagação da insolvência. Assim, a política Muito Interconectada para Falhar ou Too Interconnected to Fail, veja (GRIFFIN, 2008), parece ser 
mais eficiente em termos dos resultados a serem auferidos. A disponibilidade de melhores indicadores de risco sistêmico também teria ajudado bastante para abordar de maneira consistente à formulação de uma política alternativa a simples ajuda financeira às instituições financeiras, (ELSINGER; LEHAR; SUMMER, 2004, 2006; FURFINE, 2003; FORBES; RIGOBON, 2002; UPPER; WORMS, 2004; WELLS, 2004).

A Seção 2.3. provê detalhes sobre as instituições financeiras e detalhes sobre exposições e capitais que compõem a base de dados. A Seção 2.4. provê uma análise empírica da topologia da rede interbancária para o Sistema Financeiro brasileiro. Considerando a literatura, este é o primeiro estudo que considera apenas dados reais (em detrimento de dados estimados), proporcionando uma descrição detalhada da topologia da rede interbancária brasileira. A maioria dos estudos até o presente momento tem como escopo o sistema de pagamentos, por exemplo, Lublóy (2006), Iori et al. (2008), Cajueiro e Tabak (2008), Rørdam e Bech (2009) consideram base de dados incompletas, e Elsinger, Lehar e Summer (2004), Upper e Worms (2004), Degryse e Nguyen (2007) buscaram completar suas bases de dados por meio de métodos que visam maximizar a entropia relativa. Uma abordagem interessante foi sugerida por Elsinger, Lehar e Summer (2006), onde a análise da rede interbancária foi estendida a outras fontes de risco, tais como o crédito e riscos de mercado originados de instituições não-financeiras, porém, foi necessário assumir várias hipóteses relativas à estimação da base de dados. Na Seção 2.5. é estuda a relação entre reservas de capital e exposições. É proposto um modelo linear para o conceito de reserva de capital e prove-se resultados adicionais para um melhor entendimento do comportamento da distribuição dos resíduos do modelo proposto, complementando, desta maneira, a seção anterior. A Seção 2.6. está principalmente preocupada com a análise do risco sistêmico. Nós identificamos o impacto do contágio caso um banco, em particular, se torne inadimplente em relação as suas obrigações com as outras instituições financeiras. Com o intuito de analisar contágio neste contexto, nos definidos o conceito de inadimplência em termos de capital do Tipo 1 e Tipo 2. Esta contextualização é bastante importante e outros autores cruciais não dão a devida importância ao tema, conseqüentemente, assumindo hipóteses irreais, (MISTRULLI, 2007; CONT; MOUSSA, 2009). Nesta seção, é estendida a análise do risco sistêmico que incorpora outras fontes de risco, como mercado, crédito e riscos de liquidez. A Seção 2.7. provê a análise do estudo. 


\subsection{Descrição dos Dados}

\subsubsection{Exposições Mútuas}

O sistema financeiro brasileiro contempla cerca de 2.400 instituições financeiras supervisionadas pelo Banco Central do Brasil. A Tabela 2.1. mostra que o número de instituições financeiras do tipo I e II são menores em quantidade que as do tipo III. Instituições bancárias do tipo I têm carteiras comerciais, e as do tipo II representam todas as outras instituições bancárias, excluindo as do tipo III que estão sujeitas a regulamentos particulares, tais como as cooperativas de crédito. Apesar do número reduzido das instituições financeiras de tipos I e II, elas respondem pela maioria de ativos totais do sistema financeiro brasileiro (aproximadamente 98\%), vide Tabela 2.2.. Isto é intuitivo, pois a maioria de instituições financeiras que são de nosso interesse estão classificadas como do tipo I ou II, ou seja, bancos múltiplos, caixas econômicas, bancos de investimento, bancos de desenvolvimento, e corretoras e distribuidoras de valores. Adicionalmente, a maioria das instituições tipo I e tipo II, que podem ser entendidas como um boa aproximação do sistema financeiro brasileiro como um todo, são principalmente detidas por meio de capital privado (aproximadamente 70\%) e operam na forma de conglomerados financeiros (aproximadamente $75 \%$ ).

Como a maioria das instituições financeiras pertencem um conglomerado, é necessário analisar contágio sob uma perspectiva consolidada, pois os fundos e liquidez são administradas como que se todas as instituições financeiras afiliadas fossem apenas uma. Levando em consideração este fato, foram consideradas apenas informações consolidadas para cada conglomerado financeiro. Os padrões de contabilidade para consolidação de demonstrações financeiras eram estabelecidos através de Resoluções 2,723 e 2,743, (BACEN, 31.05.2000, 28.06.2000), e eles são bem parecidos ao IASB e diretiva do FASB. Se nós consideramos instituições financeiras de Tipo I e II como conglomera, o número de instituições está substancialmente reduzido.

Em resumo, nosso banco de dados considera 6 datas, i.e., 2007 de junho, 2007 de dezembro, 2008 de março, 2008 de junho, 2008 de setembro e 2008 de novembro. As exposições interbancárias do conglomerado financeiro contempla todas as fontes de risco, ou seja, instrumentos de renda fixa (certificado de depósitos e debêntures), empréstimos bancários (risco de crédito), derivativos (inclusive instrumentos de swap e opções) e câmbio

(moedas correntes). É importante notar que todos os derivativos foram avaliados a valores de mercado quando este for disponível, ou ou valor justo quando uma estimação baseada em modelos é necessária. Também é observar que todas as exposições representam 
operações reais, ou seja, estão lastreadas por contratos.

\subsubsection{Reserva de Capital}

Nós consideramos três tipos de capital, como definido nas diretrizes providas por Acordo de Basiléia, (BIS, 1988), quer dizer, o Capital Exigido $C_{r}$, o Capital Tipo $1 C_{1}$ e o Capital de Referência $C_{2}{ }^{1}$

Considerando o sistema legal brasileiro e os tipos de instrumentos financeiros os bancos têm acesso para financiar os seus capitais, o Banco Central do Brasil, em conformidade com os Acordos de Basiléia, Resolução 3.444 emitida pelo BACEN (28.02.2007), determinando que bancos computem o Capital Tipo 1 como o conceito contábil de patrimônio líquido mais lucros (prejuízos), deduzidos das ações preferenciais resgatáveis, reservas de capital e de reavaliação de ativos fixos, impostos deferidos, e ganhos (perdas) não realizadas, como por exemplo, os ajustes de avaliações de mercado do títulos e valores mobiliários registrados como disponíveis para venda e mantidos até o vencimento. O Capital elegível ao Tipo 2 é igual à soma das deduções supra aplicadas ao capital do tipo 1, salvo os impostos deferidos, e adicionados ao instrumentos híbridos de capital e dívida. Capital de referência é obtido pela soma dos capitais de tipo 1 e tipo 2.

O capital exigido é uma função dos riscos associados às operações de cada instituição financeira, sejam estas registradas nos demonstrativos financeiros (ativos e passivos) ou não (transações que estão fora do balanço), como definido na Resolução 3,490, (BACEN, 29.08.2007). De maneira suscinta, o Capital Exigido $C_{r}$, pode ser computado como

$$
C_{r}=\delta \times \text { Base de Risco, }
$$

onde o Sé o mínimo requerido Índice de Basiléia e Base de Risco é a soma dos componentes seguintes: exposições de crédito ponderadas pelo respectivo risco; exposições em moedas estrangeiras e ouro; exposições de taxa de juros; exposições de mercado; exposições em ações; e, exposições de risco operacional. É importante observar que estas exposições incluem todas as contrapartes - conglomerados financeiros, corporações, fundos mútuos e de hedge, indivíduos e governo - mas também que a alavancagem permitida às instituições financeiras brasileiras é aproximadamente 9.10, em vez de 12.50. Esta última observação

\footnotetext{
${ }^{1} \mathrm{O}$ Brasil está no processo de implementar as diretrizes apresentadas no Acordo de Basiléia II, (BIS, 2005). Mudanças significativas acontecerão principalmente em metodologia do capital exigido, e não nos capitais elegíveis ao Tipo 1 e 2. No entanto, avaliar as exposições com a mesma contraparte de maneira líquida netting, como contemplado no Acordo de Basiléia II, ainda não é permitido através da legislação brasileira para a maioria das operações financeiras.
} 
é uma conseqüência do mínimo Índice de Basiléia exigido de $\delta=0.11$ que é diferente do sistema financeiro americano do qual exige um mínimo para o Índice de Basiléia de $\delta=0.08$ para suas instituições financeiras.

\subsection{Topologia da Rede Interbancária}

\subsubsection{Representação da Rede}

É possível estudar o sistema interbancário por meio de uma rede (grafo) direcionada $\Gamma_{t}$ para $t=1,2, \ldots, T$. O sistema interbancário $\Gamma_{t}$ é definido como o tripé $\Gamma_{t}=\left(\mathcal{V}_{t}, \mathcal{L}_{t}, \mathcal{C}_{t}\right)$, onde os vértices $\mathcal{V}_{t}=\left\{1,2, \ldots, n_{t}\right\}$ representam as instituições financeiras que existiam no instante $t$, a matriz $\mathcal{L}_{t}$ de dimensão $n_{t} \times n_{t}$ representa as exposições entre estas instituições financeiras e $\mathcal{C}_{t}=\left\{C_{r}, C_{1}, C_{2}\right\}$ é a estrutura de capitalização do sistema. Cada elemento $\ell_{i j} \in \mathcal{L}_{t}$ representa que a instituição financeira $i$ tem uma exposição à instituição financeira $j$, em outras palavras, é a direção do fluxos de perdas no caso de inadimplência, isto é, se no instante $t$, a instituição financeira $j$ se tornar inadimplente, então a instituição financeira $i$ assumira uma perda de montante $\ell_{i j}$.

Por meio de $\mathcal{L}_{t}$, nós podemos definir a matriz adjacente $\mathcal{A}_{t}$ de dimensão $n_{t} \times n_{t}$, cujos elementos são definidos pela função indicadora nos elementos da matriz de exposições $\mathcal{L}_{t}$, ou seja, $a_{i j}=\mathbb{1}_{\left\{\ell_{i j}>0\right\}}$ para todo $a_{i j} \in \mathcal{A}_{t}$. Nós também podemos representar a matriz adjacente $\mathcal{A}_{t}$ como um vetor $\mathcal{E}_{t}$ de arestas, listando as instituições financeiras que estão conectadas, sendo os elementos de $\mathcal{E}_{t}$ definidos pelas posições dos elementos da matriz adjacente iguais a 1, i.e., todos os pares $\{(i, j)\} i, j \in \mathcal{V}_{t}$ para qual $a_{i j}=1$. Esta representação será útil para a análise de assortatividade (assortativity), agrupamento (clustering) e mistura (mixture) na Subseção 2.4.5.

Para uma rede direcionada o número de arestas de um vértice é denominado grau e este depende da direção da exposição. Desta maneira, os grau-de-entrada $k_{i n, i}$ e grau-desaída $k_{\text {out }, i}$ de uma instituição financeira $i \in \mathcal{V}_{t}$ são, respectivamente, definidos como

$$
k_{i n, i}=\sum_{j \in \mathscr{Y}_{i n, i}} a_{i j}, \quad k_{\text {out }, i}=\sum_{j \in \mathscr{Y}_{\text {out }, i}} a_{j i},
$$

onde $\mathscr{V}_{i n, i}=\left\{j: a_{i j}=1\right\}$ e $\mathscr{V}_{\text {out }, i}=\left\{j: a_{j i}=1\right\}$

Por conseguinte, o grau da instituição financeira $i$ é igual à $k_{i}=k_{i n, i}+k_{\text {out }, i}$. Do 
ponto de vista estatístico, a distribuição do graus dos vertices realiza um papel importante na geração de redes estocásticas, como apresentado na Subseção 2.4.2.

De uma maneira semelhante, o grau-de-entrada-ponderado $w_{i n, i}$, grau-de-saida-ponderado $w_{\text {out }, i}$ e grau-ponderado $w_{i}$ de uma instituição financeira $i \in \mathcal{V}_{t}$ são definidos como

$$
w_{i n, i}=\sum_{j \in \mathscr{Y}_{i n, i}} \ell_{i j}, \quad w_{\text {out }, i}=\sum_{j \in \mathscr{V}_{\text {out }, i}} \ell_{j i}
$$

e $w_{i}=w_{\text {in,i }}+w_{\text {out }, i}$. As distribuições dos grau-ponderados são analisadas em Subseção 2.4.3.

\subsubsection{Conectividade}

Um assunto importante que ainda não foi examinado na literatura de finanças, devido em grande parte à falta de dados disponíveis para diferentes datas, é se a distribuição do grau-de-entrada, grau-de-saída e grau são estacionários, ou seja, se a distribuição não depende do instante de tempo.

Conjectura 2.1 (Estacionariedade da Distribuição dos Graus) As distribuições do grau-de-entrada $\mathbb{P}\left(K_{\text {in }}=k\right)$, grau-de-saída $\mathbb{P}\left(K_{\text {out }}=k\right)$ e grau $\mathbb{P}(K=k)$ são estacionárias.

A Figura 2.2. apresenta o gráfico Q-Q da função acumulada de densidade ( $C D F$ cumulative density function $) \mathbb{P}(K \leqslant k)$ das distribuições dos graus das redes interbancárias para datas sucessivas. Assim, o gráfico Q-Q representa os quantils não-paramétricos na data $t$ versus os quantils não-paramétricos em $t+1$. É fácil de verificar, que os pontos encontram-se localizados próximos de uma linha de $45^{\circ}$, situação onde os quantils seriam idênticos, indicando, desta maneira, que não é possível descartar a hipótese nula $H_{0}$ de que distribuição do grau não muda com o tempo (estacionariedade). O teste KomolgorovSmirnov testa se as CDFs para datas sucessivas são iguais, veja (MASSEY Jr., 1951). A estatística deste pode ser escrita como $K S=\sup _{k}\left|\hat{F}_{t+1}(k)-\hat{F}_{t}(k)\right|$, onde $\hat{F}_{t}(k)$ é a CDF empírica dos graus para $t=1,2, \ldots, T-1$. Todos os p-valores são maiores que 0.6 , sugerindo que para níveis relativamente altos de significância a hipótese nula $H_{0}$ não pode ser rejeitada. Então, isto sustenta fortemente que a conectividade da estrutura da rede interbancária no Brasil é estável no tempo. Este resultado surpreende, pois as datas consideradas na análise consideram momentos econômicos turbulentos, como os anos 2007 e 2008, onde estabilidade financeira era um assunto em destaque. 
As Figuras 2.3., 2.4. e 2.5. mostram, respectivamente, o gráfico log-log da distribuição cumulativa complementar empírica para grau-de-entrada $\hat{\mathbb{P}}\left(K_{\text {in }} \geqslant k\right)$, grau-de-saída $\hat{\mathbb{P}}\left(K_{\text {out }} \geqslant k\right)$, e grau $\hat{\mathbb{P}}(K \geqslant k)$, para $k \geqslant 1$. É possível notar que valores acima de um particular limite $k_{\min }$ as distribuições demonstram uma decadência linear na cauda, sugerindo um comportamento semelhante a distribuição potência (Pareto). Esta propriedade é típica de redes livre-de-escala scale-free como a World Wide Web. Para uma descrição em profundidade de grafos livre-de-escalas veja (ALBERT-LÁsZÓ; BARABÁSI; BONABEAU, 2003) e (NEWMAN et al., 2006).

\section{Conjectura 2.2 (Cauda dos Graus segue uma Distribuição Potência (Pareto))} A cauda da distribuição dos grau-de-entrada $\mathbb{P}\left(K_{\text {in }}=k \mid K \geqslant k_{\text {min }}\right)$, grau-de-saída $\mathbb{P}\left(K_{\text {out }}=\right.$ $\left.k \mid K \geqslant k_{\text {min }}\right)$ e grau $\mathbb{P}\left(K=k \mid K \geqslant k_{\text {min }}\right)$ seguem a lei de potência discreta com parâmetros $\alpha$ e $k_{\text {min }}$ definidas como

$$
\mathbb{P}\left(K=k \mid k \geqslant k_{\text {min }}\right)=\eta k^{-\alpha},
$$

onde

$$
\eta=1 / \zeta\left(\alpha, k_{\min }\right),
$$

e $\eta$ é o recíproco da função Hurwitz (ou Riemann Zeta Generalizada) $\zeta\left(\alpha, k_{\min }\right)=$ $\sum_{k=k_{\min }}^{\infty} k^{-\alpha}$.

A distribuição potência é caracterizada relação linear $\log \left(\mathbb{P}(K \geqslant k) \mid K \geqslant k_{\min }\right)=$ $-\alpha \log (k)+c$ onde $c$ é uma constante e $\alpha$ é chamado o expoente da cauda. Considerando a abordagem MLE introduzida por (CLAUSET; SHALIZI; NEWMAN, 2009), é possível estimar conjuntamente o expoente da cauda $\alpha$ e o limiar mínimo $k_{\min }$ maximizando a função de probabilidade, veja equação (A.1) no Apêndice.

A Tabela 2.3. mostra algumas estatísticas relativas às estimativas MLE para os parâmetros $\hat{\alpha}$ e $\hat{k}_{\text {min }}$ das distribuições do grau-de-entrada, grau-de-saída e graus. É possível verificar que as estimativas MLE para o expoente de cauda $\alpha$ variam entre de 2 e 3 . Embora estes resultados concordam com verificados na rede interbancária austríaca, vide (ELSINGER; LEHAR; SUMMER, 2004), as estimativas para a rede austríaca não tomaram em consideração a estimativa conjunta de $\alpha$ e $k_{\min }$. Neste trabalho o limiar mínimo $k_{\min }$ foi determinado de maneira arbitrária, o impacta severamente a estimativa de $\alpha$.

É importante notar que estimativas de MLE não são consistentes no caso de especificação indevida da distribuição do processo gerador dados que está por trás das caudas dos graus. Desta forma, uma maneira mais interessante para testar o nível-deajuste (goodness-of-fit) da distribuição potência é testar hipótese nula $H_{0}$ por meio do teste Komolgorov-Smirnov da CDF (função de distribuição cumulativa) da distribuição 
potência, i.e., $K S=\sup _{k \geqslant k_{\text {min }}}\left|\hat{F}(k)-F\left(k \mid \alpha, k_{m i n}\right)\right|$, onde $\hat{F}$ é a CDF empírica e $F$ a distribuição potência (Pareto) com parâmetros $\alpha$ e $k_{\text {min }}$. Os resultados identificados nas Figuras 2.3., 2.4. e 2.5. apresentam ampla evidência de que a hipótese nula de que a CDF segue uma distribuição potência não pode ser rejeitada. Isto é corroborado pelos p-valores do teste KS que são sempre maior que um nível de significância maior que 1\% para todas as distribuições, com exceção de junho de 2007 e setembro de 2008 das distribuições dos grau-de-saída. Não obstante, não se pode rejeitar a hipótese nula $H_{0}$ para estas mesmas datas.

\subsubsection{Magnitude das Exposições}

Seguindo o mesmo modus operandi aplicado aos graus, a distribuição das exposições indica que estas também se comportam em acordo à lei potência.

Conjectura 2.3 (Distribuição Potência para a Magnitude das Exposições) $A$ cauda da distribuição para exposições $\mathrm{d} \mathbb{P}\left({ }_{i j} \leqslant \ell \mid \ell \geqslant \ell_{\text {min }}\right) i, j \in \mathcal{V}_{t}$ segue uma lei potência contínua com parâmetros $\alpha$ e $\ell_{\min }$, i.e.,

$$
\mathrm{d} \mathbb{P}\left(L_{i j} \leqslant \ell \mid \ell \geqslant \ell_{\text {min }}\right)=\eta \ell^{-\alpha}
$$

onde $\eta=(\alpha-1) \ell_{\min }^{\alpha-1}$.

A última coluna da Tabela 2.3. mostra algumas estimativas obtida por máxima verossimilhança (MLE) para os parâmetros de $\operatorname{MLE}\left(\hat{\alpha}, \hat{\ell}_{\min }\right)$ da distribuição potência das exposições. Vide equação (A.3) em Apêndice para um detalhe sobre a equação ML a ser maximizada neste método. É importante observar que para todas as exposição-deentradas existe uma exposição-de-saída de mesma magnitude. Assim, nesta circunstância, a distribuição da exposição-de-entrada $\ell_{\text {in }}$ e exposição de saída $\ell_{\text {out }}{ }^{2}$ seguem a mesma lei de probabilidade. A única diferença entre a distribuição destas variáveis é como as exposições são alocadas entre as instituições financeiras, ou seja, como estas exposições determinam as valores nas linhas e colunas da matriz $\mathcal{L}_{t}$ de exposições. Seguindo o mesmo modus operandi de análise da distribuição da cauda dos graus, a Figura 2.6. mostra que para níveis de significância de $1 \%$ não é possível rejeitar a hipótese nula $H_{0}$ de que as exposições para todas as datas são geradas por uma distribuição Pareto.

\footnotetext{
${ }^{2}$ As exposição-de-entrada $\ell_{i n}$ e exposição-de-saída $\ell_{i n}$, seguem de maneira análoga a notação introduzida para os grau-de-entrada $k_{i n}$ e grau-de-saída $k_{o u t}$.
} 


\subsubsection{Relação entre a Magnitude da Exposição e Conectividade}

Outra propriedade importante é a relação entre graus e a magnitude das exposições. É relativamente intuitivo que caso o conglomerado financeiro $i \in \mathcal{V}_{t}$ tenha uma baixa conectividade, i.e., um número pequeno de graus $k_{i}$, então este deveria ter um menor grau-ponderado $w_{i}$. O contrário também é verdade, quanto maior o grau do conglomerado financeiro $i$, maior a magnitude de suas exposições, e conseqüentemente, maior o grau ponderado $w_{i}$. Porém, um modo mais pertinente para determinar se há uma relação entre graus e exposições é investigar a relação entre graus $k_{i}$ e o grau-ponderado médio $w_{i} / k_{i}$.

Conjectura 2.4 (Dependência entre graus e grau-ponderado-médio) O número de graus $k_{i}$ e o grau-ponderado médio $w_{i} / k_{i}$ do conglomerado financeiro $i \in \mathcal{V}_{t}$ não são independentemente distribuídos.

Existem fortes evidências de que não é possível rejeitar a hipótese nula $H_{0}$ de que não existe uma relação linear entre as duas variáveis. A Tabela 2.4. apresenta os Coeficientes de Pearson $\rho_{\text {Pearson }}$ para a rede interbancária brasileira e os, respectivos, p-valores onde $\rho_{\text {Pearson }}$ mede a força e a direção da relação linear entre estas variáveis. Não obstante, investigar apenas relações lineares não é suficiente para garantir que grau $k_{i} \mathrm{e}$ grau-ponderado médio $w_{i} / k_{i}$ são independentemente distribuídos. Esta conjectura só seria verdadeira para uma distribuição normal multivariada, o que não é caso, haja vista, os resultados prévios que indicam caudas grossas nas distribuições dos graus e das exposições.

A Tabela 2.4. também apresenta o tau de Kendall $\tau_{\text {Kendall }}$ e o Coeficiente de Spearman $\rho_{\text {Spearman. }}$ Por um lado, o $\tau_{\text {Kendall }}$ é um coeficiente de correlação non-paramétrico que pode ser usado para avaliar correlações entre as distribuições das variáveis, e, por outro lado, $\rho_{\text {Spearman }}$ é um coeficiente de correlação de ordem rank e busca medir o quão bem funções monotônicas arbitrárias descrevem a relação entre duas variáveis aleatórias sem supor nenhum comportamento sobre as distribuições destas variáveis. Os p-valores para o coeficiente de Spearman e o tau de Kendall rejeitam a hipótese nula $H_{0}$ de que não há nenhuma relação entre grau $k_{i}$ e grau-ponderado médio. $w_{i} / k_{i}$.

Estes resultados são complementares ao Coeficiente de Pearson $\rho_{\text {Pearson }}$, no sentido de que os p-valores indicam que deveria-se rejeitar a hipótese nula para ambos, $\rho_{\text {Spearman }}$ e $\tau_{\text {Kendall }}$, não rejeitando a hipótese alternativa $H_{a}$ que há uma relação non-linear entre os graus $k_{i}$ e as exposições médias $w_{i} / k_{i}$. Como conseqüência, como há evidência em 
favor de uma relação non-linear, deveria-se considerar a modelagem destas variáveis como dependentemente distribuídas. A fonte desta dependência parece ser representada por uma forma logarítmica entre estas variáveis.

\subsubsection{Agrupamento e Afinidade}

O agrupamento clustering e afinidade mixing assortativity provem informações adicionais sobre a representação de rede interbancária. Seguindo a abordagem introduzida por Watts e Strogatz (1998), o coeficiente de agrupamento local $c_{i} \in[0,1]$ para $i \in \mathcal{V}_{t}$ avalia a densidade da conectividade ente os vertices vizinhos. Caso $c_{i}=0$, então todos os possíveis vertices na vizinhança de $i$ são desconectados, e caso $c_{i}=1$, então todos os possíveis vertices são conectados. Além disso, o coeficiente de agrupamento local $c_{i}$ do conglomerado financeiro $i$ mede a proporção do número de vértices conectados na vizinhança de $i$ em relação ao número o máximo de possíveis conexões entre estes vizinhos dados o grau $k_{i}$.

A Figura 2.7. apresenta a relação entre o coeficiente de agrupamento clustering local e número de graus da rede interbancária brasileira. O ângulo negativo mostra que conglomerados financeiros com poucas conexões (graus) possuem contrapartes mais conectadas entre elas mesmas, o que não é observado nos conglomerados financeiros com muitas conexões. Esta propriedade pode ser entendida como a existência de competição acirrada entre os conglomerados financeiros altamente conectados.

O coeficiente de afinidade mede o quanto um conglomerado financeiro está conectado a outro conglomerado financeiro com as mesmas propriedades. Então, é possível interpretar o coeficiente de afinidade assortativity como uns meios para verificar similaridades entre conglomerados financeiros, por exemplo, similaridade de graus $\rho_{k}$ ou exposições $\rho_{\ell}$. Uma maneira interessante de calcular o coeficiente de afinidade é a abordagem proposta por Newman (2003), que considera a dependência linear das propriedades entre os vértices. Desde que cada vértice $(i, j) \in \mathcal{E}_{t}$ e $i, j \in \mathcal{V}_{t}$ pode ser associado à ambos: graus $\left(k_{\text {in }, i}-1, k_{\text {out }, j}-1\right)$ e grau-ponderado $\left(w_{\text {in }, i}, w_{\text {out }, j}\right)$, Newman $(2003)$ propõem utilizar calcular a correlação entre os vértices por meio do coeficiente de Pearson, veja equações (A.7) e (A.8) no Apêndice. Como resultado, o coeficiente de afinidade assume valores no conjunto $\rho \in[-1,1]$, de forma que, caso $\rho=-1$, então a rede possui afinidade reversa perfeita, e, caso $\rho=1$, então a rede possui afinidade perfeita, e, por último, caso $\rho=0$ não há nenhum padrão de afinidade bem definido. 
Complementando a análise de agrupamento, para a rede interbancária brasileira, o coeficiente de afinidade dos graus $\rho_{k}$ mostra que os conglomerados financeiros altamente conectados possuem vértices com baixa conectividade, veja Figura 2.4.. Esta propriedade pode ser verificada pelo significante sinal negativo do coeficiente $\rho_{k}<0$ para todas as datas, e pelo baixo desvio padrão destes coeficientes. Seguindo o mesmo raciocínio, a análise do $\rho_{\ell}$ mostra que não há nenhum padrão de afinidade bem definido. Isso significa que, dado um conglomerado financeiro com grandes exposições $\left(w_{i}\right)$, espera-se que este conglomera possua igual chance de estar conectado a contrapartes com pequenas ou grandes exposições. Porém, o sinal do coeficiente $\rho_{\ell}<0$ muda ao passar do tempo de positivo para negativo, indicando uma tendência de concentração das exposições.

\subsection{Estrutura de Capital}

Para evitar qualquer abuso de notação, denota-se $\bar{B}_{2}$ : colchão-de-capital de referência ajustado para as atividades não-bancárias, $\bar{B}_{1}$ : colchão-de-capital tipo I ajusta para as atividades não-bancárias, e, $B_{2}$ : colchão-de-capital de referência. Então, a barra significa os ajustes necessários que serão realizados para atividades não-bancárias, veja equação (2.9). Observe que esta notação não altera em nada a notação $C_{2}$ : capital de referência, $C_{1}$ capital tipo I, e $C_{r}$ capital exigido.

\subsubsection{Padrões Estatísticos do Colchão-de-Capital}

Como foi anteriormente apontado na Seção 2.3., o Capital de Referência (capitais do tipo I mais tipo II) dependem da Base de Risco, que por sua vez é um indicador de risco, não apenas das operações geradas no mercado interbancário, mas de todas as operações da entidade financeira. Neste sentido, o Capital de Referência não é uma medida boa de reserva liquidez para cobrir apenas as operações geradas na rede interbancária. Além disso, no Brasil, algumas operações no mercado interbancário não requerem alocação de capital, como operações compromissadas (acordos de recompra e revenda), pois a maioria destas transações são garantidas por títulos de emissão do tesouro nacional que são isentos de exigências de capital, por serem considerados livres de risco.

Então, modelos que consideram apenas o Índice de Basiléia mínimo exigido de $\delta=0.11$, no caso brasileiro, não é muito representativo, quando o interesse é modelar o contágio e propagação do risco no horizonte de curto prazo. Outra questão importante, 
são os custos envolvidos quando bancos desejam aumentar ou reduzir o capital. Isto está mais claro para bancos que têm capital negociado na bolsa de valores, por exemplo na BOVESPA, pois qualquer procedimento de emissões no mercado primário underwriting requer despesas na preparação de demonstrações financeiras e auditoria. Assim, é natural que os bancos aloquem capital sobre os riscos que esperam assumir em suas operações futuras. Um modo interessante para analisar risco sistêmico é considerar o colchão-decapital $B$ como uma aproximação das reservas de liquidez, i.e.,

$$
B_{2}=C_{2}-C_{r}
$$

A Tabela 2.6. apresenta alguns modelos lineares plausíveis para o colchão-de-capital $B_{2}$ como definido em equação (2.7). Embora, os resultados contemplam dados agrupados de todas as datas, a robustez dos resultados também foi verificada por meio da análise das datas específicas. Os regressores que foram considerados nesta análise foram grau-deentrada $k_{i n}$, grau-de-saída $k_{\text {out }}$, grau-de-entrada-ponderado $w_{i n}$, grau-de-saída-ponderado $w_{\text {out }}$, e a interação entre estas variáveis, mais especialmente, $w_{\text {in }} \times k_{\text {in }}, w_{\text {out }} \times k_{\text {out }}, w_{\text {in }} \times w_{\text {out }}$, e $k_{\text {in }} \times k_{\text {out }}$. Inicialmente, os parâmetros $\beta$ 's dos modelos foram estimados por meio dos métodos dos mínimos quadrados (OLS), dado que não há nenhuma evidência que os resíduos seguirão uma distribuição normal.

Conjectura 2.5 (Modelo Linear para o Colchão de Capital) O grau-de-entradaponderado $w_{\text {in }}$ é a variável que mais explica o colchão de capital $B_{2}$ em um modelo linear.

As plausibilidades de diversos modelos lineares foram verificadas pelo p-valor da estatística- $F$. Para níveis de significância muito pequenos, não é possível rejeitar a hipótese nula de que os coeficientes $\beta$ 's são conjuntamente diferentes de zero para todos os modelos na Figura 2.6.

Não obstante, nem todas as estáticas- $t$ individuais dos $\beta$ 's para cada modelo parecem ser significativamente diferentes que zero. Por exemplo, os modelos 3 e 4, não incluem exposições como regressores e sugerem que a constante não é diferente que zero. Além disso, a interação entre graus e exposições normalmente têm p-valores para as estatísticas- $t$ maiores que 1\%, com exceção de modelo 14, dando evidência que a interação não melhora a substancialmente regressão.

Adicionalmente, o $R^{2}$ mostra que há modelos que explicam mais que outros. Com exceção de modelos 2, 3 e 4, todos os modelos têm um $R^{2}$ bem semelhantes, próximos 
de 0.44. No entanto, o modelo 1, que é o mais parcimonioso de todos, considera só um regressor, i.e., o grau-de-entrada-ponderado $w_{i n}$ e tem aproximadamente o mesmo poder explicativo dos outros modelos concorrentes. Isto significa que a inclusão de outras variáveis, na verdade, não contribui de maneira relevante. Por meio do $R^{2}$ dos modelos 1 e 2, fica claro que o grau-de-saída-ponderado $w_{\text {out }}$ tem pouca relevância para explicar o colchão-de-capital $B_{2}$, enquanto que o grau-de-entrada-ponderado parece dominar o conjunto informacional que explicada a variável dependente no modelo linear.

Os Critérios de Informação de Akaike (AIC) e Bayesiano (BIC) utilizados para a seleção de modelos, veja respectivamente (AKAIKE, 1974) e (SCHWARZ, 1978), confirmam que os modelos 1 e 10 representam as melhores alternativas para modelagem do colchãode-capital. Porém, como apontado anteriormente, nem todos os $\beta$ 's do modelo 10 podem ser considerados significativamente diferente de zero. Dado que o critério BIC penaliza a inclusão de mais regressores, e ambos o $R^{2}$ e os $R^{2}$-ajustados são muito próximos ao do modelo 1, justifica-se desta maneira modelar o colchão-de-capital por meio do modelo 1 , que vale ressaltar novamente, é o modelo mais parcimonioso.

Devido a estes fatos, seleciona-se o modelo 1 como o mais apropriado para modelar o comportamento de colchão-de-capital $B_{2}$, i.e.,

$$
B_{2, i}=\beta_{0}+\beta_{1} \times w_{i n, i}+\varepsilon_{i}
$$

Além das propriedades estatísticas desejadas, o modelo 1 tem uma interpretação econômica importante. É natural que o colchão-de-capital $B_{2}$ dependa do grau-de-entradaponderado, haja vista que $w_{\text {in }}$ representa a principal fonte de risco de contraparte. Para um conglomerado financeiro $i \in \mathcal{V}_{t}$ com um nível de grau-de-entrada-ponderado $w_{i n, i}$, caso um subconjunto (contido estritamente) de suas contrapartes $j \in \mathcal{U} \subset \mathscr{V}_{\text {in,i }}$ se tornem inadimplentes em honrar seus contratos, então, pode se esperar que a perda máxima a serem assumidas pelo conglomerado $i$ seja igual a $\sup \sum_{j \in \mathcal{U}} \ell_{i j}=w_{i n, i}$, proporcionando assim, um limite superior de risco de contraparte do conglomerado financeiro $i$. Por outro lado, é natural que o grau-de-saída-ponderado $w_{\text {out }, i}$ não realizará nenhum papel na alocação de recursos do colchão-de-capital, pois este não produz nenhum risco de contraparte para o conglomerado $i$ e sim para os outros conglomerados, tais como $\left\{z: z \in \mathscr{V}_{\text {out }, j}\right.$ e $\left.j \in \mathscr{V}_{\text {in,i }}\right\}$.

Neste sentido, quanto maior o número de contrapartes (em-graus) $k_{i}$ e mais elevado o risco-de-contraparte-médio $w_{i} / k_{i}$, maior será o grau-de-entrada-ponderado $w_{i}$ do conglomerado financeiro $i$ e, por conseguinte, maior a quantia de recursos que deverá ser alocada 
para colchão-de-capital para que este seja suficiente para absorver eventuais com estas contrapartes. Surpreendentemente, o modelo 1 mostra que, caso as instituições financeiras $i$

e $j$ tenham o mesmo nível de conectividade em termos de graus-de-entrada $k_{i}=k_{j}$, e o mesmo nível de grau-de-entrada-ponderado $w_{i}=w_{j}$, sendo que o risco de contraparte da instituição $i$ está concentrado principalmente em uma só contraparte, enquanto o risco da instituição $j$ está distribuído igualmente entre todas as possíveis conexões (contrapartes), ambos $i$ e $j$, alocarão a mesma quantia de recursos para o seu colchão-de-capital, apesar da instituição financeira $i$ parecer ser mais arriscada. Entretanto, estruturas distintas terão impacto bem diferente no risco sistêmico de cada uma das instituições, que não sofrerá estas discrepâncias.

As estimativas de mínimos quadrados (OLS) dos parâmetros são $\beta_{0}=50.8826$ e $\beta_{1}=0.1887$. $\beta_{0}$ que não interagem com nenhuma variável explicativa representa o colchãode-capital mínimo que é necessário para operar um negócio bancário, ou seja, BRL 50.9 milhão, e $\beta_{1}$ indica que para cada numerário (BRL) de grau-de-entrada-ponderado o banco alocará a fração de 0.1887 deste montante na constituição do seu colchão-de-capital. A Figura 2.9. (gráfico de esquerda superior) mostra os pontos de regressão linear por meio do modelo 1 descrito na equação (2.8).

\subsubsection{Distribuição dos Resíduos e Alavancagem}

Os resíduos do modelo descrito pela equação (2.8) podem ser visto como choques aleatórios que afetam o colchão-de-capital $B_{2}$. Os conglomerados financeiros são entidades dinâmicas, assim, o montante de colchão-de-capital remanescente que não é explicado pelo modelo linear da equação (2.8) pode ser entendido como recursos alocados ao colchãode-capital necessários cobrir riscos associados as expectativas de novas operações que ocorrerão no futuro ou operações não-bancárias. Os choques $\varepsilon_{i}$ parecem ser gerados por uma distribuição com caudas grossas.

Conjectura 2.6 Os resíduos $\varepsilon$ do modelo de colchão-de-capital proposto pela equação (2.8) segue uma distribuição t-student escalonada

$$
\frac{\mathrm{d}}{\mathrm{d} \varepsilon} \mathbb{P}(\varepsilon)=\frac{\Gamma\left(\frac{\alpha+1}{2}\right)}{\sigma \sqrt{\alpha \pi} \Gamma\left(\frac{\alpha}{2}\right)}\left[1+\frac{\left(\frac{\varepsilon-\mu}{\sigma}\right)^{2}}{\alpha}\right]^{-\left(\frac{\alpha+1}{2}\right)}
$$

onde $\mu$ é o parâmetro de localizaçãa, $\sigma>0$ é o parâmetro de escala, $0<\alpha<1$ é o parâmetro que determina a forma da distribuição, e $\Gamma$ e uma função Gamma $\Gamma(z)=$ $\int_{0}^{\infty} \xi^{z-1} e^{-\xi} \mathrm{d} \xi$ 
A Figura 2.9. (gráfico direito superior) mostra o gráfico de Probabilidade Normal para os resíduos obtidos pelo modelo em questão $\hat{\varepsilon}_{i}$ para $i \in \mathcal{V}_{t}$. A linha $45^{\circ}$ representa a distribuição cumulativa de uma distribuição normal padronizada. Está claro que a presença de caudas grossas na análise da distribuição. Por outro lado, os resíduos do modelo mostram um comportamento semelhante à distribuição t-student escalada. Os parâmetros da distribuição foram obtidos numericamente por meio da maximização da função de log-verossimilhança. Além disso, para altos níveis de significância o p-valor do teste Komolgorov-Smirnov proporciona fortes evidências de que não é possível rejeitar a hipótese nula de que os choques que afetam o colchão-de-capital seguem uma distribuição de t-student escalada.

Adicionalmente, a Figura 2.9. (gráfico da esquerda superior e gráficos inferiores) provê evidência suficiente de que $\alpha<1$. Cabe lembrar que $\alpha=1$ representa a distribuição de Cauchy. Ambos, a estimativa realizada por MLE $(\alpha=0.5962)$ e a estimativa obtida pelo estimator de Hill $(\alpha=0.7260)$ corroboram que o comportamento das caudas da distribuição dos resíduos tem um índice para o expoente da cauda menor que 1. Observe que o estimador de Hill foi calculado pela abordagem apresentada por Resnick (2006). A cauda grossa da distribuição t-student escalada tem que ser analisada cuidadosamente, especialmente no contexto de regressão pelo método dos mínimos quadrados (OLS) onde a esperança e variância dos resíduos devem ser finita, i.e., $\mathbb{E}(\varepsilon)<\infty$ e $\sigma^{2}(\varepsilon)<\infty$. Este não é claramente o caso quando $\alpha<1$, desde que a t-distribuição escalada que não terá bem definida a sua esperança $\mathbb{E}(\varepsilon)$ e a sua variância será infinita $\sigma^{2}(\varepsilon)=\infty$. Como consequiência, não se pode garantir nós que o $\beta$ 's para os modelos de regressão apresentados na Tabela 2.6. são estáveis em termos de consistência. Porém, isto parece ser caso, pois após estimar o modelo de regressão linear para todos os modelos apresentados na Tabela 2.6. por meio do método de máxima verossimilhança (MLE) considerando a distribuição tdistribuição escalada para os resíduos foram obtidos estimativas bem semelhantes para os $\beta$ 's, produzindo assim evidência da robustez dos resultados para o estimators OLS.

Além disso, se nós reescrevemos equação (2.8) como

$$
\frac{B_{2, i}-\beta_{0}}{w_{i n, i}}=\beta_{1}+\bar{\varepsilon}_{i},
$$

onde $\bar{\varepsilon}_{i}=\varepsilon_{i} / w_{i n, i}$ então é possível interpretar $\beta_{1}$ como o coeficiente de alavancagem. Adotando o mesmo modus operandi, é possível verificar que o coeficiente de alavancagem segue uma distribuição t-student escalonada e que o seu expoente de cauda também é menor que 1, i.e., $\alpha=0.6966$. Considerando que o coeficiente não sofre grandes modificações no modelo apresentado na equação (2.10), esta característica produz evidência adicional de que a distribuição da resíduos do modelo apresentado na equação (2.8) segue 
uma distribuição t-student escalonada.

\subsection{Risco Sistêmico}

Como já foi observado anteriormente, agências supervisoras, como bancos centrais, exigem que os conglomerados financeiros atendam exigências mínimas, tais como capital, alavancagem, e imobilização. Então, se um conglomerado financeiro apresentar um Índice de Basiléia menor que o que é estabelecido pela regulamentação em vigor, então este conglomerado é suscetível a sanções legais. O Índice de Basiléia é definido como

$$
I_{\text {Basel }}=\frac{C_{2}}{\text { Base de Risco }} \geqslant \delta
$$

onde a Base de Risco é definida na equação (2.1). Para o caso brasileiro $\delta=0.11$ e para o sistema financeiro americano $\delta=0.08$. Existe uma conexão forte entre o Índice de Basiléia $I_{\text {Basel }}$ e o colchão-de-capital $B_{2}$, dado ambos dependem das mesmas variáveis. Desta maneira é possível estabelecer uma condição equivalente em termos de colchão-decapital $B_{2}$, i.e.,

$$
B_{2} \geqslant 0
$$

É importante ressaltar que o colchão-de-capital e exposições devem representar a mesma base de ativos. Haja vista que só se considerou exposições interbancárias em nossa matriz $\mathcal{L}_{t}$, então o colchão-de-capital deve ser calculado de acordo. Dado que as exigências regulamentais requerem que os conglomerados financeiros aloquem capital para todas as exposições sejam elas provenientes de operações interbancárias ou não, uma abordagem interessante seria ajustar o capital exigido para apenas as fontes de risco contempladas nas exposições de entrada (grau-de-entrada-ponderado). Desta maneira, o colchão-deentrada só representará os recursos disponíveis para assumir perdas não relacionadas as exposições não-bancárias.

Definição 2.7 (Colchão-de-Capital) O colchão-de-capital de uma instituição financeira $i \in \mathcal{V}_{t}$ é definido como

$$
\bar{B}_{2, i}=C_{2, i}-C_{r, i}-\delta \times \sum_{j \in \mathscr{Y} i n, i} \ell_{i j} .
$$

Neste sentido, o colchão-de-capital representará os recursos exigido para cobrir perdas com as exposições bancárias (exposições de interbancárias) e qualquer recursos adicionais 
sujeitos à administração que o conglomerado julgar necessário.

Neste contexto, o modelo estabelece que o conglomerado financeiro não está em condição de absorver perdas que sejam provenientes das exposições, caso este não esteja bem capitalizado em termos de colchão-de-capital. Como não existe um consenso na definição de inadimplência, é necessário definir inadimplência (default), evitando assim, qualquer anbigüidade.

Definição 2.8 (Inadimplência) Um conglomerado financeiro $i \in \mathcal{V}_{t}$ se torna inadimplente se o colchão-de-capital for negativo, i.e.,

$$
\bar{B}_{2, i}<0 \text {. }
$$

No caso brasileiro, esta situação significaria, em casos extremos, a intervenção na administração do conglomerado financeiro ou liquidação de seus ativos por parte do Banco Central do Brasil, sanção prevista em lei.

\subsubsection{Contágio via Inadimplência}

Um modelo de contágio está relacionado com a propagação de risco. Isto significa que quando um conglomerado financeiro se torna inadimplente, uma pergunta natural surge: qual o impacto desta inadimplência default nos outros conglomerados financeiros?

Para responder esta pergunta, é importante notar que exposições não representam fluxos monetários e sim riscos associados a transações. Então, uma aproximação realista é baixar as perdas (ou perdas prováveis e conhecidas) do colchão-de-capital, prática que retrata bem as práticas bancárias. Se no instante de tempo $t$, o conglomerado financeiro $j$ acredita que sua contraparte $i$ não irá honrar a exposição $\ell_{i j}$ quando o montante for devido, então, no tempo $t$, o conglomerado financeiro $i$ deve excluir de seu balanço a exposição $\ell_{i j}$, e este procedimento afetará negativamente o seu colchão-de-capital em mesma magnitude, tratando assim a exposição $\ell_{i j}$ como uma perda. Como conseqüência, partindo do estado inicial de inadimplência do conglomerado financeiro $i \in \mathcal{V}_{t}$, outros conglomerados financeiros também podem se tornar inadimplentes no estado subseqüente, e, este processo que causa outros conglomerados financeiros se tornarem inadimplentes pode ocorrer durante vários estados até que o sistema alcança um equilíbrio (estado final), onde o conjunto de conglomerados financeiros inadimplentes não causam nenhuma nova inadimplência no sistema. Claramente, o processo de baixar as perdas do colchão-de- 
capital dirigirá o mecanismo de inadimplência neste modelo de contágio.

Definição 2.9 (Procedimento de Baixa das Perdas) Seja o conjunto

$$
\mathscr{D}^{(s)}=\left\{j \in \mathcal{V}_{t}: \bar{B}_{2, j}^{(s)}<0\right\}
$$

representante dos conglomerados financeiros inadimplentes no estado $s$, onde $\bar{B}_{2, i}^{(s)}$ para todo $i \in \mathcal{V}_{t}$ são os colchões-de-capital no estado s. Então o procedimento de baixa das perdas pela seguinte dinâmica do colchão-de-capital

$$
\bar{B}_{2, i}^{(s+1)}=\bar{B}_{2, i}^{(s)}-\sum_{j \in \mathscr{D}^{(s)}} \ell_{i j},
$$

onde $s+1$ representa o estado subseqüente.

Por meio da Definição 2.9 é possível calcular o impacto de contágio de cada conglomerado financeiro. O impacto de contágio é a soma das perdas sofridas por todos os conglomerados financeiros dentro de um sistema financeiro dado que no estágio inicial apenas um conglomerado financeiro se torne inadimplente. Desta maneira, inicialmente, é estabelecido arbitrariamente um conjunto inicial de conglomerados financeiros inadimplentes $\mathscr{D}_{0}$. O conjunto de conglomerados financeiros inadimplentes no estado $s=0$ será dado por

$$
\mathscr{D}_{0}^{(0)}=\mathscr{D}^{(0)} \bigcup \mathscr{D}_{0}
$$

onde o subscrito em $\mathscr{D}_{0}^{(s)}$ indica que este conjunto dependerá da escolha do conjunto inicial $\mathscr{D}_{0}$. Escolhe-se um conjunto não nulo $\mathscr{D}_{0} \neq \emptyset$, então, de acordo com o procedimento de baixa de perdas, os conglomerados financeiros $\Omega \backslash \mathscr{D}_{0}$ sofrerão perdas, e os seus respectivos colchões-de-capital serão negativamente impactados pela dinâmica

$$
\bar{B}_{2, i}^{(1)}=\bar{B}_{2, i}^{(0)}-\sum_{j \in \mathscr{D}_{0}^{(0)}} \ell_{i j} .
$$

No estado seguinte $s=1$, alguns dos conglomerados financeiros do conjunto $\Omega \backslash \mathscr{D}_{0}$, eventualmente, se unirão ao conjunto de conglomerados inadimplentes

$$
\mathscr{D}_{0}^{(1)}=\left\{j \in \mathcal{V}_{t}: \bar{B}_{2, j}^{(1)}<0\right\}
$$

e, conseqüentemente, novas perdas serão sofridas pelo sistema financeiro. Este processo pode levar muitos estados até o sistema financeiro atinja um estado de equilíbrio $s^{*}$ que 
pode ser caracterizado como

$$
s^{*}=\inf \left\{s: \mathscr{D}_{0}^{(s)} \backslash \mathscr{D}_{0}^{(s+1)}=\emptyset\right\} .
$$

Por conseguinte, a dinâmica apresentada por meio das equações (2.17), (2.18), (2.19) e (2.20) representará o mecanismo de contágio que é semelhante as abordagem sugeridas por Mistrulli (2007), Cont e Moussa (2009), porém adaptado ao nosso contexto.

Suponha-se que seja escolhido um conjunto inicial que contemple apenas um conglomerado financeiro, i.e., $\mathscr{D}_{0}=\{j\}$ para um $j \in \mathcal{V}_{t}$, então é possível verificar as perdas que os outros conglomerados financeiros sofrerão, e, eventualmente comparar qual dos conglomerados financeiros causam maiores perdas para o sistema financeiro como um todo.

Definição 2.10 (Impacto da Inadimplência) O Impacto da Inadimplência $D I_{j}$ referente ao conglomerado financeiro $j \in \mathcal{V}_{t}$ para $t=1, \ldots, T$ é definido como

$$
D I_{j}=\sum_{i \in \mathcal{V}_{t}}\left\{\frac{\max \left(\bar{B}_{2, i}^{(0)}, 0\right)-\max \left(\bar{B}_{2, i}^{\left(s^{*}\right)}, 0\right)}{\bar{B}_{2, i}}\right\},
$$

dado que o conjunto inicial de inadimplência é $\mathscr{D}_{0}=\{j\}$.

Por meio desta definição fica evidente que um conglomerado financeiro não pode perder mais que seu colchão-de-capital, e que o $D I_{j}$ é a soma das perdas sofrida pelo sistema no caso do conglomerado financeiro $j$ se tornar inadimplente, sendo esta somatória expressa em porcentagem da capitalização total do sistema. Então, $D I_{j} \in[0,1]$ para $j \in \mathcal{V}_{t}$ representa a porcentagem de capitalização, em termos de colchões-de-capital, que é destruída se o conglomerado financeiro $j$ se tornar inadimplente. Sob a perspectiva de um agente regulador o $D I$ é uma medida importante, porque mostra quais os conglomerados financeiros que produzem maior risco à estabilidade de sistema e como as perdas propagam ao longo da rede interbancária, ajudando, assim, estes agentes à alocarem os recursos na supervisão dos conglomerados financeiros mais arriscados.

A Figura 2.8. (gráfico inferior esquerdo) mostra o histograma da distribuição do $D I$. É possível notar a forma exponencial da distribuição, que significa que a maioria das instituições financeiras não destruirão mais que $4 \%$ da capitalização de sistema. Porém, existem algumas instituições financeiras que são muito contagiantes, podendo destruir até $15 \%$ da capitalização de sistema. Assim, argumenta-se que os bancos centrais devem focar seus esforços na supervisão das instituições financeiras que podem causar um maior 
impacto de contágio, representado pelo $D I$.

\subsubsection{Riscos de Mercado e de Crédito}

Seguindo a terminologia apresentada por Bandt e Hartmann (2000), é necessário introduzir um índice para o risco sistêmico, pois o Impacto de Contágio DI é calculado de maneira determinística e a inadimplência arbitrária dos conglomerados financeiros individualmente não pode ser entendida estritamente como um evento sistêmico. Assim, propõem-se a modelagem dos eventos sistêmicos por meio da inclusão de choques exógeneos que afetarão os colchões-de-capital dos conglomerados financeiros, e incorporando, desta maneira, informações de mercado e de crédito. A proposta do Índice de Risco Sistêmico apresentada abaixo segue a abordagem de Cont e Moussa (2009), porém o índice foi adaptado para que este reflita os resultados apresentados na Subseção 2.5.2.

Definição 2.11 (Î́ndice de Risco Sistêmico) O Índice de Risco Sistêmico do conglomerado financeiro $i \in \mathcal{V}_{t}$ é dado por

$$
S I_{i}=\mathbb{E}\left[D I_{i}^{\varepsilon} \mid \bar{B}_{2, i}+\sigma_{i} \varepsilon_{i}<0\right]
$$

o impacto de contágio $D I_{i}^{\varepsilon}$ é calculado considerando o colchão-de-capital após of efeitos dos choques exógeneos $\varepsilon_{i}$ e $\sigma_{i}$ é o fator de escala para ajustar os choques exógeneos aos risco de crédito.

Seguindo esta definição, o $S I_{i}$ é a perda esperada de contágio considerando cenários onde o colchão-de-capital do conglomerado financeiro $i$ é inteiramente consumido através de eventos sistêmicos. Observe que os choques exógeneos incluem informações de riscos de mercado e de crédito. Seja $u_{1}, u_{2}, \ldots, u_{i}, \ldots, u_{n_{t}}$ uma seqüência de variáveis aleatórias uniformes correlacionadas. ${ }^{3}$ Lehar (2005) dá estimativas para volatilidades e correlações de ativos de bancos internacionais. Seguindo estas estimativas, considerou-se um coeficiente de correlação de 0.4 para a seqüência de variáveis uniformes. Partindo da

\footnotetext{
${ }^{3}$ Um modo simplificado para obter uma seqüência de uniformes correlacionadas é gerar uma seqüência de variáveis aleatórias de dimensão $n_{t}+1$ de normais padronizadas IID $\mathcal{N}(0,1)$, i.e., $z_{0}, z_{1}, \ldots, z_{n_{t}}$. Seja $\rho$ o coeficiente de correlação desejado, utilizando a copula gaussiana (ou qualquer outro modelo de dependências, tais como modelos de fatores), tem-se

$$
u_{i}=\Phi\left(\sqrt{\rho} z_{i}+\sqrt{1-\rho} z_{0}\right)
$$

para $i=1, \ldots n_{t}$, onde $\Phi$ é a função de densidade acumulada de uma distribuição normal padronizada. Neste caso $z_{0}$ poderia ser interpretado como o evento sistêmico e $z_{i}$ os efeitos de eventos sistêmicos individuais em cada conglomerado financeiro.
} 
seqüência de uniformes, gera-se uma seqüência de variáveis aleatórias com caudas grossas $\varepsilon_{1}, \varepsilon_{2}, \ldots, \varepsilon_{i}, \ldots, \varepsilon_{n_{t}}$ obtidas através da função inversa de densidade acumulada da distribuição de t-student escalonada com parâmetros dados pelas estimativas de MLE identificadas na Subseção 2.5.2..

Embora os momentos da distribuição t-student escalonada com um expoente de cauda $\alpha<1$ não ter os momentos bem definidos, a função de densidade acumulada $F$ é bem definida, e desta maneira é possível encontrar $\sigma_{i}$, tal que a função de densidade acumulada esteja calibrada para produzir a probabilidade de inadimplência $\pi_{i}$ para o conglomerado financeiro $i$. Como a condição $\bar{B}_{2, i}+\sigma_{i} \varepsilon_{i}<0$ é equivalente à $\varepsilon_{i}<-\bar{B}_{2, i} / \sigma_{i}$, segue que a constante $\sigma_{i}$ é

$$
\mathbb{P}\left(\varepsilon_{i}<-\frac{\bar{B}_{2, i}}{\sigma_{i}}\right)=F\left(-\frac{\bar{B}_{2, i}}{\sigma_{i}}\right)=\pi_{i} \Leftrightarrow \sigma_{i}=-\frac{\bar{B}_{2, i}}{F^{-1}\left(\pi_{i}\right)} .
$$

Para calcular o Índice de Risco Sistêmico dado pela equação (2.22), considerou-se simulações de Monte Carlo com 10,000 repetições, e, aplicou-se o método de Importância de Amostragem importance sampling que melhora o desempenho numérico do algoritmo, veja por exemplo (ASMUSSEN; GLYNN, 2007). Adicionalmente, as probabilidades de inadimplências $\pi$ 's foram obtidas basicamente por meios de agências de avaliação de risco de crédito, como Standard \& Poor's, Moody's, e Fitch. A Figura 2.8. (gráfico da esquerda superior) mostra o histograma da distribuição do SI. É possível notar a forma log-normal da distribuição com uma assimetria positiva. A assimetria sugere heterogeneidade entre os conglomerados financeiros que compõem o $S I$, e pode ser explicada principalmente pelas caudas grossas da distribuição t-student escalonada e as probabilidades de inadimplência idiossincráticas, respectivamente, representando os fatores de risco de mercado e de risco de crédito. Além disso, tem-se que a moda do histograma encontra-se entre o intervalo de $15 \%$ para $20 \%$ que é relativamente mais alto que o DI. Seguindo a mesma análise, algumas instituições financeiras são muito perigosas, e isso poderia destruir até $40 \%$ da capitalização de sistema.

\subsubsection{Efeito de Liquidez}

Além dos riscos de mercado e de crédito, durante uma crise financeira, os eventos sistêmicos são reforçados pela falta de liquidez. Nesta situação, o risco de liquidez realiza um papel crucial na análise do risco sistêmico em condições de estresse onde os conglomerados financeiros podem ter dificuldades de acessar recursos para financiar o colchão-de-capital. 
Incorporar o risco de liquidez nesta análise pode ser facilmente realizado ao considerar o colchão-de-capital do conglomerado financeiro em termos do capital de tipo $1 C_{1}$. Isto é equivalente a substituir o Capital de Referência $C_{2}$ pelo capital de tipo $1 C_{1}$, obtendo um choque-de-capital igual a

$$
\bar{B}_{1, i}=C_{1, i}-C_{r, i}-\delta \times \sum_{j \in \mathscr{Y}_{i n, i}} \ell_{i j} .
$$

A idéia atrás desta análise é considerar apenas o capital que está sujeito a inteira discricionariedade dos administradores da instituição financeira. Então, o capital tipo 1 é o único capital que realmente está sob controle da administração, e, por conseguinte o único instrumento disponível para administrar liquidez e alavancagem, especialmente durante uma crise. Desta maneira, argumenta-se a favor de que o capital do tipo 1 é a maneira conservadora de calcular a força de uma instituição financeira sob a perspectiva de agentes reguladores. Esta abordagem é endorssada por representantes de outros órgãos reguladores governamentais e não-governamentais, como as Security and Exchange Commission (SEC) e Financial Services Authority (FSA), veja (COX, 2008). Neste contexto, o capital do tipo $1 C_{1}$ é visto como uma medida de capital permanente que rende uma melhor medida do quanto as instituições financeiras são capazes de absorver perdas por meio de seu capital dentro de um horizonte de tempo de curto prazo.

A Figura 2.8. (gráficos direitos superior e inferior) mostra o histograma, respectivamente, das distribuições do $S I$ e $D I$ considerando o cenário de estresse onde os conglomerados financeiros só podem ter certeza de controle sobre o seu capital do tipo 1. As formas das distribuições são claramente iguais as obtidas pela análise sem a incorporação do risco de liquidez, todavia, é possível notar que as distribuições se deslocam ao longo do tempo. Seria natural esperar que o histograma localizado na extrema direita indique períodos onde liquidez é relevante, como os momentos de crises financeiras. Isto é exatamente o que é observado em ambos, o $S I$ e o $D I$. O histograma da extrema esquerda representa os dados de Junho/2007 e o histograma da extrema direita representa os dados de Junho/2008, onde o primeiro pode ser associado com a fase de desenvolvimento da crise financeira nos Estados Unidos, onde notícias negativas do mercado de renda fixa e de crédito estavam afetando a confiança de investidores, e, a data posterior é associada com o apogeu da crise financeira onde bancos, tais como o Lemon Brothers e Merrill Lynch solicitaram o pedido de falência e o banco Citibank sofreu perdas significativas apresentando problemas sérios de liquidez. Adicionalmente, em Junho/2008, o Índice de Risco Sistêmico SI contemplava conglomerados financeiros que poderiam destruir até o dobro da capitalização de sistema financeiro (80\%) quando comparados com os efeitos sem o risco de liquidez. Para o Impacto da Inadimplência DI este efeito parece ser ainda mais dramático, indicando destruição de até seis vezes quando comparado com a análise 
sem levar em consideração o risco de liquidez.

\subsection{Análise}

Nas seções precedentes foi explorada a estrutura e dinâmica das exposições interbancárias utilizando um conjunto de dados único que considera todas as exposições entre as instituições financeiras no Brasil, como também as reservas de capital destas, abrangendo diversos períodos que percorrem os anos de 2007 e 2008. Também foi investigado a relação entre conectividade de um vértice e o seu colchão-de-capital. Foi apresentado, em detalhe, as propriedades estatísticas que emergem do estudo empírico de uma topologia de rede de interbancária. As propriedades mencionadas são livres de qualquer modelo no sentido de que elas derivam não de hipóteses paramétricas da topologia de rede mas de hipótese que levam em consideração a natureza qualitativa da rede. Como tal, estes resultados devem ser vistos como restrições de um gráfico estocástico que descreve o comportamento de uma rede interbancária tem que reproduzir, para que este apresente as propriedades estatísticas da rede com precisão. Infelizmente, a maioria dos modelos existentes não reproduz estas características estatísticas ao mesmo tempo, sugerindo assim o limite de escopo destes modelos. Não obstante, parece que um modelo interessante que de fato poderia capturar adequadamente a maioria destas propriedades seria um rede dirigido de escala-livre (ponderada) com graus seguindo distribuições com caudas grossas.

Finalmente, é importante mencionar os assuntos que não foram discutidos neste estudo. Uma pergunta importante é se estas propriedades são pertinentes de um ponto de vista econômico. Em outras palavras, estes fatos empíricos podem ser usados para confirmar ou rejeitar certas abordagens de modelagem utilizadas na teoria econômica? Outra pergunta é se estes fatos empíricos são úteis sob a perspectiva de agentes supervisores, como bancos centrais. Por exemplo, a presença de distribuições com caudas grossas para a conectividade e exposições insinua risco sistêmico mais elevado e, eventualmente, maiores exigências de capitais. Talvez a resposta para esta pergunta é sim, mas não se explorou em detalhes este assunto sendo possível extrair uma conclusão científica. Além disso, não foram explorados os efeitos de usar técnicas de estimação para o banco de dados, como mínima entropia relativa, e como estes métodos podem ser usados para completar a matriz de exposições sem perder as propriedades estatísticas desejáveis. 


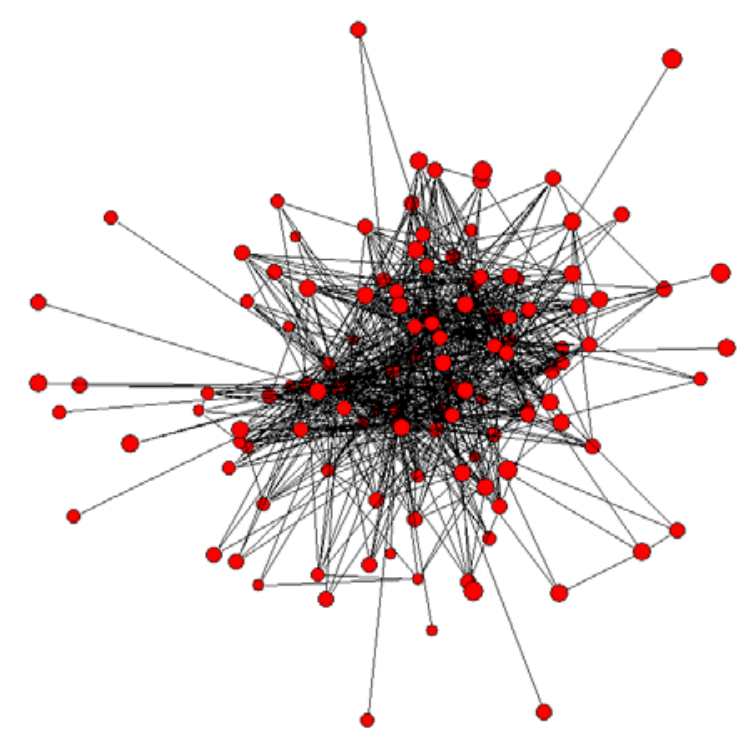

Figura 2.1.: Rede interbancária brasileira em Dezembro de 2007.
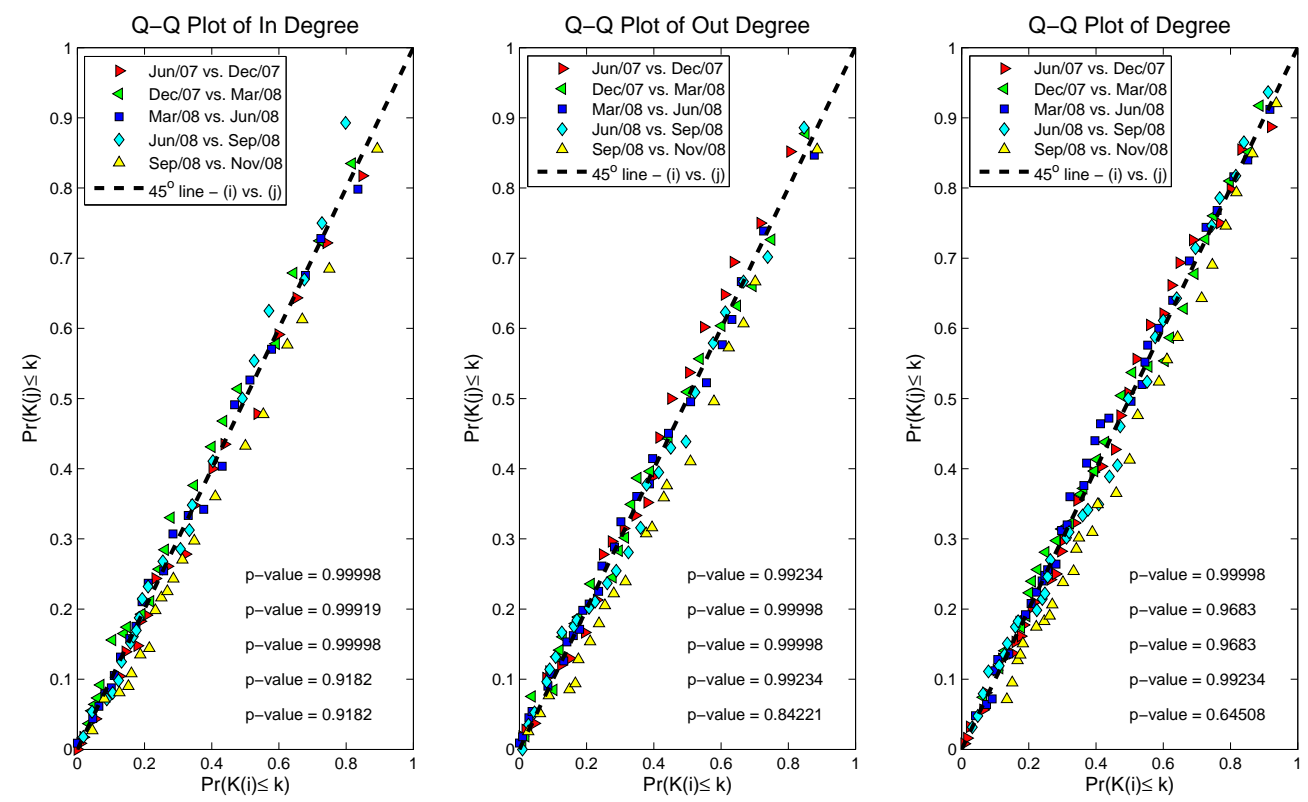

Figura 2.2.: Gráfico Q-Q da distribuição dos graus da rede interbancária brasileira para datas consecutivas. 


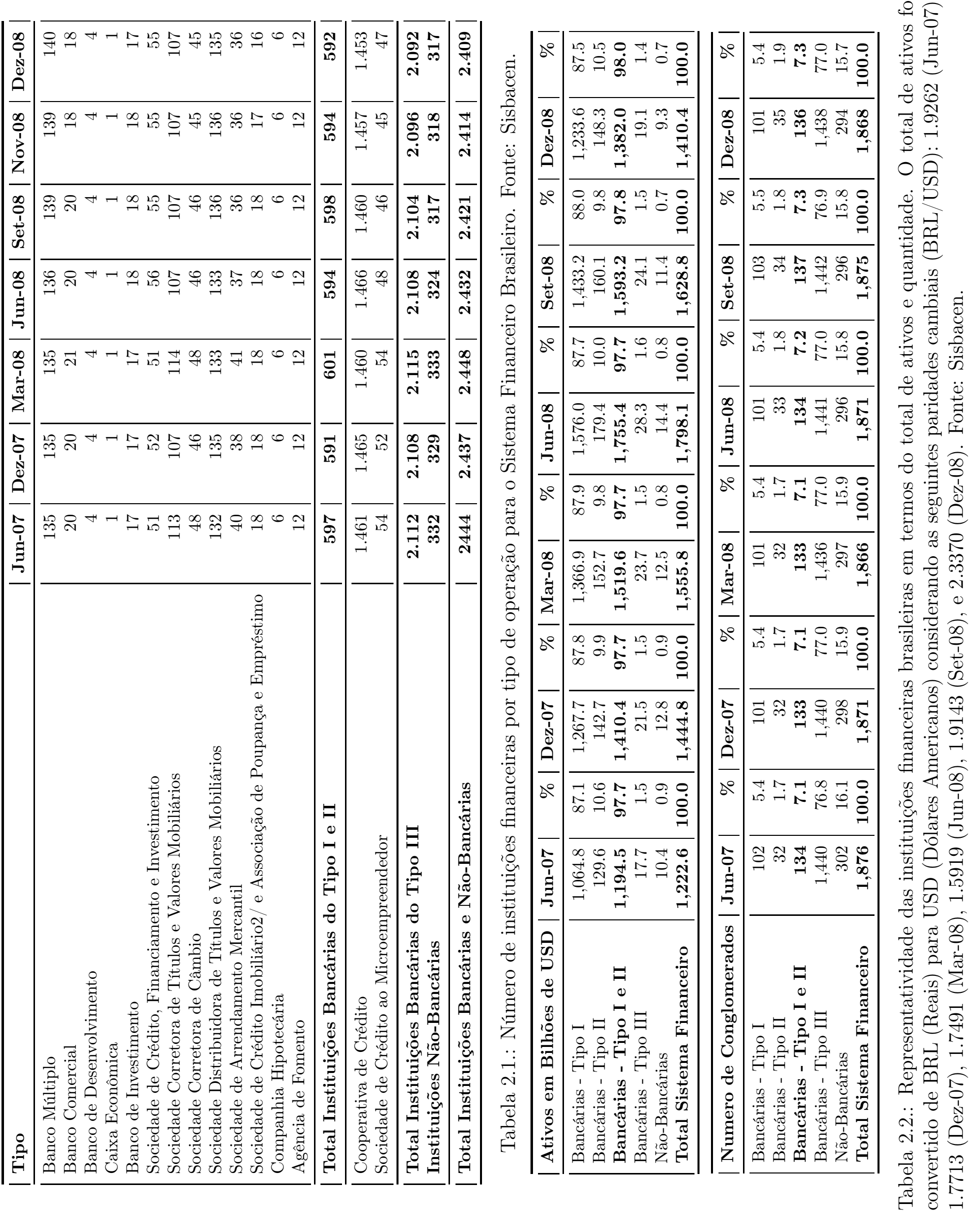




\begin{tabular}{|c|c|c|c|c|c|c|c|}
\hline Grau-de-entrada & Jun-07 & Dez-07 & Mar-08 & Jun-08 & Set-08 & Nov-08 & Média \\
\hline$\hat{\mathbb{E}}\left(K_{i n}\right)$ & 8.6 & 8.6 & 8.8 & 9.0 & 9.0 & 7.9 & 8.6 \\
\hline$\hat{\sigma}\left(K_{i n}\right)$ & 10.8 & 10.9 & 10.6 & 11.2 & 11.3 & 11.0 & 11.0 \\
\hline $\min \left(k_{i n}\right)$ & 0 & 0 & 0 & 0 & 0 & 0 & 0.0 \\
\hline $\max \left(k_{i n}\right)$ & 54 & 54 & 51 & 57 & 60 & 62 & 56.3 \\
\hline$\hat{\alpha}^{M L E}$ & 2.1997 & 2.7068 & 2.2059 & 3.3611 & 2.1610 & 2.1320 & 2.4611 \\
\hline$\hat{\sigma}\left(\hat{\alpha}^{M L E}\right)$ & 0.4887 & 0.4692 & 0.4756 & 0.5336 & 0.4722 & 0.4417 & 0.4802 \\
\hline$\hat{k}_{i n, \min }^{M L E}$ & 6 & 13 & 7 & 21 & 6 & 5 & 9.7 \\
\hline Grau-de-saída & Jun-07 & Dez-07 & Mar-08 & Jun-08 & Set-08 & Nov-08 & Mean \\
\hline$\hat{\mathbb{E}}\left(K_{\text {out }}\right)$ & 8.6 & 8.6 & 8.8 & 9.0 & 9.0 & 7.9 & 8.6 \\
\hline$\hat{\sigma}\left(K_{\text {out }}\right)$ & 8.7 & 8.8 & 9.0 & 9.4 & 9.4 & 8.8 & 9.0 \\
\hline $\min \left(k_{\text {out }}\right)$ & 0 & 0 & 0 & 0 & 0 & 0 & 0.0 \\
\hline $\max \left(k_{\text {out }}\right)$ & 36 & 37 & 39 & 41 & 39 & 44 & 39.3 \\
\hline$\hat{\alpha}^{M L E}$ & 1.9855 & 3.4167 & 3.4000 & 2.9110 & 2.4302 & 2.8861 & 2.8383 \\
\hline$\hat{\sigma}\left(\hat{\alpha}^{M L E}\right)$ & 0.6359 & 0.5914 & 0.4884 & 0.4384 & 0.4174 & 0.4955 & 0.5112 \\
\hline$\hat{k}_{\text {out }, \text { min }}^{M L E}$ & 5 & 15 & 16 & 12 & 9 & 11 & 11.3 \\
\hline Graus & Jun-07 & Dez-07 & Mar-08 & Jun-08 & Set-08 & Nov-08 & Média \\
\hline$\hat{\mathbb{E}}(K)$ & 17.1 & 17.2 & 17.5 & 18.0 & 18.0 & 15.8 & 17.3 \\
\hline$\hat{\sigma}(K)$ & 17.5 & 17.5 & 17.5 & 18.2 & 18.6 & 18.3 & 17.9 \\
\hline $\min (k)$ & 1 & 1 & 1 & 1 & 1 & 1 & 1.0 \\
\hline $\max (k)$ & 86 & 87 & 80 & 87 & 90 & 106 & 89.3 \\
\hline$\hat{\alpha}^{M L E}$ & 2.6163 & 3.3750 & 2.2997 & 2.4840 & 2.2705 & 2.2311 & 2.5461 \\
\hline$\hat{\sigma}\left(\hat{\alpha}^{M L E}\right)$ & 0.5222 & 0.4767 & 0.4834 & 0.4124 & 0.4394 & 0.3580 & 0.4487 \\
\hline$\hat{k}_{\min }^{M L E}$ & 17 & 34 & 12 & 15 & 12 & 10 & 16.7 \\
\hline Exposições* & Jun-07 & Dez-07 & Mar-08 & Jun-08 & Set-08 & Nov-08 & Média \\
\hline$\hat{\mathbb{E}}(L)$ & $1,214.8$ & 872.5 & 914.3 & 954.0 & 977.1 & $1,364.8$ & $1,049.6$ \\
\hline$\hat{\sigma}(L)$ & $3,785.5$ & $1,952.6$ & $2,029.6$ & $2,018.3$ & 2,309.9 & $3,565.7$ & $2,610.2$ \\
\hline $\min (\ell)$ & 0.0 & 0.3 & 0.5 & 0.0 & 0.1 & 0.0 & 0.2 \\
\hline $\max (\ell)$ & $30,106.6$ & $12,874.9$ & $12,979.5$ & $12,863.2$ & $15,814.1$ & $23,664.9$ & $18,050.5$ \\
\hline$\hat{\alpha}^{M L E}$ & 1.9792 & 2.2297 & 2.2383 & 2.3778 & 2.2766 & 2.5277 & 2.2716 \\
\hline$\hat{\sigma}\left(\hat{\alpha}^{M L E}\right)$ & 0.0260 & 0.6000 & 0.2140 & 0.6920 & 0.3840 & 0.9820 & 0.4830 \\
\hline$\hat{\ell}_{\min }^{M L E}$ & 39.5 & 74.0 & 80.0 & 101.7 & 93.4 & 336.7 & 120.9 \\
\hline
\end{tabular}

*valores em milhões de BRL (Reais)

Tabela 2.3.: Estatísticas gerais e estimativas MLE para os parâmetros da distribuição potência: expoente de cauda $\alpha$, valores mínimo da cauda para o grau-de-entrada $k_{i n, \min }$, grau-de-saída $k_{o u t, m i n}$, graus $k_{m i n}$, e exposições $\ell_{\text {min }}$. 

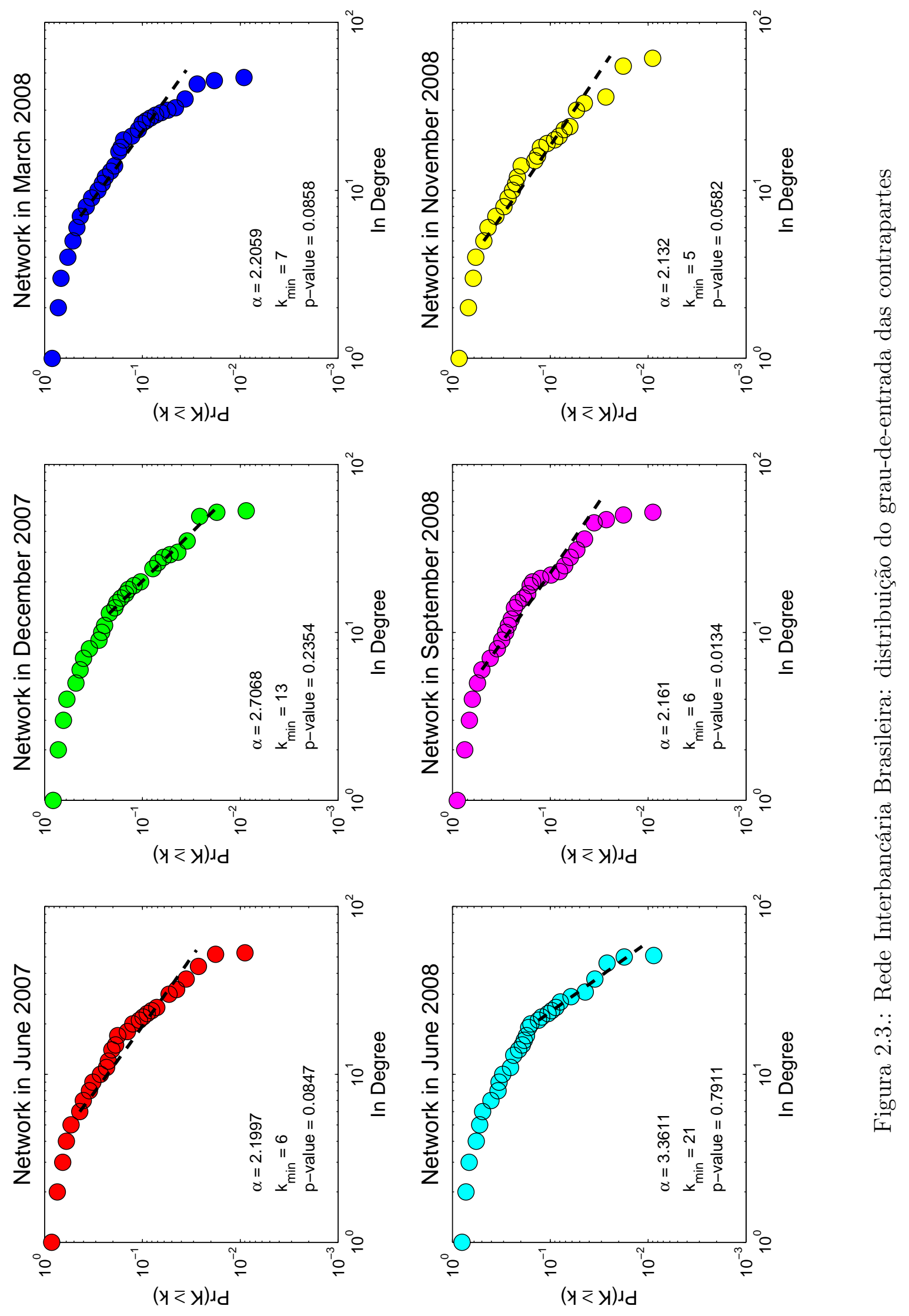

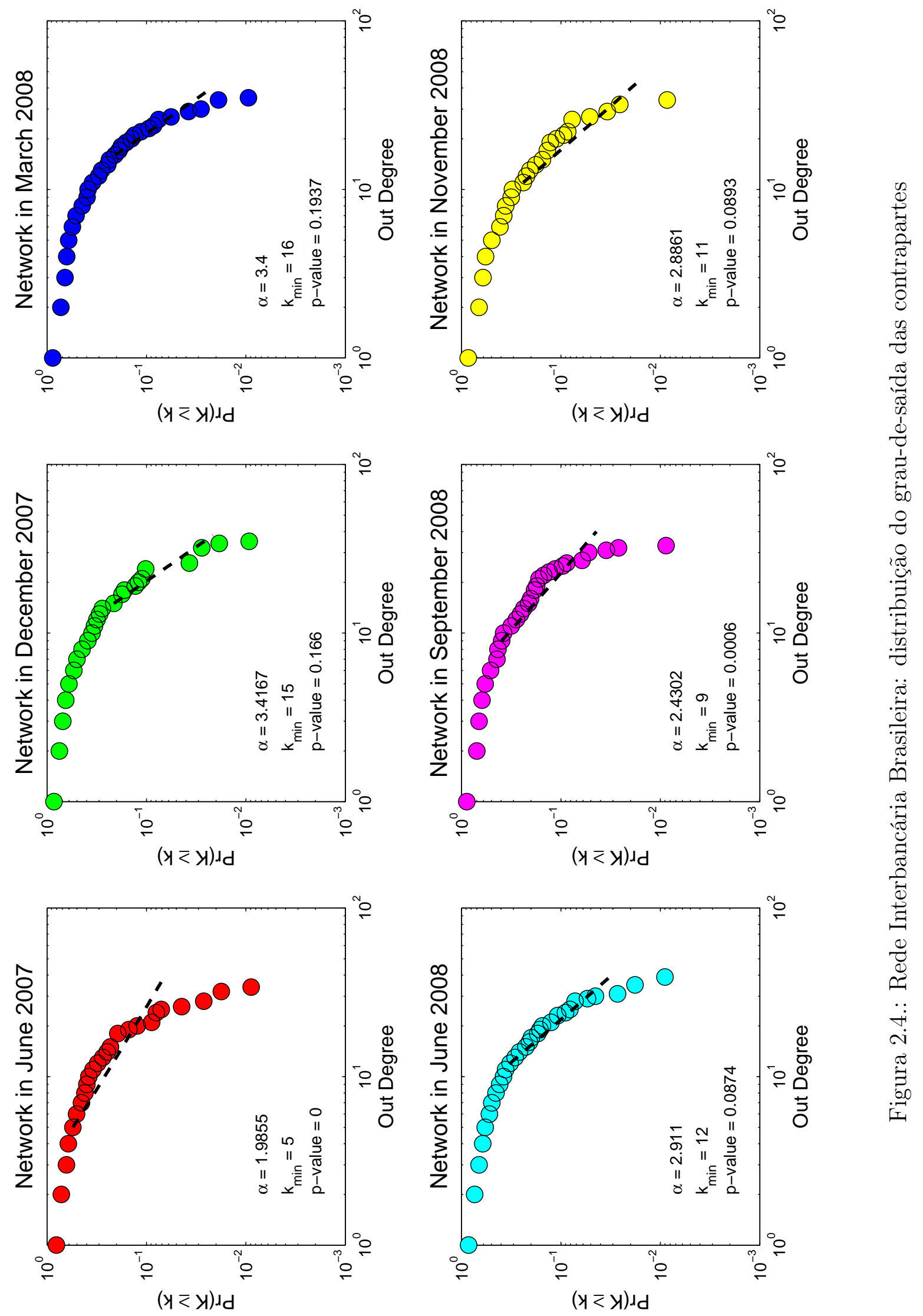

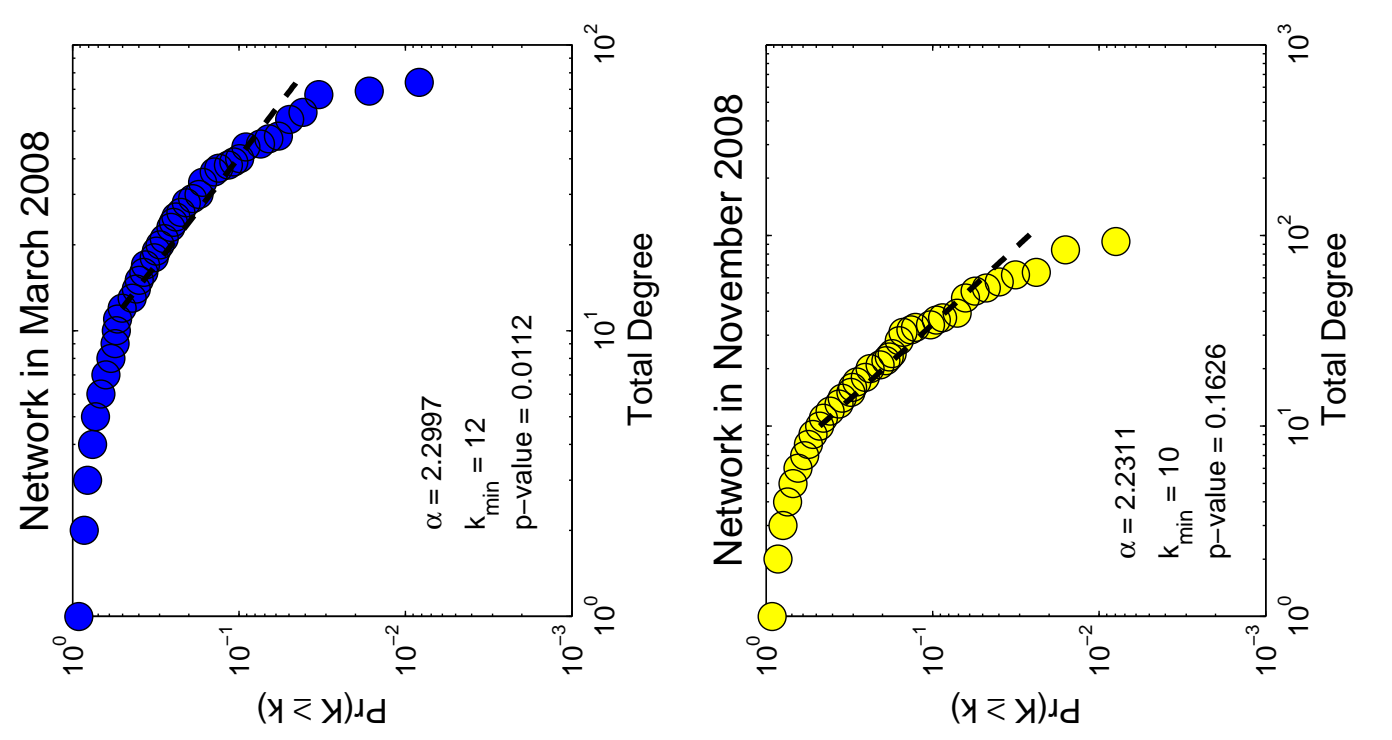

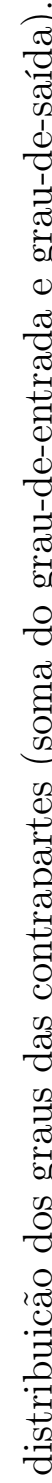
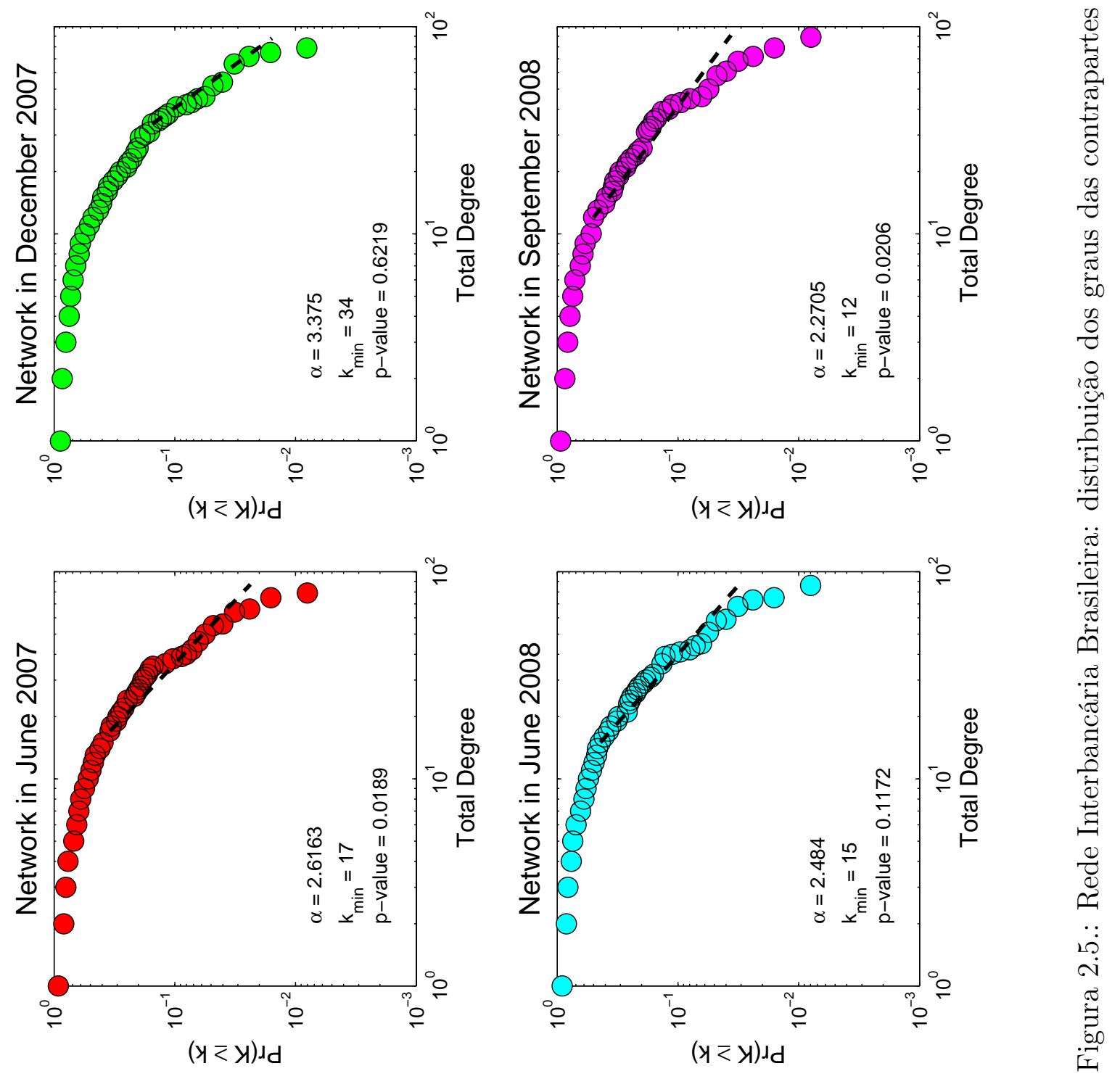

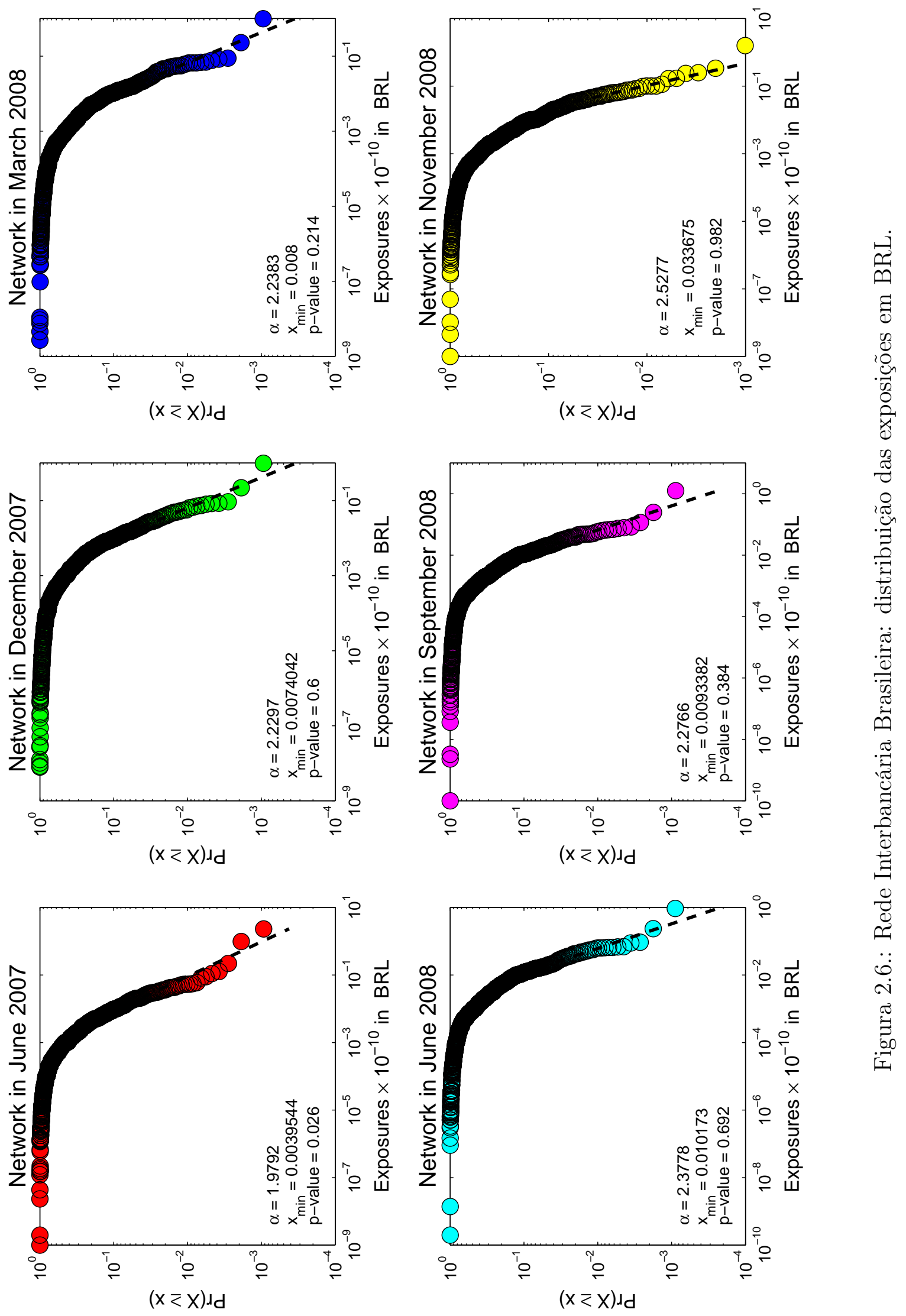


\begin{tabular}{|c|cccccc|}
\hline$k_{\text {in }}$ vs. $w_{\text {in }} / k_{\text {in }}$ & Jun-07 & Dez-07 & Mar-08 & Jun-08 & Set-08 & Nov-08 \\
\hline$\rho_{\text {Pearson }}$ & 0.0381 & -0.0353 & -0.0410 & -0.0359 & -0.0379 & -0.0303 \\
(p-valor) & $(0.6900)$ & $(0.7082)$ & $(0.6724)$ & $(0.7047)$ & $(0.6915)$ & $(0.7523)$ \\
$\tau_{\text {Kendall }}$ & 0.2839 & 0.2554 & 0.2294 & 0.2648 & 0.2409 & 0.2144 \\
(p-valor) & $(0.0000)$ & $(0.0001)$ & $(0.0006)$ & $(0.0001)$ & $(0.0002)$ & $(0.0013)$ \\
$\rho_{\text {Spearman }}$ & 0.3907 & 0.3508 & 0.3109 & 0.3642 & 0.3328 & 0.2876 \\
(p-valor) & $(0.0000)$ & $(0.0001)$ & $(0.0010)$ & $(0.0001)$ & $(0.0003)$ & $(0.0022)$ \\
\hline$k_{\text {out }}$ vs. $w_{\text {out }} / k_{\text {out }}$ & $\mathbf{J u n - 0 7}$ & $\mathbf{D e z - 0 7}$ & Mar-08 & Jun-08 & Set-08 & Nov-08 \\
\hline$\rho_{\text {Pearson }}$ & 0.0315 & 0.2456 & 0.2415 & 0.2543 & 0.2302 & 0.0200 \\
$(\mathrm{p}$-valor) & $(0.7402)$ & $(0.0104)$ & $(0.0126)$ & $(0.0071)$ & $(0.0137)$ & $(0.8301)$ \\
$\tau_{\text {Kendall }}$ & 0.2728 & 0.2807 & 0.3143 & 0.3274 & 0.3440 & 0.3025 \\
$(\mathrm{p}$-valor) & $(0.0000)$ & $(0.0000)$ & $(0.0000)$ & $(0.0000)$ & $(0.0000)$ & $(0.0000)$ \\
$\rho_{\text {Spearman }}$ & 0.3787 & 0.3969 & 0.4329 & 0.4562 & 0.4704 & 0.4241 \\
$(\mathrm{p}$-valor) & $(0.0000)$ & $(0.0000)$ & $(0.0000)$ & $(0.0000)$ & $(0.0000)$ & $(0.0000)$ \\
\hline$k$ vs. $w$ & Jun-07 & Dez-07 & Mar-08 & Jun-08 & Set-08 & Nov-08 \\
\hline$\rho_{\text {Pearson }}$ & -0.0130 & -0.0573 & -0.0607 & -0.0531 & -0.0539 & -0.0280 \\
$(\mathrm{p}$-valor) & $(0.8854)$ & $(0.5270)$ & $(0.5085)$ & $(0.55610$ & $(0.5489)$ & $(0.7552)$ \\
$\tau_{\text {Kendall }}$ & 0.2460 & 0.2487 & 0.2179 & 0.2378 & 0.2386 & 0.2309 \\
$(\mathrm{p}$-valor) & $(0.0001)$ & $(0.0001)$ & $(0.0005)$ & $(0.0001)$ & $(0.0001)$ & $(0.0002)$ \\
$\rho_{\text {Spearman }}$ & 0.3370 & 0.3550 & 0.3086 & 0.3337 & 0.3336 & 0.3329 \\
$(\mathrm{p}$-valor) & $(0.0001)$ & $(0.0001)$ & $(0.0006)$ & $(0.0001)$ & $(0.0001)$ & $(0.0001)$ \\
\hline
\end{tabular}

Tabela 2.4.: Rede interbancária brasileira: Coeficientes de Pearson $\rho_{\text {Pearson }}$, Kendall $\tau_{\text {Kendall }}$ e Spearman $\rho_{\text {Spearman }}$ para grau-de-entrada $k_{i n}$ vs. exposições-de-entrada $w_{i n}$, grau-de-saída $k_{\text {out }}$ vs. exposições-de-saída $w_{\text {out }}$, e graus $k$ vs. exposições $w$.

\begin{tabular}{|c|cccccc|}
\hline & Jun-07 & Dez-07 & Mar-08 & Jun-08 & Set-08 & Nov-08 \\
\hline$\rho_{k}$ & -0.2546 & -0.2870 & -0.2783 & -0.2972 & -0.3207 & -0.3548 \\
$\sigma^{2}\left(\rho_{k}\right)$ & 0.0008 & 0.0008 & 0.0009 & 0.0008 & 0.0008 & 0.0008 \\
\hline$\rho_{\ell}$ & 0.0262 & 0.0070 & 0.0115 & -0.0196 & -0.0102 & -0.0578 \\
$\sigma^{2}\left(\rho_{\ell}\right)$ & 0.0019 & 0.0013 & 0.0013 & 0.0011 & 0.0012 & 0.0009 \\
\hline $\mathbb{E}(c)$ & 0.1759 & 0.1718 & 0.1745 & 0.1774 & 0.1960 & 0.1951 \\
\hline$d$ & 2.7043 & 2.7103 & 2.7313 & 2.6651 & 2.6460 & 2.6618 \\
\hline
\end{tabular}

Tabela 2.5.: Rede interbancária brasileira: coeficiente de afinidade para a matriz adjacente $\rho_{k}$ e para a matriz de exposições $\rho_{\ell}$, e suas respectivas variâncias $\sigma^{2}\left(\rho_{k}\right)$ e $\sigma^{2}\left(\rho_{\ell}\right)$, coeficiente de agrupamento global $\mathbb{E}(c)$ e diâmetro da rede $d$. 

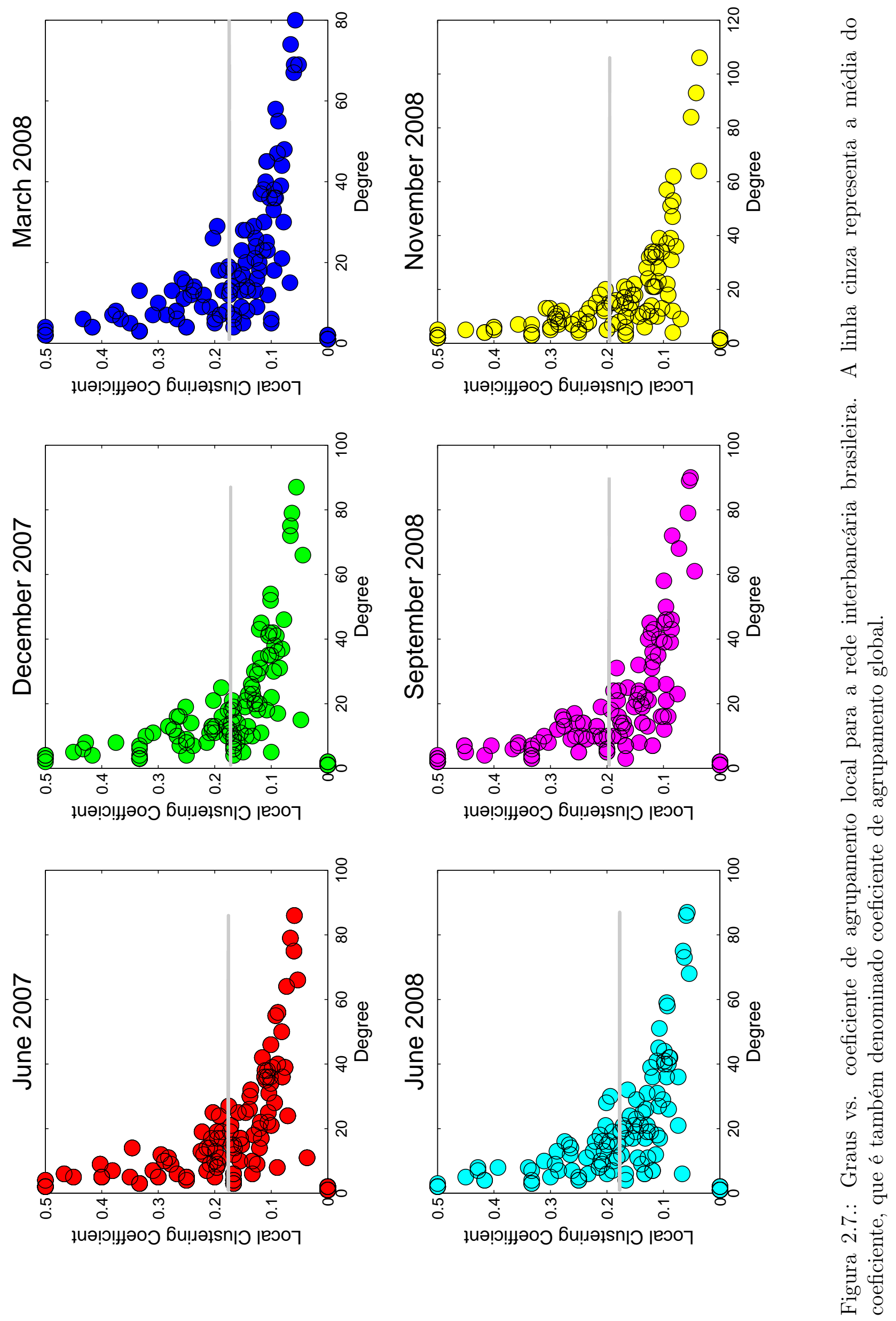

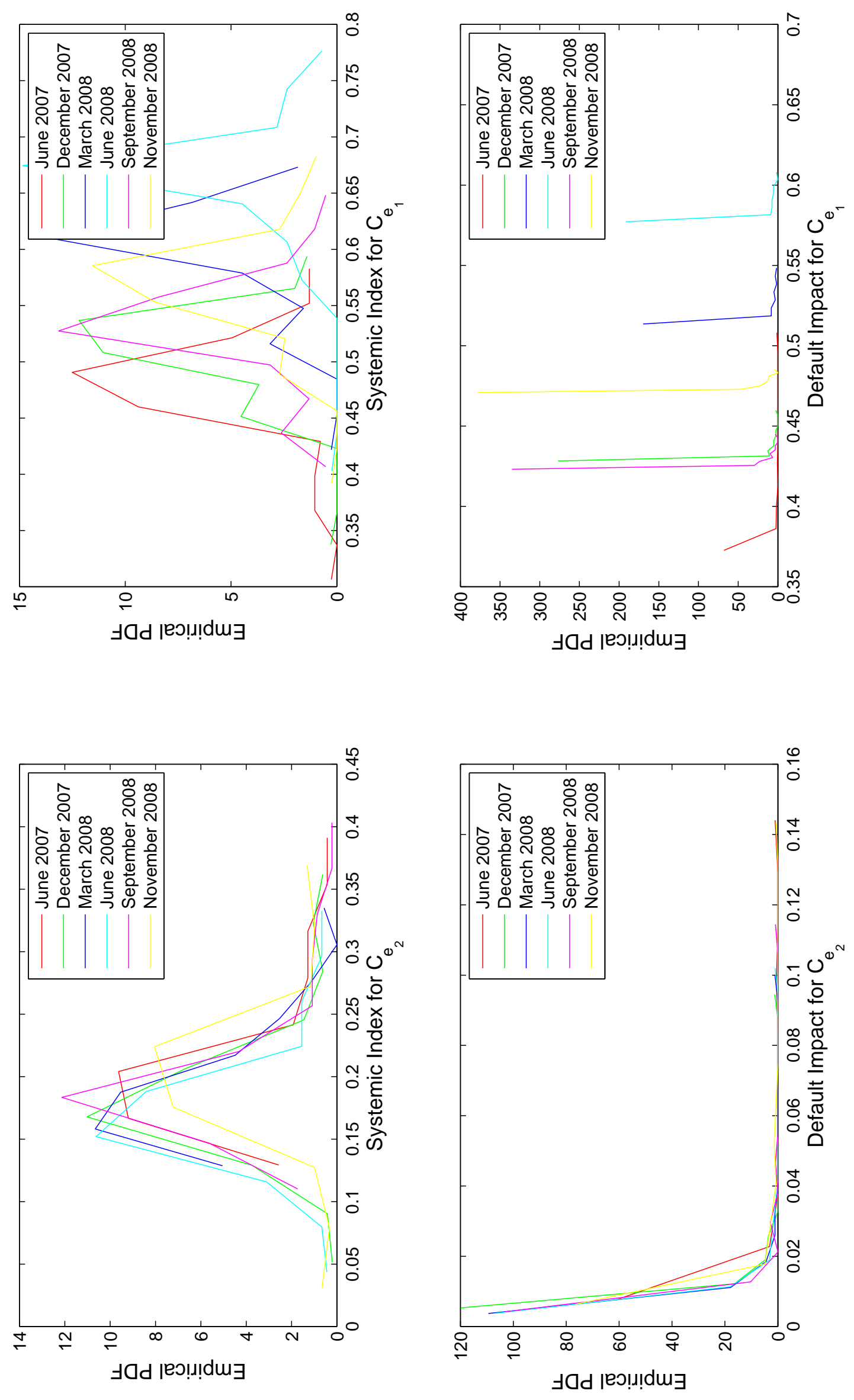

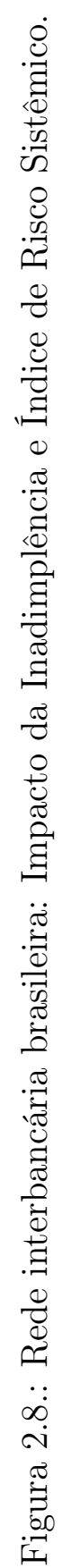




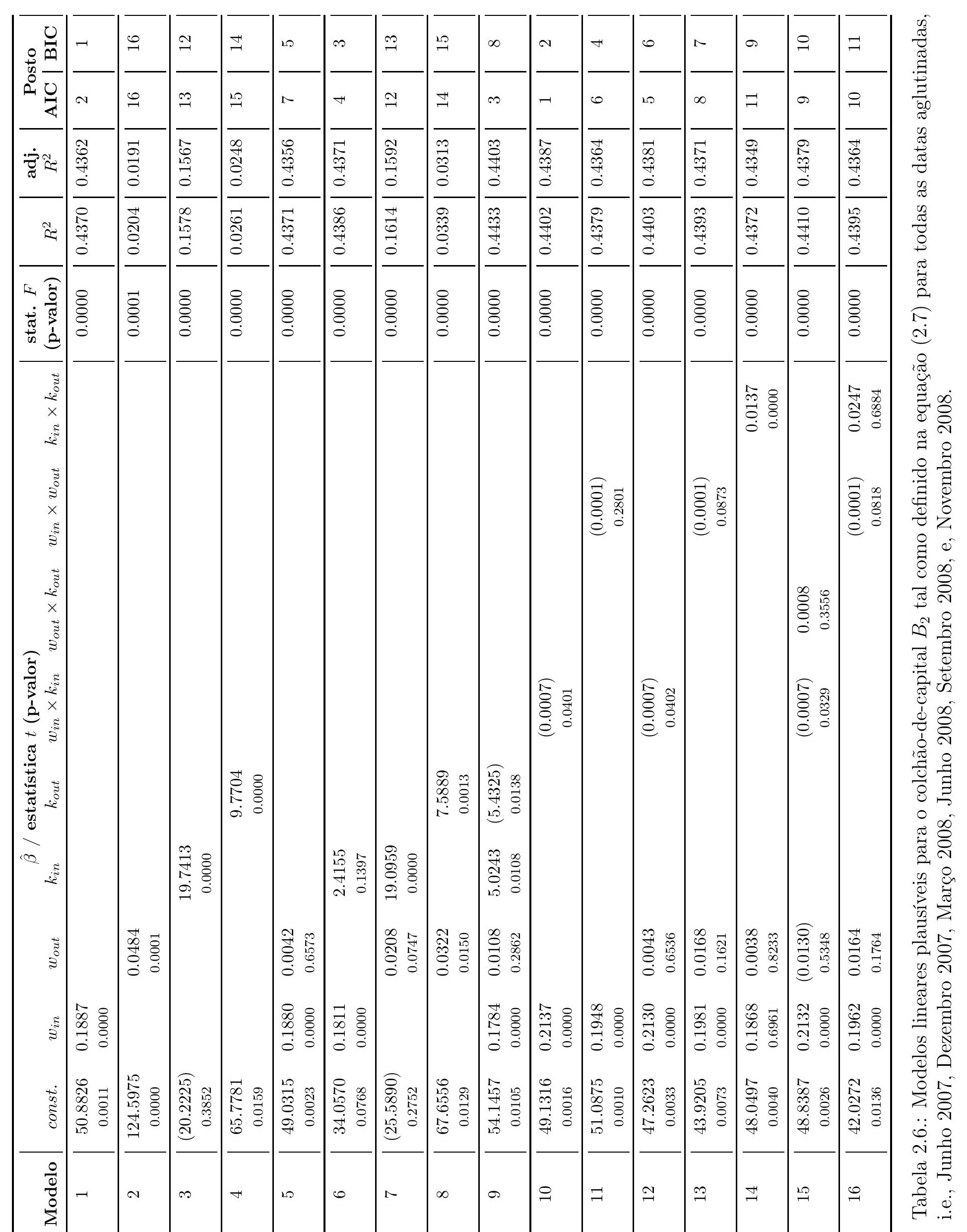



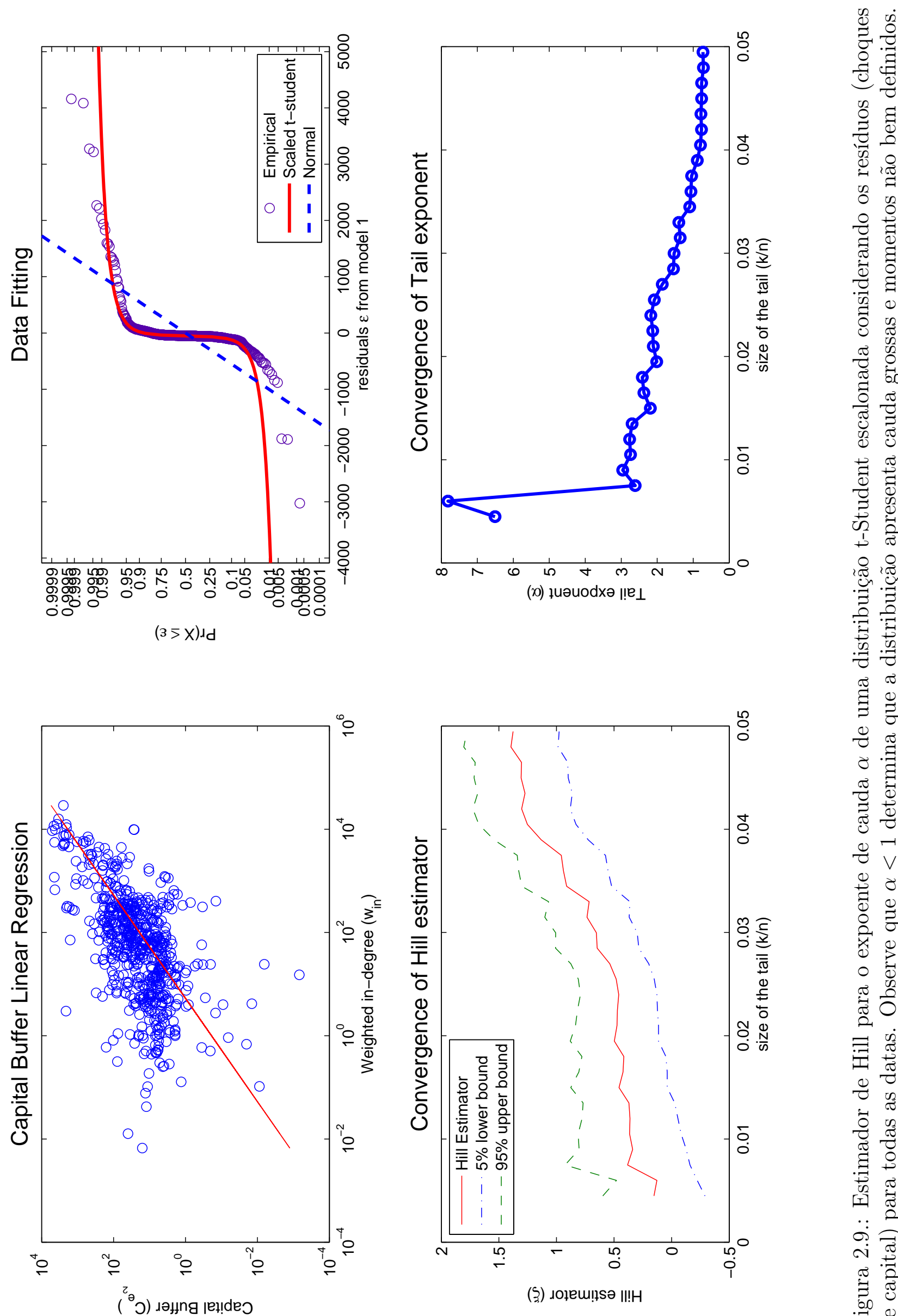

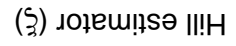

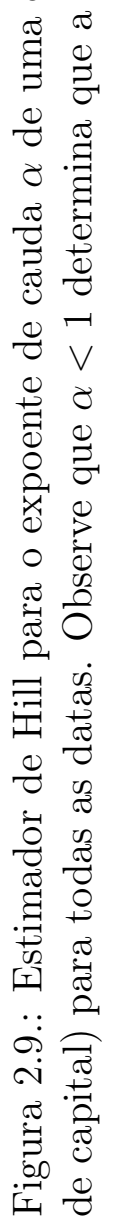




\section{Conclusões}

Esta tese buscou investigar dois problemas propostos na Introdução, i.e., (i) modelar o apreçamento de opções multidimensionais com dependências na trajetória e (ii) identificar as características da topologia da rede interbancária no Brasil e avaliar a propagação do risco sistêmico. Adotando-se uma abordagem de métodos quantitativos, podemos concluir que: com relação ao problema de apreçamento (Capítulo 1) foi proposta uma maneira sistematizada de descrever a estrutura entre processos estocásticos com descontinuidades nas trajetórias (processos de Lévy) por meio de cópulas dinâmicas, permitindo mitigar de uma maneira mais eficiente o processo de apreçamento dos instrumentos financeiros acima citados. Também foi apresentado um modelo didático, considerando as suas preocupações econométricas e utilizando técnicas de simulação de Monte Carlo. Este exemplo visou estabelecer uma conexão entre a teoria desenvolvida e a sua aplicação na área de apreçamento de contratos derivativos, mostrando que o método sugerido neste artigo é viável e computacionalmente eficiente. Com relação ao problema do risco sistêmico (Capítulo 2), explorou-se com detalhes a estrutura e dinâmica interbancária das exposições mútuas entre as instituições financeiras no Brasil, bem como a reserva de capital destas instituições, utilizando um conjunto de dados únicos que considera vários períodos entre 2007 e 2008. Para isto foi mostrado que a rede de exposições pode ser modelada adequadamente como um gráfico estocástico dirigido de escala-livre (ponderada) seguindo distribuições que apresentam caudas grossas. As propriedades mencionadas são livres de qualquer modelo no sentido de que elas derivam não de hipóteses paramétricas da topologia de rede, mas de hipótese que levam em consideração a natureza qualitativa da rede. Também foi proposto um modelo linear para descrever o comportamento do colchão-de-capital, haja vista que a estrutura de capitalização do sistema executa um papel fundamental na avaliação do risco sistêmico. E, por último, foi proposto um Índice de Risco Sistêmico, que buscou incorporar as principais fontes de risco que afetam a rede interbancária, tais como o contágio originado por inadimplências, risco de crédito, risco de mercado e risco de liquidez.

Neste sentido destaca-se que a tese buscou ser inovadora na sua maior parte, sugerindo novas abordagens e modelos que visaram contribuir para a busca de uma solução aos problemas inicialmente propostos. Assim, corroborando estes esforços, são enumeradas as contribuições individuais mais relevantes desta tese:

- Desenvolvimento da Família Frank Generalizada de Copulas de Lévy (Exemplo 1.16)

- Especificação dos momentos até quarta ordem da distribuição do processo de Lévy 
orientado por processos Gammas. [equações (1.51) até (1.54)] para implementação do método de estimação GMM [equações (1.55) e (1.56)].

- Generalização do algorítimo de Rosiński para simulação de processos gamma [equação (1.58)]

- Análise numérica comparativa das famílias generalizadas de Clayton e Frank para opções multidimensionais com dependência na trajetória via métodos de Monte Carlo (Subseção 1.5.3.)

- Proposição da generalização do Tau de Kendall para processos estocásticos (Seção 1.6.).

- Comprovação da hipótese de que o comportamento das distribuições dos grau-deentrada, grau-de-saída, exposições são dirigidas por caudas grossas, tais como a distribuições pontências discreta e contínua (Subseções 2.4.2. e 2.4.3.).

- Identificação das relações não lineares entre a magnitude das exposições e conectividade (Subseção 2.4.4.).

- Proposição do modelo linear de colchão-de-capital, equação (2.8), e avaliação do comportamento dos resíduos deste modelo por métodos paramétricos (MLE) e não paramétricos (OLS) e estimador de Hill (Subseção 2.5.2.).

- Proposição dos Índices de Impacto da Inadimplência [equação (2.21)], e Índice de Risco Sistêmico [equação (2.22)]. 


\section{REFERÊNCIAS BIBLIOGRÁFICAS}

AKAIKE, H. A new look at the statistical model identification. IEEE Transactions on Automatic Control, v. 19, n. 6, p. 716-723, dez. 1974.

ALBERT-LÁSZÓ, E. M.; BARABÁSI, E. M.; BONABEAU, E. Scale-free networks. Scientific American, v. 288, n. 5, p. 60-60, maio 2003.

ASMUSSEN, S.; GLYNN, P. W. Stochastic Simulation: Algorithms and Analysis. New York: Springer, 2007. (Stochastic Modelling and Applied Probability, 100).

BACEN. Circular $n^{o}$ 3.410. Brasil, 13.10.2008. Disponível em: <http://www3.bcb.gov.br/normativo/detalharNormativo.do?N=108099396\&method $=$ detalharNormativo $>$. Acesso em: 8.12.2008.

Circular $n^{o}$ 3.411. Brasil, 13.10.2008. Disponível em: <http://www3.bcb.gov.br/normativo/detalharNormativo.do?N=108100145\&method $=$ detalharNormativo $>$. Acesso em: 8.12.2008.

- Circular $n^{o}$ 3.412. Brasil, 13.10.2008. Disponível em: <http://www3.bcb.gov.br/normativo/detalharNormativo.do?N=108099445\&method $=$ detalharNormativo $>$. Acesso em: 8.12.2008.

- Resolução $n^{o} \quad$ 3.444. Brasil, 28.02.2007. Disponível em: $<$ http://www3.bcb.gov.br/normativo/detalharNormativo.do?N=107067242\&method $=$ detalharNormativo $>$. Acesso em: 8.12.2008.

- Resolução $n^{o} \quad$ 2.743. Brasil, 28.06.2000. Disponível em: <http://www3.bcb.gov.br/normativo/detalharNormativo.do?N=100117491\&method $=$ detalharNormativo $>$. Acesso em: 8.12.2008.

—. Resolução $n^{o} \quad$ 3.490. Brasil, 29.08.2007. Disponível em: $<$ http://www.bcb.gov.br/Htms/Normativ/RESOLUCAO3490.pdf $>$. Acesso em: 8.12.2008.

—. Resolução $n^{\circ}$ 2.723. Brasil, 31.05.2000. Disponível em: $<$ http://www3.bcb.gov.br/normativo/detalharNormativo.do?N=100098469\&method $=$ detalharNormativo $>$. Acesso em: 8.12.2008.

—. Resolução $n^{o} \quad$ 3.622. Brasil, 9.10.2008. Disponível em: <http://www3.bcb.gov.br/normativo/detalharNormativo.do?N=108098613\&method $=$ detalharNormativo $>$. Acesso em: 8.12.2008.

BANDT, O. de; HARTMANN, P. Systemic Risk: A Survey. Frankfurt, Germany, nov. 2000.

BARNDORFF-NIELSEN, O. E. Normal inverse gaussian distributions and stochastic 
volatility modelling. Scandinavian Journal of Statistics, v. 24, n. 1, p. 1-13, 1997.

. Processes of normal inverse gaussian type. Finance and Stochastics, v. 2, n. 1, p. 41-68, 1998.

BIS. International Convergence of Capital Measurement Standards. Basiléia, 1988. Disponível em: <http://www.bis.org/publ/bcbs04a.pdf>. Acesso em: 8.12.2008. - International Convergence of Capital Measurement Standards: A Revised Framework. Basiléia, 2005. Disponível em: <http://www.bis.org/publ/bcbs118.pdf>. Acesso em: 15.10.2007.

BRASIL. Medida provisória $n^{o}$ 442. Brasil, 6.10.2008. Disponível em: $<$ http://www.camara.gov.br/sileg/integras/601463.pdf>. Acesso em: 8.12.2008.

BROOCK, W. A. et al. A test for independence based on the correlation dimension. Econometric Reviews, v. 15, n. 3, p. 197-235, 1996.

CAJUEIRO, D. O.; TABAK, B. M. The role of banks in the brazilian interbank market: Does bank type matter? Physica A: Statistical Mechanics and its Applications, v. 387, n. 27 , p. $6825-6836,2008$.

CHERUBINI, U.; LUCIANO, E. Bivariate option pricing with copulas. Applied Mathematical Finance, v. 9, n. 2, p. 69-85, jun. 2002.

CHERUBINI, U.; LUCIANO, E.; VECCHIATO, W. Copula Methods in Finance. West Sussex: John Wiley \& Sons, 2004. (Wiley Finance Series).

ClauseT, A.; SHALIZI, C. R.; NEWMAN, M. E. J. Power-law distributions in empirical data. Working Paper. 2009. Disponível em: $<$ http://arxiv.org/PS_cache/arxiv/pdf/0706/0706.1062v2.pdf $>$. Acesso em: 04.22.2008.

CONT, R.; MOUSSA, A. Too interconnected to fail: contagion and systemic risk in financial networks. New York, USA, 2009.

CONT, R.; TANKOV, P. Financial Modelling with Jump Processes. Boca Raton: Chapman \& Hall/CRC, 2004. (Financial Mathematics Series).

COVER, T. M.; THOMAS, J. A. Elements of Information Theory. 2nd. ed. New York: John Wiley \& Sons, 2006. (Wiley Series in Telecommunications and Signal Processing).

COX, C. Letter to Basel Committee in Support of New Guidance on Liquidity Management. [S.1.], March 2008.

DEGRYSE, H.; NGUYEN, G. Interbank exposures: An empirical examination of contagion risk in the belgian banking system. International Journal of Central Banking, p. 123-171, jun. 2007. 
DELBAEN, F.; SCHACHERMAYER, W. The fundamental theorem of asset pricing for unbounded stochastic processes. Mathematische Annalen, v. 312, n. 2, p. 215-250, out. 1998.

EBERLEIN, E. Application of generalized hyperbolic lévy motions in finance. In: BARNDORFF-NIELSEN, O. E.; MIKOSCH, T.; RESNICK, S. I. (Ed.). Lévy Processes: theory and applications. Basel: Birkhäuser, 2001. p. 319-336.

ELSINGER, H.; LEHAR, A.; SUMMER, M. The network topology of the interbank market. Quantitative Finance, 2004.

. Risk assessment for banking systems. Management Science, v. 52, n. 9, p. 13011314, set. 2006.

FAJARDO, J.; FARIAS, A. Generalized hyperbolic distributions and brazilian data. Brazilian Review of Econometrics, v. 24, n. 2, p. 249-271, nov. 2004.

. Derivative pricing using multidimensional generalized hyperbolic distributions. In: Proccedings of the Seventh Brazilian Society Meeting. São Paulo: Sociedade Brasileira de Econometria, 2007.

FAJARDO, J.; MORDECKI, E. Pricing derivatives on two-dimensional lévy processes. International Journal of Theoretical and Applied Finance, v. 9, n. 2, p. 185-197, mar. 2006.

FORBES, K. J.; RIGOBON, R. No contagion, only interdependence: Measuring stock market comovements. Journal of Finance, v. 57, n. 5, p. 2223-2261, out. 2002.

FRITTELLI, M. The minimal entropy martingale measure and the valuation problem in incomplete markets. Mathematical Finance, v. 10, n. 1, p. 39-52, jan. 2000.

FURFINE, C. H. Interbank exposures: Quantifying the risk of contagion. Journal of Money, Credit and Banking, v. 35, n. 1, p. 111-128, fev. 2003.

GEBER, H. U.; SHIU, E. S. W. Option pricing by esscher transform. Transactions of the Society of Actuaries, v. 46, p. 99-191, 1994.

GRIFFIN, K. Testimony of to the House Committee on Oversight and Government Reform. [S.1.], 2008. November 13th. Disponível em: <http://oversight.house.gov/documents/20081113120556.pdf>. Acesso em: 07.07.2009.

HALL, A. R. Generalized Method of Moments. Oxford: Oxford University Press, 2005. (Advanced Texts in Econometrics).

HUBALEK, F.; SGARRA, C. Esscher transforms and the minimal entropy martingale measure for exponential lévy models. Quantitative Finance, v. 6, n. 2, p. 125-145, abr. 2006. 
IORI, G. et al. A network analysis of the italian overnight money market. Journal of Economic Dynamics \& Control, v. 31, n. 1, p. 259-278, jan. 2008.

JOE, H. Relative entropy measures of multivariate dependence. Journal of the American Statistical Association, v. 84, n. 405, p. 157-164, mar. 1989.

- Multivariate Models and Dependence Concepts. Boca Raton: Chapman \& Hall/CRC, 1997. (Monographs on Statistics and Applied Probability, v. 73).

KALLSEN, J.; TANKOV, P. Characterization of dependence of multidimensional lévy processes using lévy copulas. Journal of Multivariate Analysis, v. 97, n. 7, p. 15511572, ago. 2006.

KAROUI, N. E.; QUENEZ, M.-C. Dynamic programming and pricing of contingent claims in an incomplete market. SIAM Journal on Control and Optimization, v. 33, n. 1, p. 29-66, jan. 1995.

KOLEV, N.; ANJOS, U. dos; MENDES, B. V. de M. Copulas: a review and recent developments. Stochastic Models, v. 22, n. 4, p. 617-660, dez. 2006.

KOU, S. G. A jump-diffusion model for option pricing. Management Science, v. 48, n. 8, p. 1086-1101, ago. 2002.

. Option pricing under a double exponential jump difusion model. Management Science, v. 50, n. 9, p. 1178-1192, set. 2004.

LEHAR, A. Journal of banking \& finance. Measuring systemic risk: A risk management approach, v. 29, n. 10, p. 2577-2603, out. 2005.

LINDSKOG, F.; MCNEIL, A. J. Common poisson shock models applications to insurance and credit risk modelling. Working Paper. jan. 2001. Disponível em: $<$ http://www.risklab.ch/ftp/papers/CommonPoissonShockModels.pdf > . Acesso em: 27.12 .2008 .

LUBLOYY, A. Topology of the Hungarian large-value transfer system. Budapest, jul. 2006.

LUCIANO, E.; SCHOUTENS, W. A multivariate jump driven financial asset model. Quatitative Finance, v. 6, n. 5, p. 385-402, out. 2006.

MADAN, D. B.; CARR, P. P.; CHANG, E. C. The variance gamma processes and option pricing. European Finance Review, v. 2, n. 1, p. 79-105, jan. 1998.

MADAN, D. B.; SENETA, E. The variance gamma (v.g.) model for share market returns. Journal of Business, v. 63, n. 4, p. 511-524, out. 1990.

MADDALA, G. S.; KIM, I.-M. Unit Roots, Cointegration, and Structural Change. Cambridge: Cambridge University Press, 1999. (Themes in Modern Econometrics).

MASSEY Jr., F. J. The kolmogorov-smirnov test for goodness of fit. Journal of the American Statistical Association, v. 46, n. 253, p. 68-78, mar. 1951. 
MATACHE, A.-M.; PETERSDORFF, T. von; SCHWAB, C. Fast deterministic pricing of options on lévy driven assets. ESAIM: Mathematical Modelling and Numerical Analysis, v. 38, n. 1, p. 37-71, jan.-fev. 2004.

MERTON, R. C. Option pricing when the underlying stock returns are discontinuous. Journal of Financial Economics, v. 3, n. 1-2, p. 125-144, jan.-mar. 1976.

MISTRULLI, P. E. Assessing Financial Contagion in the Interbank Market: Maximum Entropy Versus Observed Interbank Lending Patterns. Rome, Italy, set. 2007.

NELSEN, R. B. An Introduction to Copulas. New York: Springer-Verlag, 1999. (Lecture Notes in Statistics, v. 139).

NEWEY, W. K.; WEST, K. D. A simple, positive semi-definite, heteroskedasticity and autocorrelation consistent covariance matrix. Econometrica, v. 55, n. 3, p. 703-708, maio 1987.

NEWMAN, M. et al. The Structure and Dynamics of Networks. Princeton: Princeton University Press, 2006. (Princeton Studies in Complexity).

NEWMAN, M. E. J. Mixing patterns in networks. Physical Review Letters, v. 67, n. 2, p. 026126, fev. 2003.

PRAUSE, K. The Generalized Hyperbolic Model: Estimation, Financial Derivatives, and Risk Measures. Tese (Dissertation zur Erlangung des Doktorgrades) - Universitüt Freiburg, Mathematischen Fakultät der Albert-Ludwigs, Freiburg, out. 1999.

RESNICK, S. I. Heavy-Tail Phenomena: Probabilistic and Statistical Modeling. New York: Springer, 2006. (Springer Series in Operations Research and Financial Engineering).

RODRIGUEZ, J. C. Measuring financial contagion: A copula based approach. Journal of Empirical Finance, v. 14, n. 3, p. 401-423, jun. 2007.

RØRDAM, K. B.; BECH, M. L. The Topology of Danish Interbank Money Flows. Copenhagen, Denmark, 2009.

ROSIŃSKI, J. Series representations of lévy processes from the perspective of point processes. In: BARNDORFF-NIELSEN, O. E.; MIKOSCH, T.; RESNICK, S. I. (Ed.). Lévy Processes: theory and applications. Basel: Birkhäuser, 2001. p. 401-415.

ROUGE, R.; KAROUI, N. E. Pricing via utility maximization and entropy. Mathematical Finance, v. 10, n. 2, p. 259-276, abr. 2000.

SCHWARZ, G. Estimating the dimension of a model. The Annals of Statistics, v. 6, n. 2, p. 461-464, mar. 1978.

SHIRYAEV, A. N. Essentials of Stochastic Finance: Facts, Models, Theory. Danvers: World Scientific Publishing, 1999. (Advanced Series on Statistical Science and Applied Probability, v. 3). 
TALEB, N. Dynamic Hedging: Managing Vanilla and Exotic Options. New York: John Wiley \& Sons, 1997. (Wiley series in financial engineering).

UPPER, C.; WORMS, A. Estimating bilateral exposures in the german interbank market: Is there a danger of contagion? European Economic Review, v. 48, n. 4, p. 827-849, 2004.

WATTS, D. J.; STROGATZ, S. H. Collective dynamics of 'small-world' networks. Nature, v. 393, n. 4, p. 440-442, jun. 1998.

WELLS, S. Financial interlinkages in the United Kingdom's interbank market and the risk of contagion. London, 2004. 


\section{Apêndice}

\section{A.1. Estimativas de Máxima Verossimilhança}

De acordo com (CLAUSET; SHALIZI; NEWMAN, 2009), a função de verossimilhança para as estimativas conjuntas dos parâmetros de uma distribuição potência discreta of é dado por

$$
\left(\hat{\alpha}, \hat{k}_{\text {min }}\right)=\arg \max \left\{n_{t} \log \left(\zeta\left(\alpha, k_{\text {min }}\right)\right)-\alpha \sum_{i=1}^{n_{t}} \log \left(k_{i}\right)\right\},
$$

onde o erro da estimativa $\hat{\alpha}$ é dado por

$$
\sigma(\hat{\alpha})=\frac{1}{\sqrt{n_{t}\left[\frac{\zeta^{\prime \prime}\left(\hat{\alpha}_{,}, \hat{k}_{\text {min }}\right)}{\zeta\left(\hat{\alpha}, \hat{k}_{m i n}\right)}-\left(\frac{\zeta^{\prime}\left(\hat{\alpha}, \hat{k}_{m i n}\right)}{\zeta\left(\hat{\alpha}, \hat{k}_{m i n}\right)}\right)^{2}\right]}}
$$

onde $\zeta^{\prime}\left(\hat{\alpha}, \hat{k}_{\text {min }}\right)$ e $\zeta^{\prime \prime}\left(\hat{\alpha}, \hat{k}_{\text {min }}\right)$ são, respectivamente, a primeira e segunda derivadas da função Zeta $\zeta$ com respeito a $\hat{\alpha}$.

Similarmente, a função de verossimilhança da estimativa conjunta dos parâmetros de uma distribuição potência contínua é dado por

$$
\left(\hat{\alpha}, \hat{\ell}_{\text {min }}\right)=\arg \max \left\{1+n_{t}\left[\sum_{i=1}^{n_{t}} \log \left(\frac{\ell_{i}}{\ell_{\text {min }}-\frac{1}{2}}\right)\right]^{-1}\right\},
$$

e o erro $\hat{\alpha}$ é igual a

$$
\sigma(\hat{\alpha})=\frac{\hat{\alpha}-1}{\sqrt{n_{t}}} .
$$

\section{A.2. Coeficiente de Afinidade}

Seguindo (NEWMAN, 2003), tem se que o coeficiente de assortatividade para os pares

$$
e_{y, k}^{(i, j)}=\left(k_{\text {in }, i}-1, k_{\text {out }, j}-1\right)
$$

e

$$
e_{y, \ell}^{(i, j)}=\left(w_{i n, i}, w_{\text {out }, j}\right)
$$

podem ser expressos como

$$
\rho=\frac{\sum_{y=1}^{E_{t}} e_{y}^{(i, \cdot)} e_{y}^{(\cdot, j)}-\frac{1}{E_{t}} \sum_{y=1}^{E_{t}} e_{y}^{(i, \cdot)} \sum_{y^{\prime}=1}^{E_{t}} e_{y^{\prime}}^{(\cdot, j)}}{\sigma\left(e_{y}^{(i, \cdot)}\right) \sigma\left(e_{y}^{(\cdot, j)}\right)}
$$


onde

$$
\begin{aligned}
\sigma^{2}\left(e_{y}^{(i, \cdot)}\right) & =\sum_{y=1}^{E_{t}}\left(e_{y}^{(i, \cdot)}\right)^{2}-\frac{1}{E_{t}}\left(\sum_{y=1}^{E_{t}} e_{y}^{(i, \cdot)}\right)^{2}, \\
\sigma^{2}\left(e_{y}^{(\cdot, j)}\right) & =\sum_{y=1}^{E_{t}}\left(e_{y}^{(\cdot, j)}\right)^{2}-\frac{1}{E_{t}}\left(\sum_{y=1}^{E_{t}} e_{y}^{(\cdot, j)}\right)^{2},
\end{aligned}
$$

onde $y=1, \ldots, E_{t}$ é a enumeração dos vertices, i.e., $E_{t}=\#\left\{(i, j) \in \mathcal{E}_{t}\right\}$, e, a variância $\rho$ é dad por

$$
\sigma^{2}(\rho)=\sum_{y=1}^{E_{t}}\left(\rho-\rho_{y}\right)^{2}
$$

onde $\rho_{y}$ e o valor de $\rho$ caso o vértice $e_{y}$ seja excluído da rede. 